\title{
The Ties that Bind: Railroad Gauge Standards, Collusion, and Internal Trade in the 19th Century U.S.
}

\section{Citation}

Gross, Daniel P. "The Ties That Bind: Railroad Gauge Standards and Internal Trade in the 19th Century U.S." Harvard Business School Working Paper, No. 17-044, December 2016.

\section{Permanent link}

http://nrs.harvard.edu/urn-3:HUL.InstRepos:29988897

\section{Terms of Use}

This article was downloaded from Harvard University's DASH repository, and is made available under the terms and conditions applicable to Open Access Policy Articles, as set forth at http:// nrs.harvard.edu/urn-3:HUL.InstRepos:dash.current.terms-of-use\#OAP

\section{Share Your Story}

The Harvard community has made this article openly available.

Please share how this access benefits you. Submit a story.

\section{Accessibility}




\section{The Ties that Bind: Railroad Gauge Standards, Collusion, and Internal Trade in the 19th Century U.S.}

Daniel P. Gross

Working Paper 17-044 


\section{The Ties that Bind: Railroad Gauge Standards, Collusion, and Internal Trade in the 19th Century U.S.}

Daniel P. Gross

Harvard Business School

Working Paper 17-044 


\title{
The Ties that Bind: Railroad Gauge Standards, Collusion, and Internal Trade in the 19th Century U.S.
}

\author{
Daniel P. Gross* \\ Harvard Business School and NBER
}

November 30, 2016

(first draft: March 22, 2016)

\begin{abstract}
:
Technology standards are pervasive in the modern economy, and a target for public and private investments, yet evidence on their economic importance is scarce. I study the conversion of 13,000 miles of railroad track in the U.S. South to standard gauge between May 31 and June 1, 1886 as a large-scale natural experiment in technology standards adoption that instantly integrated the South into the national transportation network. Using route-level freight traffic data, I find a large redistribution of traffic from steamships to railroads serving the same route that declines with route distance, with no change in prices and no evidence of effects on aggregate shipments, likely due to collusion by Southern carriers. Counterfactuals using estimates from a joint model of supply and demand for North-South freight transport suggest that if the cartel were broken, railroads would have passed through 50 percent of their cost savings from standardization, generating a 10 percent increase in trade on the sampled routes. The results demonstrate the economic value of technology standards and the potential benefits of compatibility in recent international treaties to establish transcontinental railway networks, while highlighting the mediating influence of product market competition on the public gains to standardization.
\end{abstract}

JEL Classification: F15, L15, L92, N71

Keywords: Railroad gauge; Standards; Integration; Incompatibility; Trade

*Address: Harvard Business School, Soldiers Field Road, Boston, MA 02163, USA; email: dgross@hbs.edu. I am grateful to Dominick Bartelme, Brad DeLong, Barry Eichengreen, Shane Greenstein, Josh Lerner, Marty Olney, and Claudia Steinwender for their feedback at various stages of this project, and to audiences at BU Questrom, Harvard (Economics and HBS), Haverford, LMU-Munich, MIT Sloan, NYU Stern, Queen's University in Canada, Tufts, Vanderbilt, Yale, the 2016 Georgetown Colloquium on the Economics and Regulation of the Freight Rail Industry, and the 2017 ASSA meetings for comments. I also thank the Historical Collections team at Baker Library for their phenomenal support in providing access to historical data, and the Berkeley Economic History Lab and the Harvard Business School Division of Faculty and Research for financial support. This research began during graduate studies and was thus was conducted in part with the support of NSF Graduate Research Fellowship Grant No. DGE-1106400 and an EHA Graduate Fellowship. All errors are my own. 
On November 10, 2006, seventeen Asian countries ratified the Trans-Asian Railway Network Agreement, under which they agreed to integrate into a continental railroad network by connecting lines but refrained from adopting standards for interoperability (UNTC 2006), namely a common gauge (track width). This agreement culminated over 50 years of negotiations, during which proposals were "frustrated to a large extent by a lack of uniform railway gauge" across national boundaries (UNESCAP 1996), much like similar proposed treaties in Europe and in the Middle East (UNTC 1991, 2003). To this day, there are at least five distinct gauges in use across the proposed Asian network, necessitating costly interchange where railroads connect.

Compatibility standards are not only an important feature of transportation infrastructure: they are pervasive in the modern economy, most notably in networked industries, as evidenced by the vast collection of standards and standards-setting organizations (SSOs) convened around the world today (Baron and Spulber 2015). ${ }^{1,2}$ In theory, incompatibilities impose a tax on transactions in the form of a fixed cost of conversion, but there is little evidence that documents whether these costs are large enough to materially affect economic activity or justify ex-post standardization of systems that naturally, and perhaps efficiently, evolved to be incompatible (Liebowitz and Margolis $1995)$ - especially when adapters are available to help bridge the gap. Due to the difficulty of tying economic outcomes to compatibility, and a lack of standards-adoption events at large enough scale to be of economic significance, questions such as these remain unanswered.

This paper studies the conversion of all 13,000 miles of non-standardized railroad track in the U.S. South to a standard-compatible gauge on May 31 and June 1, 1886 as a large-scale natural experiment in standards adoption. In the 1860s, breaks in gauge were pervasive across the U.S. railway network, with railroads constructed in as many as 23 distinct gauges (Siddall 1969). By the 1880s, this count had effectively narrowed to two: 5' 0" gauge in the South, and 4' 8.5" ("standard") gauge throughout the rest of the country. The gauge change instantly integrated Southern states

\footnotetext{
${ }^{1} \mathrm{~A}$ significant economics literature on compatibility standards has developed over the last 30 years, in the context of research on information and communications technology with network effects. The theoretical literature traces back to the seminal contributions of Farrell and Saloner (1985, 1986, 1988, 1992) and Katz and Shapiro (1985, 1986). The empirical literature is considerably less developed, due to a lack of data (as noted by Baron and Spulber 2015). Existing empirical research has studied related topics, such as standards battles in consumer electronics (Augereau et al. 2006) and the behavior, impacts, and antitrust treatment of SSOs (e.g., Simcoe 2012, Rysman and Simcoe 2008, Anton and Yao 1995). A third subliterature studies path dependence in standards and technological lock-in, concentrating on the history of the QWERTY keyboard as an example (Arthur 1989, David 1985, Liebowitz and Margolis 1990). However there are few papers that examine the impacts of standards directly.

${ }^{2}$ Technical standards for interoperability also have a long history: standardization was one of the hallmark features of the American system of manufacturing that propelled the U.S. to the forefront of industrialization in the 19th century and is now pervasive in the U.S. and abroad (Hounshell 1985). Even the adoption of a common currency can be interpreted as a technical standard for payments, yielding benefits from compatibility and integration (e.g., Frankel and Rose 2002, Rose and van Wincoop 2001).
} 
into the national transportation network. Using historical freight traffic data from the Southern Railway \& Steamship Association - a cartel of the major Southern railroads and steamship lines this paper estimates the effects of railroad gauge standardization on trade between the developing South and the industrial North at the end of the century.

I find that the gauge change triggered a significant redistribution of freight traffic into the South from steamships to railroads but did not generate an increase in total shipments. Over this same period, records show that the cartel maintained its prices, implying that railroads did not pass through any of the cost-savings achieved by the conversion. I then estimate supply and demand for freight transport on the sampled routes and show that had the cartel been broken, the gauge change would have produced a 10 percent average decline in freight rates and a corresponding 9 percent increase in aggregate shipments on the sampled routes. The effects of the gauge change were thus large but simultaneously hindered by the collusive conduct of the industry.

The first U.S. railroads were constructed as local and regional enterprises to serve local needs. At this time, opinions over the optimal gauge varied, and technical specifications of each railroad were in the hands of the chief engineer. Without the vision of a national network, distinct gauges were adopted by early railroads in different parts of the country, and subsequent construction tended to adopt the neighboring gauge - leading to the formation of nine different "gauge regions" in the U.S., and a tenth in eastern Canada, by the 1860s (Puffert 2000, 2009). As a national network began to emerge, the costs of these incompatibilities became too great to bear, and railroads gradually converged on a common gauge, through conversion and new construction.

By the 1880s, nearly all U.S. railroads had adopted the 4' 8.5" gauge, except for those in the South. Data from both the U.S. Department of the Interior and Poor's Manual of Railroads confirm that whereas other regions had $95 \%$ or more of their track in standard gauge, $75 \%$ of that in Southern states was in an incompatible, 5' 0'" gauge (even more if excluding Virginia and North Carolina). Though adapters had developed to overcome breaks in gauge, all were imperfect, and accounts suggest they were a substantial second-best to a fully integrated network.

In 1884 and 1885, two major 5' $0^{\prime \prime}$ railroads connecting the South to the Midwest converted their tracks to standard gauge, increasing pressure on the remaining Southern railroads to follow suit and providing a template for execution. In early 1886, the members of the Southern Railway \& Steamship Association (SRSA) cartel, which together comprised a majority of mileage in the South, agreed to convert all track to the standard-compatible gauge of $4^{\prime} 9^{\prime \prime}$ en masse over the two days of May 31 and June 1, 1886, with all traffic halting on May 30 and resuming by the evening of 
June 1, effortlessly traversing the former breaks in gauge. ${ }^{3}$ The conversion was carefully planned, seamlessly executed, and thoroughly documented by contemporaries.

The principal purpose of the cartel was to create and enforce noncompetitive pricing. It pursued this goal with rate maintenance agreements and an enforcement mechanism whereby members were allotted a fraction of route-level traffic, and those in excess of their allotment would have to pay the excess revenue into a central fund for redistribution to other members. To implement this mechanism, the SRSA administrative office collected, by submission and audit, records of freight traffic carried to and from the Southern cities where two or more cartel members operated, which were then circulated to member railroad and steamship carriers.

I use SRSA freight traffic and revenue data for individual carriers at the route- by year-level to estimate the effects of the gauge change on merchandise shipments from the North into the South. Invoking a variant on a triple-differences design, I compare within-route traffic borne by railroads versus steamships before and after the conversion to $4^{\prime} 9^{\prime \prime}$ gauge, relaxing the effects to vary with route distance. Steamships serve as a natural control for railroad traffic, as seaborne freight entirely circumvented the gauge breaks and was therefore operationally unaffected by the conversion to a compatible gauge. This framework identifies the elasticity of freight traffic with respect to the unit cost of a break in gauge, which will be inversely proportional to route length.

The source material yields a balanced panel of 52 routes with inbound merchandise shipments data both pre- and post-standardization. Within this sample, I find sharp effects of standardization on rail-borne merchandise traffic from the North to the South, with about a $250 \%$ relative increase in railroad traffic and revenue on short routes that decreases with distance; when split across the two all-rail pathways into the South, I find relatively larger increases for the less-trafficked path. Across all specifications, I find that the effects of conversion dissipate after about 700 to 750 miles. The results are robust to a variety of fixed effects and within assorted subsamples.

Market share models return similar results, showing a large redistribution of traffic from steamships to railroads, with effects dissipating at similar distances. However, I find no evidence of growth in aggregate shipments through 1890: the effects appear to be limited to substitution across modes. To better understand the reasons for this result, I examine cartel pricing for several routes in the

\footnotetext{
${ }^{3}$ The gauge of $4^{\prime} 9^{\prime \prime}$ was selected to conform to that of the Pennsylvania Railroad - an important connecting line and with the belief that a smaller change would reduce the expense of converting rolling stock, but it was understood to be compatible with the 4' 8.5" standard (Taylor and Neu 1956, Puffert 2009). As Taylor and Neu write, "such a deviation was not considered a serious obstacle to through shipment." The U.S. Government similarly noted in 1880 that "gauges from 4' 9.375 " to 4' 8" may be considered standard," as the same rolling stock may be used on either "without objection" (U.S. Department of the Interior 1883).
} 
sample, finding that prices were stable over the sample period. While the gauge change affected quality of service by improving rail transit times and reducing the risk of property loss, it evidently was not sufficient to attract new traffic to the market absent price adjustments. The cartelization of Southern transportation is thus critical to interpreting these results.

To evaluate whether the consumer welfare gains were constrained by collusion, I estimate a joint model of supply and demand for freight transport over the sampled routes, and use the estimates to evaluate a counterfactual in which all-rail and steamship carriers compete. I find that if the cartel were broken, the conversion to a compatible gauge would have increased total traffic by roughly 10 percent, primarily due to a significant reduction in prices: in stark contrast to realized history, on average 50 percent of railroads' post-change cost savings are passed through to consumers in the counterfactual. However, it is important to note that in a competitive environment, the gauge change could itself come into question, as collusion or common ownership was required for railroads to internalize the potentially large external returns to standardization, and non-competitive prices were essential to recouping the fixed costs of the conversion.

The results add a new dimension to existing research on how transport infrastructure historically facilitated trade (Donaldson 2015) and created economic value (Fogel 1964, Donaldson and Hornbeck 2016, Swisher 2014), bringing out the importance of compatible gauge in railway networks and physical and technological barriers to trade more generally. The results also offer lessons for present-day investments in compatibility, which this paper shows can have large effects on economic activity in settings where traffic is exchanged across interconnected networks, such as communications and transportation. In doing so, the paper contributes to a gap in the literature relating compatibility standards to trade, an issue which "has long been reflected in multilateral trade rules" (WTO 2005) but on which there is almost no empirical work (Gandal 2001), excepting two recent studies on containerization in international shipping (Rua 2014, Bernhofen et al. 2016). The present paper provides insight into the role that interoperability in transport networks can play in promoting trade, and the findings acquire increased urgency in light of recent efforts to integrate domestic railways into international networks without standardizing the gauge.

Finally, this paper highlights a tension between standardization and product market competition in networked environments: collusion (or consolidation) is necessary for developers to internalize the external returns to compatibility, but it also reduces the likelihood that resulting cost savings will be passed through to consumers, limiting the scope for welfare gains from standardization. It may be desirable to instead have a government simultaneously promote competition while mandating 
or subsidizing ex-post standardization, particularly if the social returns are believed to exceed the cost of conversion. To my knowledge, this tension has not been fully explored, but further study is beyond the scope of the paper, and I thus leave it to future research.

The paper is organized as follows. Section 1 reviews U.S. railroad history and the natural experiment at the heart of this paper. Section 2 introduces the data and describes the empirical strategy. Section 3 estimates the effects of the gauge change on mode traffic shares and combined shipments and explores potential explanations, emphasizing the importance of the institutional environment. Section 4 then estimates supply and demand for freight transport, and Section 5 uses the results to evaluate the effect of the gauge change in a counterfactual with competition. Section 6 discusses the key lessons, particularly as related to (i) the benefits of interoperability and (ii) the mediating influence of product market competition, as well as implications for the design of international rail transportation agreements. Section 7 concludes.

\section{History of U.S. Railroads and Gauge Standards}

Diversity in gauge characterized U.S. railroads for most of the 19th century. The first railroads were built with a local, or at most regional, scope, and "there was little expectation that [they] would one day form an independent, interconnected" network (Puffert 2009), obviating any perceived benefits of coordinating on a common gauge. Gauges were instead chosen by each railroad's chief engineer, and without clear evidence of an optimal gauge standard, diversity proliferated. As Puffert (2009) recounts, the first wave of construction in the 1830s used four distinct gauges $\left(4^{\prime} 8.5^{\prime \prime}, 4^{\prime} 9^{\prime \prime}, 4^{\prime} 10^{\prime \prime}\right.$, and $\left.5^{\prime} 0^{\prime \prime}\right)$, a second wave in the 1840 s added three broader gauges to the mix (5' 4', $\left.5^{\prime} 6^{\prime \prime}, 6^{\prime} 0^{\prime \prime}\right)$, and a "third wave of experimentation" in the second half of the century introduced several narrow gauges, the most common of which were $3^{\prime} 0^{\prime \prime}$ and $3^{\prime} 6^{\prime \prime}$. Amongst this set, only $4^{\prime} 8.5^{\prime \prime}$ and $4^{\prime} 9^{\prime \prime}$ were mutually compatible and allowed for seamless interchange of traffic. ${ }^{4}$

The industry nevertheless recognized the advantages of interoperability, as subsequent construction typically adopted the gauge of neighboring railroads. By the 1860s, a national network had begun to emerge, but it was plagued by breaks in gauge as well as minor gaps in the physical network such that there were nine distinct "gauge regions" in the U.S. during the Civil War, and a tenth in

\footnotetext{
${ }^{4}$ See Puffert (2009) for a comprehensive discussion of the origins of U.S. railroad gauge. To this day, experts' opinion over the optimal gauge varies, though the choice is (i) understood to vary with operating conditions, and (ii) involves tradeoffs, such that there is no dominating standard. Even so, experts tend to agree that wider gauge is preferable to the modern standard (4' 8.5') for its speed, stability, and carrying capacity (Puffert 2009).
} 
Canada, each predominantly using a different gauge than neighboring regions. Panel (A) of Figure 1 gives a flavor of the state of U.S. railroads east of the Mississippi River at this time, showing lines in 4' 8.5" ("standard" gauge), 5' 0" ("Southern" gauge), and other widths.

[Figure 1 about here]

Contemporaries in the 1850s noted that each break in gauge imposed a full-day delay on through shipments and necessitated significant labor and capital for transshipment, which at the time was performed manually, aided by cranes (Poor 1851, Taylor and Neu 1956). Diversity also required railroads to preserve a large fleet of idle rolling stock at each break for transferring freight. Several adapters developed to reduce these costs, such as bogie exchange (whereby each rail car would be hoisted, and its chassis replaced with one of a different gauge), transporter cars (which carried cars of a different gauge), adjustable-gauge wheels, and multiple-gauge track. Although bogie exchange was the most common means of interchange, it was time-consuming and yielded a mismatched car and bogie, which ran at reduced speeds and were prone to tipping on curves. The alternatives were equally deficient: transporter cars were difficult to load and similarly created instability; variablegauge wheels loosened, causing derailment; and third rails required a gauge differential of at least eight inches and were prohibitively expensive to construct and maintain.

After the Civil War, several pressures coincided to induce private efforts towards standardization, including growing demand for interregional freight traffic and increasing trade in perishable goods, which were heavily taxed by delays at breaks in gauge; competition within routes (to provide faster service); and consolidation across routes (internalizing externalities of conversion). Despite known technical shortcomings (Puffert 2009), 4' 8.5" became the standard to which railroads conformed: not only did standard gauge comprise a majority of U.S. mileage in every decade since the first railroads were built, but it was also the principal gauge in the Northeast and Midwest, the loci of trade in manufactured and agricultural goods. By the early 1880s, the common-gauge regions using $4^{\prime} 10^{\prime \prime}, 5^{\prime} 6^{\prime \prime}$, and $6^{\prime} 0^{\prime \prime}$ had all converted to standard gauge, effectively leaving only two gauges in widespread use: $5^{\prime} 0^{\prime \prime}$ in the South, and $4^{\prime} 8.5^{\prime \prime}$ in the rest of the country. ${ }^{5}$

\footnotetext{
${ }^{5}$ Concurrent with these conversions, physical gaps in the network were being closed around the country: cross-town connections between depots were being built (e.g., Richmond in 1867) and rivers were being bridged (e.g., the Ohio River at Louisville in 1868 and Cincinnati in 1877), such that differences in gauge were the only remaining obstacle to a physically integrated network. A third impediment to through traffic was the moral hazard inherent to relinquishing control over rolling stock on adjoining lines, or allowing other railroads' cars to use (and potentially damage) one's own tracks. These issues were resolved around the same time by contracting innovations that established joint ownership of rolling stock (Puffert 2009). Vertical relationships are discussed further in Appendix C.
} 


\subsection{The Southern Railway \& Steamship Association}

Concurrent with (but independent of) these trends, Southern freight carriers self-organized into the SRSA cartel in 1875 , following a series of rate wars. The cartel's express purpose was rate maintenance: the preamble to the cartel agreement asserts the intent of achieving "a proper correlation of rates," to protect both its members and consumers from "irregular and fluctuating" prices and "unjust discrimination" that favored certain markets over others (SRSA 1875). Membership was open to all railroads and steamships operating south of the Potomac and Ohio Rivers and east of the Mississippi and included nearly all major carriers in the region.

Though it had a rocky start, the SRSA grew into a sophisticated and highly successful organization that was "one of the most powerful and disciplined" traffic pools in the country (White 1993) and has been documented several times over (e.g., Hudson 1890, Joubert 1949, Argue 1990). ${ }^{6}$ The cartel had its own central administration composed of representatives from its constituents, which had the responsibility of carrying out the terms of the cartel agreement, making new rules as necessary, and providing a venue for settling differences. This administration thus provided a government for Southern freight carriers, with an executive, a legislature, and a judiciary.

The cartel administration included a Rate Committee, which determined prices for each route. The mechanism used to ensure that members adhered to these prices was apportionment: carriers serving a competed route were allotted a fixed proportion of traffic, determined by "the average amount of freight hauled in past years" (Joubert 1949). In the early years of the cartel, carriers who exceeded their allotment were required to submit the excess revenues to the cartel for redistribution to other members, less a half-cent per ton-mile allowance for the expense of carriage. This plan quickly unraveled when members reneged ex-post, and the agreement was amended to require members to deposit $20 \%$ of revenue with the cartel at the time of shipment, out of which these transfers would be made. To enforce the agreement, the cartel installed agents at stations to record carriers' daily traffic and revenue, appointed inspectors to ensure that freight was being properly weighed and classified, and regularly audited members' accounting records. These records were compiled into monthly tables reporting traffic and revenue by route and carrier, which were then circulated to members - and which have since been preserved.

The SRSA initially governed inbound merchandise shipments, and outbound cotton and textiles,

\footnotetext{
${ }^{6}$ The SRSA in fact preceded, was the model for, and shared a common founder with the Joint Executive Committee, a cartel of railroads running between the Midwest and East Coast that has been widely studied in the economics literature (e.g., Ulen 1979, Porter 1983, Ellison 1994, and others).
} 
between Atlanta, Augusta, Macon, and points in the North. Coverage soon grew to include several other interior Southern cities (e.g., Newnan, West Point, Opelika, Montgomery, Selma). In 1885, the cartel was expanded to cover passenger traffic on these routes, and in 1887, it folded rapidlygrowing "Western" routes (between the South and the Midwest) into the agreement. Given the late addition of these routes to the cartel, this paper focuses on the effects of the gauge standardization on so-called "Eastern" traffic between the North and South.

The amended mechanism proved so effective that in 1887, the cartel reported that "since 1878, all balances have been paid and rates thoroughly maintained," excepting one month in 1878 (Hudson 1890) - a sharp contrast to frequent pre-cartel rate wars. There are several reasons why the cartel was successful, beginning with the mechanism itself, which muted carriers' incentives to cut prices to capture a greater share of traffic. Railroads that refused to join the cartel were denied through traffic, which effectively amounted to a boycott. And the SRSA demonstrated early on that when carriers (members or not) deviated from cartel prices, it would act quickly and decisively by cutting rates to destructively low levels until the deviator complied.

The passage of the Interstate Commerce Act (ICA) in February 1887 presented a new kind of threat to the cartel. The ICA prohibited traffic pooling, making the cartel's apportionment mechanism illegal, however the act "by no means put an end to the power of the Association" (Hudson 1890). ${ }^{7}$ The SRSA responded by transitioning to a system of fines for price deviations, with mileage-based deposits, and it continued collecting and disseminating members' traffic and revenue. The SRSA continued to operate in this way until 1890, when the Sherman Act delivered the lethal blow by prohibiting combinations in restraint of trade. At this point, the cartel stopped circulating traffic tables. Though it took several years for the courts to resolve initial ambiguities over whether the SRSA met the statute's definition, by 1897 the cartel had dissolved.

\subsection{The Gauge Change}

As trade between the South and other regions accelerated during Reconstruction, incompatibilities became increasingly costly: by the 1880s, "not a prominent point could be found on the border [of

\footnotetext{
${ }^{7}$ The act had little impact in its early years, and if anything may have empowered carriers and helped stabilized prices (Prager 1989, Blonigen and Cristea 2013), consistent with the revisionist interpretation of Kolko (1965), who notes that railroads welcomed the regulation. Other sources suggest that the content of the ICA, and the Interstate Commerce Commission it created, were subject to near-total regulatory capture. Gilligan et al. (1990) point out that Albert Fink, the founder and first commissioner of the SRSA and "among the most respected railway officials in the nation" (White 1993), provided much of the structure for the ICA, and that southern railroads were among its "chief beneficiaries" as evidenced by abnormal stock price returns following its enactment - despite the fact that these were railroads with "allegedly the most effective private cartels."
} 
the South] without its hoist and acres of extra trucks" (Hudson 1887), and the total cost of delays were growing one-for-one with volume. The first cracks in the 5' $0^{\prime \prime}$ network developed in 1884 and 1885, when two major lines linking the South to the Midwest (the Illinois Central and the Mobile \& Ohio) converted their tracks to standard gauge, increasing pressure on their Southern competitors and connections to follow suit, and providing a template for execution.

On February 2-3, 1886, cartel members convened to discuss the compatibility problem and agreed to convert all of their track to a 4' 9"', standard-compatible gauge on May 31 and June 1 of that year. ${ }^{8}$ The gauge change was carefully planned and seamlessly executed: in the weeks leading up to the event, railroads removed the ties on their tracks and took a subset of their rolling stock (rail cars, locomotives) out of service to adjust its gauge; then, on the evening of May 30, all traffic halted, and teams of hired labor worked up and down each line, removing remaining ties, shifting one rail 3 " inwards, resetting ties, and moving to the next segment. By midday on June 1, 13,000 miles of track had been converted to 4' 9", and traffic had resumed, with freight now moving freely across Southern borders in a physically integrated railroad network. ${ }^{9}$

The scale, operational details, and anticipated effects of the gauge change were widely discussed in railroad journals and Southern newspapers in the months leading up to the conversion (Appendix B). To verify the scale of the conversion, I collect individual railroads' gauges and mileage from Poor's Manual of Railroads (1882-1890), an annual compendium listing the universe of U.S. railroads. Table 1 shows the miles of railroad in $4^{\prime} 8.5-9^{\prime \prime}, 5^{\prime} 0^{\prime \prime}$, and other gauges by region and year throughout the 1880s. Whereas other regions generally had $95 \%$ of their track in standard or standard-compatible gauge by 1881 , nearly $70 \%$ of Southern railroad mileage began the decade in 5' $0^{\prime \prime}$ gauge. The discrepancy remained until the year of the gauge change: between 1885 and 1887 , the total in 5' 0" gauge declined by 13,006 miles, and the fraction of Southern railroad in standard or standard-compatible gauge discretely jumped from $29 \%$ to $92 \%$. Panels (B) and (C) of Figure 1 show the updated gauge of the 1861 railroad network as of 1881 and 1891, respectively (omitting new construction), illustrating the geographic scope of the conversion.

[Table 1 about here]

\footnotetext{
${ }^{8}$ The 4' 9" gauge was selected to match the Pennsylvania Railroad system, an important connection in the MidAtlantic, and because it was thought that smaller adjustments were less costly (Puffert 2009).

${ }^{9}$ The execution of the gauge change is covered in greater depth by several other sources. For extended summaries, see Taylor and Neu (1956) or Puffert (2009). For a detailed, contemporary discussion of the nuts and bolts of the planning and execution, see Hudson (1887). Extrapolating from the costs of converting the Louisville \& Nashville

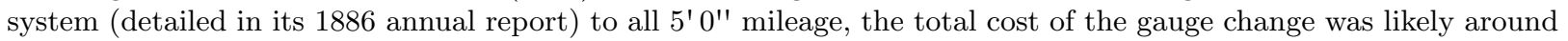
$\$ 1.2$ million in 1886 , equivalent to $\$ 31$ million today. To put the cost in perspective, the L\&N's expenditure on conversion was roughly $30 \%$ of its investment in infrastructure in 1886 and $37 \%$ of net income.
} 
The historical record indicates that network externalities were important in propelling the gauge change and were recognized by contemporaries. The returns to adopting a compatible gauge were low for railroads on the periphery if interior neighbors did not follow - the effect would be to shift the break from the top to the bottom of the line, with no benefits to through traffic - and negative for interior railroads acting alone. But the gains to all parties were high under a coordinated, regional conversion. Because the returns to conversion were increasing in the size of the standard gauge network, one large system could also induce a cascade of standardization. ${ }^{10}$

The cartel served three important roles that enabled conversion to take place. First, it provided an institutional venue for coordinating on a common gauge and organizing the conversion, similar to SSOs today. More importantly, collusion internalized the externalities to adopting the common standard, and non-competitive pricing ensured that railroads could recoup the expense of conversion. Without either collusion or consolidation, the gauge change itself would be in question, and integration would likely have been significantly retarded.

\section{Data and Empirical Strategy}

I use the SRSA records of freight traffic into and out of the South by railroad and steamship to study the effects of the gauge change. I restrict attention to annual totals of merchandise shipped from Northern port cities to the interior South, as merchandise shipments comprised the largest fraction of tonnage in the South (35\% of total; see U.S. Department of Interior 1883) and an even greater fraction of revenue, and cotton shipments in the reverse direction yield a smaller sample and may be confounded if destined for foreign markets. ${ }^{11}$ The sample throughout the paper consists of 52 North-South routes formally apportioned and monitored by the cartel both before and after the gauge change (4 origins x 13 destinations), and a sample period spanning the 1883-84 to 1889-90 fiscal years. Table 2 lists - and Figure 2 maps - the origins and destinations in the sample. The gauge change coincides precisely with the end of the 1885-86 fiscal year, such that the pre-period consists of FY84 to FY86, and the post-period FY87 to FY90.

\footnotetext{
${ }^{10}$ As one contemporary noted, once the Louisville \& Nashville (the largest railroad in the South at the time, with over 2,000 miles) determined that it must adopt a standard-compatible gauge to compete for interregional traffic, other large systems recognized that they "must move with the Louisville and Nashville," and smaller railroads then "had no choice in the matter but to join ranks" (Hudson 1887, p. 668).

${ }^{11}$ Invoking the annual data smooths out higher-frequency fluctuations and significantly simplifies the data collection, while still providing enough variation to identify the effects of the gauge change. The choice to restrict attention to inbound merchandise shipments is further motivated by the fact that outbound cotton shipments were dwindling over the period, diverted by growing demand from Southern textile manufacturers.
} 
[Table 2 and Figure 2 about here]

Due to the diffuse ownership of the network, shipments to the interior South necessarily traversed multiple railroads, or a steamship and a railroad, to reach their destination. The SRSA tables report sequence-specific traffic and revenue, which I aggregate up to mode: all-rail versus steamship. I include separate observations for the two all-rail paths into the South, the "Atlantic Coast Line" (ACL) and the "Piedmont Air Line" (PAL, see Appendix A), each of whose constituent railroads shared a common owner, and which are explicitly denoted in the SRSA tables. The primary sample thus has $1,092(=52 \cdot 3 \cdot 7)$ observations at the route-mode-year level. ${ }^{12}$

The empirical strategy compares all-rail and steamship traffic within routes before and after the gauge change. Because seaborne freight bypassed breaks in gauge, steamships were not directly affected by the conversion and accordingly provide a control group for the treated all-rail mode. In all cases, I relax the effects to vary with distance: breaks in gauge imposed a fixed cost on through traffic, such that the per ton-mile unit costs were inversely proportional to route length. The first set of specifications thus take the following form:

$$
\begin{aligned}
\ln \left(Q_{m r t}\right)= & \beta_{0}+\beta_{1} \text { Rail }_{m r t}+\beta_{2} \text { Post }_{t}+\beta_{3} \text { Rail }_{m r t} \text { Post }_{t} \\
& +\beta_{4} \text { Rail }_{m r t} \text { Post }_{t} \text { Dist }_{r}+X_{m r t} \gamma+\varepsilon_{m r t}
\end{aligned}
$$

where $Q_{m r t}$ is pounds of traffic carried by mode $m$, on route $r$, in year $t ; R a i l_{m r t}$ is an indicator for the all-rail mode (ACL and PAL); Post $_{t}$ indicates the post-period; and Dist $r_{r}$ is the distance from origin to destination. Throughout the analysis, I measure distance as straight-line distance, rather than traveled distance, which is not observed (contemporary sources indicate the two are in roughly fixed proportion; see Appendix A). The $X_{m r t}$ term includes all other interactions plus fixed effects. In all specifications, I cluster standard errors by route.

As Appendix Table A.2 shows, the sampled routes provide sufficient variation in distance (from 500 to 1,100 miles) to identify the elasticity of all-rail traffic with respect to the distributed (unit) costs of gauge breaks. However, with imperfect competition in the market for freight transport, the gauge change may affect steamship traffic indirectly in general equilibrium, contaminating the control group. In a second set of specifications, I therefore estimate a model on market shares, rather than quantities, which can account for this interdependence. Suppose mode shares are generated by discrete consumer choices, where each mode has latent utility:

\footnotetext{
${ }^{12}$ To simplify the exposition, the specifications below are presented as if the ACL and PAL were aggregated into a single observation, but the tables in Section 3 include them as separate observations.
} 


$$
\begin{aligned}
u_{i m r t}=[ & \beta_{0}+\beta_{1} \text { Rail }_{m r t}+\beta_{2} \text { Post }_{t}+\beta_{3} \text { Rail }_{\text {mrt }} \text { Post }_{t} \\
& \left.+\beta_{4} \text { Rail }_{m r t} \text { Post }_{t} \text { Dist }_{r}+X_{m r t} \gamma+\xi_{m r t}\right]+\eta_{i m r t} \equiv \mu_{m r t}+\eta_{\text {imrt }},
\end{aligned}
$$

where $\eta_{i m r t}$ is an error term distributed type-I extreme value. The market share for each mode

is then $s_{m r t}=\frac{\exp \left(\mu_{m r t}\right)}{\sum_{\ell=1,2} \exp \left(\mu_{\ell r t}\right)}$, which is jointly determined with that of the other mode. Indexing railroads as $m=1$ and steamships as $m=2$, we can write:

$$
\begin{aligned}
\ln \left(s_{1 r t}\right) & -\ln \left(s_{2 r t}\right)=\mu_{1 r t}-\mu_{2 r t} \\
& =\tilde{\beta}_{0}+\tilde{\beta}_{1} \text { Post }_{t}+\tilde{\beta}_{2} \text { Post }_{t} \text { Dist }_{r}+\gamma_{r}+\varepsilon_{r t},
\end{aligned}
$$

where the $\gamma_{r}$ are route fixed effects (which will subsume the Dist $t_{r}$ variable). This model can then be estimated by OLS on a sample of the all-rail observations.

Finally, to evaluate the effects of the gauge change on combined traffic, I collapse the sample to route-years and estimate a specification for total shipments:

$$
\ln \left(Q_{r t}\right)=\beta_{0}+\beta_{1} \text { Post }_{t}+\beta_{2} \text { Post }_{t} \text { Dist }_{r}+\gamma_{r}+\varepsilon_{r t}
$$

\section{Standardization and Internal Trade}

Though adapters like steam hoists were being used across the South by the 1880s, contemporaries nonetheless believed that the gauge change would generate substantial growth in all-rail traffic. As the secretary of the SRSA noted in a U.S. Treasury Department report on Southern transportation, "the [current] movement via all-rail lines is very small, but will in the next few years develop very much, because of the late change of all lines to one uniform gauge" (Sindall 1886, p. 679). Was the conversion to the 4' 9" gauge a large-enough improvement over the available adapters to affect internal trade between the South and other regions, as predicted?

In this section, I show that the adoption of compatible gauge indeed provoked a large redistribution of freight traffic on North-South routes from steamships to railroads, but it does not appear to have increased shipments in the aggregate. It may be helpful to provide a roadmap to this section in advance. I first contextualize the event within broader trends in trade between the South and other U.S. regions, which was growing rapidly in the 1870 s and 1880 s. I then estimate the effects of the gauge change on all-rail and steamship traffic, as well as on aggregate shipments. At the end of the section, I consider explanations for these results, focusing on the ways in which collusion may 
have constrained consumers' gains from standardization.

\subsection{North-South Trade}

Southern freight traffic grew rapidly over the 1870s and 1880s, during and after Reconstruction. Until the early 1880s, the vast majority of Southern trade was with the North, and this trade was conducted almost entirely by coastal steamship, in connection with interior railroad lines running from those points (Sindall 1886, p. 679). However, with the growth of the Southern rail network (Table 1) and Midwest industry and agriculture, the Southern trade expanded to the west over the decade, to the point where "Western" traffic was incorporated into the cartel in 1887, and all-rail shipping became a viable alternative for "Eastern" routes as well.

Table 3 shows overall trends in merchandise shipments for the sampled routes from 1884 to 1890. Over the six-year interval, total shipments increased by $25 \%$, driven by growth in steamship traffic. The table also demonstrates heterogeneity in all-rail shares across origins - though this variation will be subsumed by route fixed effects in regressions. Given the limited sample of routes, it will nevertheless be important to test robustness across individual origins and destinations in the data. Note that these totals likely understate growth in trade between the South and other regions, as they do not account for the growth in Western traffic and on routes that entered service over the decade as the transportation network expanded.

[Table 3 about here]

\subsection{Effects of the Gauge Change}

\subsubsection{Distributional Effects}

Table 4 provides the initial test of the effects of the gauge change, estimating the specification in Equation (1), which regresses log traffic at the route-mode-year level on indicators for the all-rail mode and the post-period, their interaction, and an additional interaction with route length (in units of 100 miles), with the remaining interactions included but not listed for brevity. Column (1) estimates this model as specified, while Columns (2) through (6) add an assortment of fixed effects for routes, modes, years, route-modes, and route-years.

[Table 4 about here] 
The table shows the treatment effect and its interaction with distance, suppressing the other parameters. I find that the gauge change caused all-rail traffic to increase by $240-250 \%$ relative to steamship traffic on short routes, with the effect diminishing on longer routes, reaching zero after roughly 740 miles. This effect is stable across specifications.

In Table 5, I explore heterogeneity in these effects across the two all-rail paths between the North and South, the ACL and PAL. This exercise is also in part a robustness check to see that both lines were affected by the conversion to the new gauge. The results show that they were, with the less-trafficked line (the ACL) experiencing a larger percentage increase in traffic. I find that the effects dissipate at similar distances for both carriers, roughly 700 miles - statistically comparable to the break-even distance in the previous table at usual significance levels. The effects are again estimated to be larger relative to route-year averages versus other fixed effects.

[Table 5 about here]

As previously discussed, the estimates in Tables 4 and 5 may not be properly identified, due to the interdependence of all-rail and steamship traffic in an imperfectly competitive market. ${ }^{13}$ In Table 6, I estimate a model that accounts for this interdependence (Equation 2), in which the outcome variable is the log difference in all-rail and steamship shares. In taking this difference, most fixed effects from the previous table are eliminated, such that Table 6 includes only two variants of the regression: absent and with route fixed effects (Columns 1 and 2, respectively).

[Table 6 about here]

We continue to see positive effects of the gauge change on all-rail shares that decline with distance, significant well beyond the one percent level. The estimates are similar across the two specifications, and the effect of the gauge change is again estimated to dissipate at roughly 730 miles, as in Table 4. In Table 7, I split the effects out for the ACL and PAL. The effects are present for both carriers, continue to be relatively larger for the ACL (the smaller of the two carriers), and again dissipate after roughly 700 miles - much as in Table 5.

[Table 7 about here]

\footnotetext{
${ }^{13}$ In the language of causal inference, the risk is a violation of the stable unit treatment value assumption (SUTVA): the assumption that untreated observations are unaffected by the treatment. In an imperfectly competitive market, steamships (the control group) may be indirectly affected by the gauge change if they lose traffic to railroads. In this case, a direct comparison would overstate its effects on growth in all-rail traffic.
} 
I also examine variation in the effects of the gauge change over time. A priori it is not obvious whether the effects would be immediate or would phase in: on the one hand, the change was immediate and comprehensive, and improved service available from the first day after the conversion; on the other hand, it may have taken time for information to spread, and for shippers to adjust. To evaluate this question, as well as to test for pre-trends, Table 8 re-estimates the model in Equation (2), allowing the coefficients to vary by year.

\section{[Table 8 about here]}

Relative to the omitted year of 1884, the table shows that all-rail and steamship shares did not change in a statistically significant way over the next two years leading up to the gauge change (if anything, the signs of the estimates suggest all-rail shares were declining). Beginning in the first year post-gauge change, we see a significant jump in all-rail shares that grows each year through the end of the panel, and it appears to level out around 1890.

In Appendix D, I test the sensitivity of these results to dropping individual origins, destinations, and years from the cartel sample. Given the limited number of routes (52) and the somewhat short panel (3 years pre-gauge change, 4 years post), these checks are necessary to establish that the results are not driven by outliers or subsamples (for example, by routes originating in Baltimore, the origin nearest to the South). I find consistent results throughout. I also run similar regressions for revenue, which is provided alongside the traffic statistics in the SRSA tables, and find identical effects of the gauge change in sign and magnitude. This result is a natural consequence of the high correlation $(\rho=0.99)$ between traffic and revenue in the data.

\subsubsection{Aggregate Effects}

The previous results established that the gauge change caused growth in all-rail freight shipments relative to steamship traffic, but leave ambiguous to what degree this effect reflects displacement of existing traffic versus the generation of new traffic. Table 9 answers this question, collapsing the data to the route level and looking at the effects of the gauge change on total route traffic and revenue (Equation 3). The even-numbered columns include route fixed effects. Across all specifications, the change in traffic and revenue is not significantly different from zero. In particular, we see no increase in traffic on shorter routes (where previous tables showed the gauge change had the strongest effects on shares) relative to longer routes: the variation in the growth in route traffic and revenue vis-à-vis distance is a precisely-estimated zero. 
[Table 9 about here]

\subsection{Explaining the Results}

That the standardization of railway gauge caused economic activity to shift to the all-rail mode is plausible, albeit not ex-ante obvious, given the widespread use gateway technologies pre-gauge change that reduced the cost of incompatibility. This evidence alone implies welfare gains for the switchers. But the lack of an effect on the extensive margin - the absence of an increase in aggregate shipments - is surprising, and suggests that the consumer welfare gains were in fact constrained to existing traffic. The most likely reason was the cartel itself.

Though the conversion to a compatible gauge increased railroads' capacity and reduced costs by eliminating interchange, cartel freight rates held constant around the conversion, which may have precluded any change in aggregate shipments. The SRSA's Circular Letters include tables with the issued rates for shipments between various cities within and outside of the South, which list prices by class of merchandise and were revised and republished every time rates were adjusted. ${ }^{14}$ These tables make it possible to track route-level price changes over time.

Figure 3 show the distribution of rate changes on the routes in these circulars that are also in the sample for this paper (total of 36 routes, out of the 52 routes in the previous tables). Each observation in the figure is a route-class; with 36 routes and 13 classes, there are 468 observations per period. The left panel of the figure shows the change in rates from February 1885 to March 1886 (a few months prior to the gauge change), and the right panel shows the change from March 1886 to July 1887 (over a year after the gauge change).

[Figure 3 about here]

An overwhelming fraction of routes do not update prices over this period. The handful of price adjustments following the gauge change were increases, rather than decreases, and were limited to two routes: Philadelphia-Montgomery and Philadelphia-Selma. ${ }^{15}$

\footnotetext{
${ }^{14}$ The SRSA classified freight into 13 different categories (classes) and set prices at the route and class level. More irregular, fragile, or valuable goods were classified into higher classes, which were charged the highest rates. Rates on lower classes were generally a fixed proportion of the first-class rate for each route.

${ }^{15}$ Cartel prices were not always so steady: until the early 1880 s, prices were reduced regularly, under pressures of competition from alternative routing outside the scope of the cartel. Multiple sources have documented this decline, while also observing that price reductions ended in the early- to mid-1880s (e.g., Hudson (1890) documents prices from Boston, New York, Philadelphia, and Baltimore to Atlanta from 1875 onwards, and shows that rate reductions occurred every 1-2 years until 1884, after which rates went unchanged).
} 
Theoretical predictions for prices are ambiguous if demand for all-rail service shifted out concurrently with supply. But with the absence of an effect on total shipments, the evidence is puzzling: if demand and supply shift similarly, prices may hold but total traffic should grow. And if demand were insensitive to the gauge change, then prices should decline, with some of the railroads' costsavings passed through. Gauge-inelastic demand is also inconsistent with the growth in all-rail market share and the motivations for the gauge change itself.

A closer reading of SRSA documents suggests a potential reason why railroads' cost-savings may not have been passed through to prices: the rate-setting process was contentious, and revisions required the unanimous approval of a committee composed of representatives from member carriers. Compounding this obstacle was the fact that the cartel issued uniform rates for all carriers, likely to avoid perceptions that individual members were being favored, and without comparable cost reductions for steamships, it was difficult to get their representatives to consent to rate reductions on the grounds of the gauge change alone. However, in the event of deadlock, proposed rate changes would be evaluated by the cartel's board of arbitration, which would then issue a ruling by simple majority. In practice, many rate changes were enacted this way.

Another interpretation is that the cartel avoided pass-through and in turn suppressed the welfare gains that would have otherwise been realized by the conversion to a compatible gauge. The natural question is then: what would have happened to prices and total traffic had the cartel been broken? The remainder of the paper seeks to answer this question.

\section{The Market for Shipping}

To evaluate counterfactual prices and traffic under competition, I model the market for North-South freight shipment. The model assumes shippers in a given route and year make a discrete choice between the all-rail and steamship modes to maximize utility, and that railroads and steamships concurrently set prices to maximize joint or individual profits (under collusion or competition, respectively), under the constraint that collusive prices must be the same for railroads and steamships serving a given route - as was the case for the SRSA cartel.

In this model, markets are defined as route-years. Though there are $364(=52 \cdot 7)$ markets in the full sample, there are only 288 for which I have price data, such that the sample for this exercise will be restricted to $N=288$ markets. Within each of these markets, I observe the share of traffic supplied by all-rail and steamship modes, but as in other models of demand I must assume a total 
market size, which I fix to twice the observed traffic.

Each market is characterized by prices $\left\{P_{1 r t}, P_{2 r t}\right\}$, quantities $\left\{Q_{1 r t}, Q_{2 r t}\right\}$, and marginal costs $\left\{M C_{1 r t}, M C_{2 r t}\right\}$ where $m=1$ denotes the all-rail mode and $m=2$ denotes the steamship mode. Under the cartel, $P_{1 r t}=P_{2 r t}=P_{r t}$, whereas under competition mode prices are allowed to differ. Quantities throughout this and the next section are measured in 100-pound units, while prices and marginal costs are in dollars per 100 pounds of freight on the given route. ${ }^{16}$ Though the SRSA priced freight according to a complex classification scheme (with more valuable, irregular, or fragile goods charged higher prices, and bulk commodities charged the lowest prices), the SRSA traffic tables aggregate shipments across classes of merchandise. I thus calculate a weighted average price for each route, weighting by the share of route traffic in each class in 1880, and treat freight as being homogeneous in composition and priced at this index.

\subsection{Demand}

Suppose the latent utility of each mode $m$ for shipper $i$ on route-year $r t$ is $u_{i m r t}$, and shippers make a discrete choice over mode to maximize utility, as follows:

$$
\max _{m} u_{i m r t}=G_{m r t}\left(\beta_{1}+\beta_{2} D i s t_{r}\right)-\alpha P_{m r t}+\gamma_{m}+\xi_{m r t}+\eta_{i m r t} \equiv \delta_{m r t}+\eta_{i m r t}
$$

where $G_{m r t}$ indicates that mode $m$ requires transshipment in route-year $r t$, Dist $r$ is distance between route $r$ origin and destination, $P_{m r t}$ is the price of mode $m$ in route-year $r t$ (calculated as the weighted average of rates across all classes of merchandise, as before), $\gamma_{m}$ represents mode dummies, $\xi_{m r t}$ is a mean-zero, route-mode-year specific unobservable, and $\varepsilon_{i m r t}$ is an i.i.d. typeI extreme value error. Mean utility of each mode is denoted as $\delta_{m r t}$, and the outside option (withholding shipment) is indexed $m=0$ and normalized to have $\delta_{0 r t}=0$.

Under this specification, consumers may have an inherent preference for each mode, but choices are also influenced by prices and by the necessity of transshipment. From this specification of utility, we get choice probabilities (market shares) of the following form:

$$
s_{m r t}\left(P_{m r t}\right)=\frac{\exp \left(\delta_{m r t}\left(P_{m r t}\right)\right)}{1+\sum_{\ell} \exp \left(\delta_{\ell r t}\left(P_{\ell r t}\right)\right)}
$$

As in Equation (2), we can log-difference the outside market share to obtain the following reduced-

\footnotetext{
${ }^{16}$ Marginal costs should be interpreted as the cost of transporting 100 pounds on a given route, via a given mode, in a given year, which is a function of the mode, distance, and transshipment (if required).
} 
form equation, which can be used to estimate the demand parameters:

$$
\ln \left(s_{m r t}\right)-\ln \left(s_{0 r t}\right)=G_{m r t}\left(\beta_{1}+\beta_{2} \text { Dist }_{r}\right)-\alpha P_{m r t}+\gamma_{m}+\xi_{m r t}
$$

When this model is taken to the cartel data, $P_{m r t}$ will effectively be reduced to $P_{r}$, as prices on the sampled routes are constant within routes across modes and nearly constant over time. I estimate this model by 2SLS, instrumenting for prices with route length, a principal determinant of costs and prices for long-distance freight shipment. The necessary assumption to satisfy the exclusion restriction is that distance only affects demand through prices.

\subsection{Supply}

The cartel is assumed to set prices on each route to maximize joint profits, subject to the constraint of a single price for all carriers. Formally, the cartel's problem is:

$$
\begin{aligned}
\max _{P_{r t}} \Pi_{r t} & =\sum_{m}\left(P_{r t}-M C_{m r t}\right) \cdot Q_{m r t}\left(P_{r t}\right) \\
& =M_{r t} \sum_{m}\left(P_{r t}-M C_{m r t}\right) \cdot s_{m r t}\left(P_{r t}\right)
\end{aligned}
$$

with

$$
M C_{m r t}=\lambda_{m} \text { Dist }_{r}+\theta_{m} G_{m r t}+\omega_{r t},
$$

where $\lambda_{m}$ is the marginal cost of shipping an additional 100 pounds of freight per 100 miles of route length via mode $m, \theta_{m}$ is the cost of interchange at breaks in gauge (for all-rail traffic) or transshipment at port (for steamship traffic), and $\omega_{r t}$ is a mean-zero cost shock shared by both modes on a given route, in a given year.

The cartel's first-order condition for each route-year is then:

$$
\left(s_{1}+s_{2}\right)+\left(P-M C_{1}\right) \cdot \frac{\partial s_{1}(P)}{\partial P}+\left(P-M C_{2}\right) \cdot \frac{\partial s_{2}(P)}{\partial P}=0
$$

which can be rewritten to be linear in the cost parameters, as in Equation (5) below. I invoke this 
equation to estimate the supply parameters by OLS.

$$
\begin{aligned}
\left(P+\frac{s_{1}+s_{2}}{\partial s_{1} / \partial P+\partial s_{2} / \partial P}\right)=\lambda_{1} & \left(\frac{D i s t_{r}\left(\partial s_{1} / \partial P\right)}{\partial s_{1} / \partial P+\partial s_{2} / \partial P}\right)+\lambda_{2}\left(\frac{D i s t_{r}\left(\partial s_{2} / \partial P\right)}{\partial s_{1} / \partial P+\partial s_{2} / \partial P}\right) \\
& +\theta_{1}\left(\frac{G_{1}\left(\partial s_{1} / P\right)}{\partial s_{1} / \partial P+\partial s_{2} / \partial P}\right)+\theta_{2}\left(\frac{G_{2}\left(\partial s_{2} / \partial P\right)}{\partial s_{1} / \partial P+\partial s_{2} / \partial P}\right)+\omega
\end{aligned}
$$

\subsection{Estimation}

I proceed with estimation via a bootstrap procedure, in five steps: ${ }^{17}$

1. Estimate demand (Equation 4) via 2SLS, with clustered standard errors

2. Draw demand parameters from their joint distribution

3. Use draws to predict market shares and calculate elasticities

4. Estimate supply (Equation 5) via OLS with clustered SEs

5. Bootstrap: Repeat steps 2 through 5 (x2000)

This procedure will return a single set of estimates for demand, with standard errors clustered by route as before, and 2,000 sets of estimates for supply, which account for the parameters' sampling variance as well as the variance of the predicted market shares and elasticities entering the supply equation, which are generated from estimated parameters themselves.

\subsection{Parameter Estimates}

Table 10 shows the results for both demand and supply. The demand estimates (left panel) show an embedded preference for steamships over the all-rail mode and a negative effect of transshipment on demand, diminishing with route length as in previous results, breaking even around 800 miles. We also see that distance strongly predicts freight tariffs $(F>200)$, validating the choice of instrument, and a negative price coefficient of sensible magnitude $(\alpha=-9)$.

[Table 10 about here]

\footnotetext{
${ }^{17}$ In concept, a supply and demand system can be jointly estimated via GMM or by a bootstrap, but a GMM procedure here is complicated by the different dimensionalities of the demand and pricing equations (specified at the level of route-mode-years and route-years, respectively) and sensitive to starting values. Given its transparency and computational simplicity in this setting, I opt for the bootstrap.
} 
The marginal cost estimates (right panel) show that breaks in gauge impose a large fixed cost on interregional freight traffic, roughly $\$ 0.08$ per 100 pounds (over $10 \%$ of the median freight tariff for routes in this sample). This estimate reflects not only the direct cost of interchange, but also the indirect costs of time delays, the large fleet of idle rolling stock kept at points of interchange, and the purchase and maintenance of steam hoists themselves, which will be capitalized into prices (White 1993). Though expensive, bogie exchange was still cheaper than breaking bulk: transshipment costs at port are nearly $\$ 0.21$ per 100 pounds, due to the increased labor requirements, time delays, and risk of stolen or damaged goods. We also see similar operating costs per 100 miles of straight-line distance for each mode, at around $\$ 0.04$ per 100 pounds, or 0.8 cents per ton-mile. Though the cost of carriage by sea was at this time lower than costs by rail per mile traveled, steamships (and their last-mile railroad connections) would have had to travel a longer, less-direct path to interior Southern cities, offsetting this cost advantage in the estimates. ${ }^{18}$

Besides the functional form, recall that the principal assumption of this model is that the total latent market size for each route-year is twice the observed traffic. As in other examples of demand estimation (e.g., Berry et al. 1995), this assumption is necessary to compute outside shares, though its choice is validated by the fact that the estimates, and the counterfactuals simulated from them, are nonsensical under alternatives. The estimates and counterfactuals should nevertheless be interpreted as suggestive rather than incontrovertible evidence; in other words, the usual caution in interpreting structural estimates continues to apply.

\section{Standardization with Competition}

The question motivating the estimation was whether the gauge change would have increased trade in a competitive environment. To answer this question, I apply the estimates to simulate a counterfactual in which the two modes compete on prices in a Nash-Bertrand equilibrium. This exercise assumes a single price-setter for each mode, and thus only partially breaks the cartel, since there were two all-rail service providers and multiple steamship lines. Given the limitations of the data (which, as previously described, are provided at the level of paths, which sometimes involved mul-

\footnotetext{
${ }^{18}$ To put these estimates in perspective, note that observers in the 1850 s estimated that breaks in gauge generated handling costs of $\$ 0.25-0.50$ per ton in the 1850 s and a delay of 24 hours, equivalent to roughly 300 miles' distance at typical speeds (Poor 1851, Dartnell 1858). These costs (handling and time delays) would have been significantly reduced by steam hoists and other adapters in use by the 1880 s, which made breaking bulk unnecessary, but contemporaries' figures do not account for indirect costs (e.g., the cost of maintaining excess rolling stock), which may be large. As a benchmark for operating costs, recall that the SRSA permitted members exceeding their quota a 0.5 cent per ton-mile allowance for the cost of carriage before exacting penalties.
} 
tiple carriers and were not all present in every market), as well as recurrent distinctions between all-rail and steamship modes in both the data and the narrative record (in which contemporaries predicted that all-rail traffic would grow relative to steamship traffic under a uniform gauge), reducing the dimensionality of the counterfactual to modes (rather than paths, or carriers) is a natural choice, and sufficient for evaluating the question at hand.

To simulate this counterfactual, we need to solve for the competitive equilibrium. Each mode $m$ will set prices to maximize profits, with the following first-order condition:

$$
s_{m r t}\left(P_{1 r t}, P_{2 r t}\right)+\left(P_{m r t}-M C_{m r t}\right) \cdot \frac{\partial s_{m r t}}{\partial P_{m r t}}=0
$$

This condition can be rearranged into the familiar pricing equation:

$$
\left[\begin{array}{l}
P_{1 r t} \\
P_{2 r t}
\end{array}\right]=\left[\begin{array}{l}
M C_{1 r t} \\
M C_{2 r t}
\end{array}\right]+\left[\begin{array}{cc}
\frac{\partial s_{1 r t}}{\partial P_{1 r t}} & 0 \\
0 & \frac{\partial s_{2 r t}}{\partial P_{2 r t}}
\end{array}\right]^{-1}\left[\begin{array}{l}
s_{1 r t}\left(P_{1 r t}, P_{2 r t}\right) \\
s_{2 r t}\left(P_{1 r t}, P_{2 r t}\right)
\end{array}\right]
$$

into which we can plug the parameter estimates and numerically solve for prices $\left\{\tilde{P}_{m r t}\right\}$, which in turn imply quantities $\left\{Q_{m r t}\left(\tilde{P}_{1 r t}, \tilde{P}_{2 r t}\right)\right\}$ and profits $\left\{\Pi_{m r t}\left(\tilde{P}_{1 r t}, \tilde{P}_{2 r t}\right)\right\}$.

The results are provided in both tabular and graphical form in Table 11 and Figure 4. The table summarizes prices, traffic, and profits for the all-rail and steamship modes separately for the preperiod (Panel A) and the post-period (Panel B). In the pre-period, competition would drive down the average all-rail tariff by $27 \%$ and steamship tariff by $6 \%$. The reduction in prices generates a $21 \%$ increase in total traffic, powered by a near doubling in all-rail shipments. Industry profits fall sharply, with a $56 \%$ decline for all-rail and $47 \%$ decline for steamships.

[Table 11 about here]

Recall that the gauge change eliminated a fixed cost of interchange at breaks in gauge. I find that in a competitive market, railroads would have passed nearly half of these cost-savings through to prices, yielding even larger reductions in all-rail tariffs and increases in all-rail and total traffic in the post-period. As in the pre-period, competition would drive down profits for all firms, with a net $33 \%$ decline in profits for Southern freight carriers as a whole - although railroad profits would have been insulated by their newly developed advantage in providing uninterrupted service post-gauge change. Figure 4 provides a visualization of these effects. 
[Figure 4 about here]

A more direct test of impact that uniform gauge would have had on total shipments in a competitive market structure is to simulate a competitive post-period with and without breaks in gauge. This comparison avoids any potential contemporaneous changes in the market that could challenge the attribution of pre- versus post-gauge change differences in Table 11 to compatibility alone. Table 12 provides this comparison, showing that relative to a competitive post-period without the gauge change, compatibility reduces all-rail prices by $10 \%$ and increases total traffic by $9 \%$, driven entirely by growth in all-rail traffic, which comes partly from stealing market share from steamships and partly by drawing new traffic into the market.

[Table 12 about here]

\section{Results in Context: Standardization in Other Regions}

Though data are not available to study earlier conversions in other regions, which anyway occurred piecemeal and at smaller scale, we can look to the historical record for external validation. The most quantitative discussion of the effects of standardized gauge on railroad operations comes from the Erie Railway Company in the early 1870s, when it was considering conversion from 6 ' $0^{\prime \prime}$ to standard gauge. According to Blanchard (1873), the motivation for conversion was that the Erie's broad gauge was costing it substantial traffic, because shippers "demand quick time" and preferred routing that carried freight all the way to its destination "under lock and seal" as opposed to requiring transfers, which "increase the probabilities of loss, damage, and detention." As evidence of the potential returns, he evaluates the most recent example of conversion in North America (the Grand Trunk Railway of Canada, in 1873), and notes that its net income in the subsequent nine weeks (up to the date of publication) had grown $15 \%$ over the previous nine weeks and over the same nine weeks in the prior year, due to both lower costs and greater revenue, while its Canadian and American competitors had concurrently lost revenue.

\section{Implications for Research and Policy}

These results offer lessons for both research and policy. The foremost lesson is that standards can be economically important. Despite a large theoretical literature on compatibility, and a recent body 
of work on standards-setting organizations, there is little evidence explicitly linking compatibility to economic outcomes. In showing that the standardization of railroad gauge in the 1880s materially affected trade, this paper has implications for other settings where traffic is exchanged across connecting, incompatible networks. For example, early efforts at computer networking yielded to multiple networks that developed alongside the Internet, each of which used a proprietary naming system for addressing email traffic; intercommunication was enabled by gateways but was so complex that that only the most technical users could do so until these networks adopted the domain name system as a common standard (Greenstein 2015, Partridge 2008).

The results also yield a deeper lesson on the interaction of standards with product market competition. In many settings, transactions must be executed via intermediaries who provide physical or digital infrastructure for transmission, such as freight carriers (for physical trade), Internet service providers (for communications), and financial exchanges (for asset purchases). These intermediaries often must interconnect with others for delivery. This paper shows that compatibility at connection points can generate large welfare gains - but only if the cost savings are passed through to consumers, which is unlikely to occur if service is not competed. Because these settings experience network effects and are inherently likely to be concentrated, a lack of competition is often a reality, and the results of this paper immediately relevant.

\section{Direct Applications: Modern International Railways}

In addition to these contributions, the results have direct bearing on modern-day railway networks. Breaks in gauge are still common around the world, especially in developing regions such as South Asia, Africa, and Latin America. These breaks often occur at national boundaries, though in some cases they are present within them as well - most notably in India, which is nearing the end of an

effort to standardize the gauge of its 100,000-mile network. Appendix Figure E.1 illustrates how pervasive the problem is, showing a world map of countries color-coded by the principal gauge of their railways. Developing regions generally have 3 or 4 gauges in use.

The problem has not escaped the attention of policymakers: resolving differences in gauge has been a focal point in repeated international negotiations to integrate domestic railways into transcontinental networks in places like Europe, Asia, and the Middle East. The most recent example of such an agreement was the United Nations-brokered Trans-Asian Railway (TAR) Network Agreement, ratified by 17 Asian countries in 2006 (UNTC 2006). The negotiations behind this agreement date back to the 1950s, when the U.N. Economic Commission for Asia and the Far East (now the U.N. 
Economic and Social Commission for Asia and the Pacific, or UNESCAP) set out to link Istanbul and Singapore (UNESCAP 1996). The intent was to establish more direct, overland routes between Europe and East Asia to support and promote international trade. Integrating the transportation network became increasingly imperative as trade grew over the following decades, but "this proposal, and the many that followed it, were frustrated ... by the lack of a uniform railway gauge ... and by the presence of gaps, or missing links, in the route" (UNESCAP 1996). Gaps could be filled, but it proved impossible to negotiate a common gauge standard, and when a treaty was finally ratified, it contained no provisions for standardizing the gauge.

As a result, while there are now major lines connecting all parts of the continent, freight moving between Europe and Southeast Asia must cross three breaks in gauge (see Appendix Figure E.2). These breaks remain costly, interrupting the movement of both passengers and cargo and imposing delays. And although more than a century has passed, the same adapters are still being used today: documentation points to transshipment, bogie exchange, and variable gauge as the principal means of interchange. The TAR is also not unique in this regard: a similar agreement in Europe (UNTC 1991) lists the stations where interchange would have to occur and specifies whether it would be conducted by transshipment or bogie exchange (Appendix Table E.2).

In this context, the results of this paper offer lessons for present-day treaties and policies governing transport network integration. The main lesson is that eliminating breaks in gauge significantly improves the quality of rail-based freight shipping services, enough to divert traffic from other modes - and if operators' cost-savings are passed through to consumers, enough to increase the total volume of trade. It is important to nevertheless be cautious in extending these results to a different time period, geography, and market structure (many railroads are nationalized), but given the parallels, it seems appropriate to view the evidence in this paper as instructive of the potential benefits of interoperability under a common gauge.

\section{Conclusion}

This paper studies the conversion of 13,000 miles of railroad in the U.S. South to a standardcompatible gauge in 1886 on internal trade between the South and the North. The gauge change integrated the South into the national railroad network and provides a large-scale natural experiment for studying the effects of interoperability standards on economic activity. Using comprehensive records of merchandise shipments on 52 North-to-South routes from a cartel that governed this 
traffic, I find that the gauge change precipitated a large transfer of market share from steamships to railroads that declines with distance but did not affect total shipments.

To reconcile these results, I turn attention to the cartel itself, which held prices constant around the conversion - likely limiting any response on the extensive margin. The natural question is then whether standardization would have led to lower prices and increased trade in a competitive market. To evaluate this question, I estimate a model of the industry and simulate counterfactuals in which the all-rail and steamship transport modes compete. The results of this exercise suggest that in a competitive industry, the standardization of the gauge would have generated a $27 \%$ reduction in all-rail prices and $20 \%$ growth in aggregate shipments.

The results offer several lessons, the foremost of which is that compatibility can have a large, material effect on economic activity in industries where exchange takes place over interconnected networks. The paper in particular sheds light on the potential benefits to standardizing the gauge of global railroad networks, which continue to suffer from breaks in gauge that necessitate costly interchange. Finally, the results point to a complex interaction of standardization and product market competition in networked environments. While collusion (or consolidation) increases firms' incentives to make their networks interoperable by internalizing the externality, it also harms consumers and limits the welfare gains from standardization. This tension presents an important tradeoff for antitrust regulators that is underappreciated in the literature on standards or competition but is ripe for attention, given recent antitrust scrutiny on several large Internet and communications firms with products that benefit from interoperability. 


\section{References}

Anton, James J. and Dennis A. Yao, "Standard-setting Consortia, Antitrust, and High-technology Industries," Antitrust Law Journal, 1995, 64 (1), 247-265.

Argue, David A., Cartel Operation with Revenue Pooling and Output Quotas: The Southern Railway and Steamship Association 1990. Unpublished dissertation.

Arthur, W. Brian, "Competing Technologies, Increasing Returns, and Lock-in by Historical Events," The Economic Journal, 1989, pp. 116-131.

Atack, Jeremy, Historical Geographic Information Systems (GIS) database of U.S. Railroads for 1861 September 2015.

- and Robert A. Margo, "The Impact of Access to Rail Transportation on Agricultural Improvement: The American Midwest as a Test Case, 1850-1860," Journal of Transport and Land Use, 2011, 4, 5-18.

_ , Michael Haines, and Robert A. Margo, "Railroads and the Rise of the Factory: Evidence for the United States, 1850-1870," in Paul W. Rhode, Joshua Rosenbloom, and David Weiman, eds., Economic Evolution and Revolutions in Historical Time, Palo Alto: Stanford University Press, 2011.

Augereau, Angelique, Shane Greenstein, and Marc Rysman, "Coordination versus Differentiation in a Standards War: 56k Modems," The RAND Journal of Economics, 2006, 37 (4), 887-909.

Baron, Justus and Daniel F. Spulber, Technology Standards and Standards Organizations: Introduction to the Searle Center Database. 2015. Working paper.

Bernhofen, Daniel M., Zouheir El-Sahli, and Richard Kneller, Estimating the Effects of the Container Revolution on World Trade. 2013. CESifo Working Paper Series No. 4136.

Berry, Steven, James Levinsohn, and Ariel Pakes, "Automobile Prices in Market Equilibrium," Econometrica, 1995, 63, 841-890.

Blonigen, Bruce A. and Anca Cristea, "The Effects of the Interstate Commerce Act on Transport Costs: Evidence from Wheat Prices," Review of Industrial Organization, 2013, 43 (1-2), 41-62.

David, Paul A., "Clio and the Economics of QWERTY," American Economic Review, 1985, 75 (2), 332-37.

Davis, Champion McDowell, Atlantic Coast Line: Fragments of its History During Over a CEntury, New York: Newcomen Society in North America, 1950a.

Donaldson, Dave, "Railroads of the Raj: Estimating the Impact of Transportation Infrastructure," American Economic Review, 2015, forthcoming.

Ellison, Glenn, "Theories of Cartel Stability and the Joint Executive Committee," The RAND Journal of Economics, 1994, 25 (1), 37-57.

Farrell, Joseph and Garth Saloner, "Standardization, Compatibility, and Innovation," The RAND Journal of Economics, 1985, 16 (1), 70-83.

_ and _, "Installed Base and Compatibility: Innovation, Product Preannouncements, and Predation," American Economic Review, 1986, 76 (5), 940-955.

_ and _, "Coordination through Committees and Markets," The RAND Journal of Economics, 1988, 19 (2), 235-252.

_ and _ , "Converters, Compatibility, and the Control of Interfaces," Journal of Industrial Economics, 1992, $40(1), 9-35$. 
Fogel, Robert W., Railroads and American Economic Growth: Essays in Economic History, Baltimore: Johns Hopkins University Press, 1964.

Frankel, Jeffrey and Andrew K. Rose, "An Estimate of the Effect of Common Currencies on Trade and Income," Quarterly Journal of Economics, 2002, 117 (2), 437-466.

Gandal, Neil, "Quantifying the Trade Impact of compatibility Standards and Barriers: An Industrial Organization Perspective," in K.E. Maskus and J.S. Wilson, eds., Quantifying the Impact of Technical Barriers to Trade: Can it be Done?, Univeristy of Michigan Press 2001, pp. 137-154.

Greenstein, Shane, How the Internet Became Commercial: Innovation, Privatization, and the Birth of a new Network, Princeton: Princeton University Press, 2015.

Hornbeck, Richard and Dave Donaldson, "Railroads and American Economic Growth: A "Market Access" Approach," Quarterly Journal of Economics, 2016, 131, 799-858.

Hudson, Henry, "The Southern Railway and Steamship Association," Quarterly Journal of Economics, 1890, 5 (1), 70-94.

Joubert, Willam H., Southern Freight Rates in Transition, Gainesville: University of Florida Press, 1949.

Katz, Michael L. and Carl Shapiro, "Network Externalities, Competition, and Compatibility," American Economic Review, 1985, 75 (3), 424-440.

_ and _ , "Technology Adoption in the Presence of Network Externalities," Journal of Political Economy, $1986,94(4), 822-41$.

Kolko, Gabriel, Railroads and Regulation, 1877-1916, Princeton: Princeton University Press, 1965.

Liebowitz, S. J. and Stephen E. Margolis, "The Fable of the Keys," Journal of Law 83 Economics, 1990, 33 (1), 1-25.

_ and _, "Path Dependence, Lock-in, and History," Journal of Law, Economics, and Organization, 1995, $11(1), 205-226$.

Louisville \& Nashville Railroad, Annual Report to Investors 1886. Fiscal year ending June 30, 1886.

Minnesota Population Center, National Historical Geographic Information System: Version 2.0, Minneapolis: University of Minnesota, 2011.

Organization, World Trade, World Trade Report 2005: Exploring the Links between Trade, Standards, and the WTO. 2005.

Partridge, Craig, "The Technical Development of Internet Email," IEEE Annals of the History of Computing, 2008, 1 (2), 3-29.

Poor, Henry V., "Cincinnati and Seaboard Railways," American Railroad Journal, 1851, 7 (37), 386.

_, Poor's Manual of Railroads of the United States. 1868. Volumes 1882, -84, -86, -88, -90.

Porter, Robert H., "A Study of Cartel Stability: The Joint Executive Committee, 1880-1886," The Bell Journal of Economics, 1983, 14 (2), 301-314.

Prager, Robin A., "Using Stock Price Data to Measure the Effects of Regulation: The Interstate Commerce Act and the Railroad Industry," The RAND Journal of Economics, 1989, 20 (2), 280-290.

Puffert, Douglas J., "The Standardization of Track Gauge on North American Railways, 1830-1890," The Journal of Economic History, 2000, 60 (4), 933-960. 
_ , "Path Dependence in Spatial Networks: The Standardization of Railway Track Gauge," Explorations in Economic History, 2002, 39 (3), 282-314.

_, Tracks across Continents, Paths through History: The Economic Dynamics of Standardization in Railway Gauge, Chicago: University of Chicago Press, 2009.

Rose, Andrew K. and Eric Van Wincoop, "National Money as a Barrier to International Trade: The Real Case for Currency Union," American Economic Review, 2001, 91 (2), 386-390.

Rua, Gisela, Diffusion of Containerization. 2014. FRB Finance and Economics Discussion Series No. 2014-88.

Rysman, Marc and Timothy Simcoe, "Patents and the Performance of Voluntary Standard-setting Organizations," Management science, 2008, 54 (11), 1920-1934.

Siddall, William R., "Railroad Gauges and Spatial Interaction," Geographical Review, 1969, 59 (1), 29-57.

Simcoe, Timothy, "Standard Setting Committees: Consensus Governance for Shared Technology Platforms," American Economic Review, 2012, 102 (1), 305-336.

Sindall, Charles A., "Development of the Traffic between the Southern States and the Northern and Northwestern States," in Treasury Department, ed., Report on the Internal Commerce of the United States, Washington: Government Printing Office, 1886.

Southern Railway and Steamship Association (SRSA), Circular Letters. 1875. Volumes 13-24.

Swisher, Scott, Reassessing Railroads and Growth: Accounting for Transport Network Endogeneity 2014. Working paper.

Taylor, George R. and Irene D. Neu, The American Railroad Network, 1861-1890, Urbana and Chicago: University of Illinois Press, 1956.

Ulen, Thomas S., Cartels and Regulation: Late Nineteenth Century Railroad Collusion and the Creation of the Interstate Commerce Commission 1979. Unpublished dissertation.

_-, "The Market for Regulation: The ICC from 1887 to 1920," American Economic Review: Papers and Proceedings, 1980, 70 (2), 306-310.

United Nations Economic and Social Commission for Asia and the Pacific (UNESCAP), TransAsian Railway Route Requirements: Development of the Trans-Asian Railway in the Indo-China and ASEAN Subregion. 1996.

United Nations Treaty Collection (UNTC), European Agreement on Important International Combined Transport Lines and Related Installations (AGTC). February 1991.

_, Agreement on International Railways in the Arab Mashreq. April 2003.

_, Intergovernmental Agreement on the Trans-Asian Railway Network. April 2006.

U.S. Department of the Interior, Statistical Report of the Railroads in the United States in 1880, Washington: GPO, 1883. 


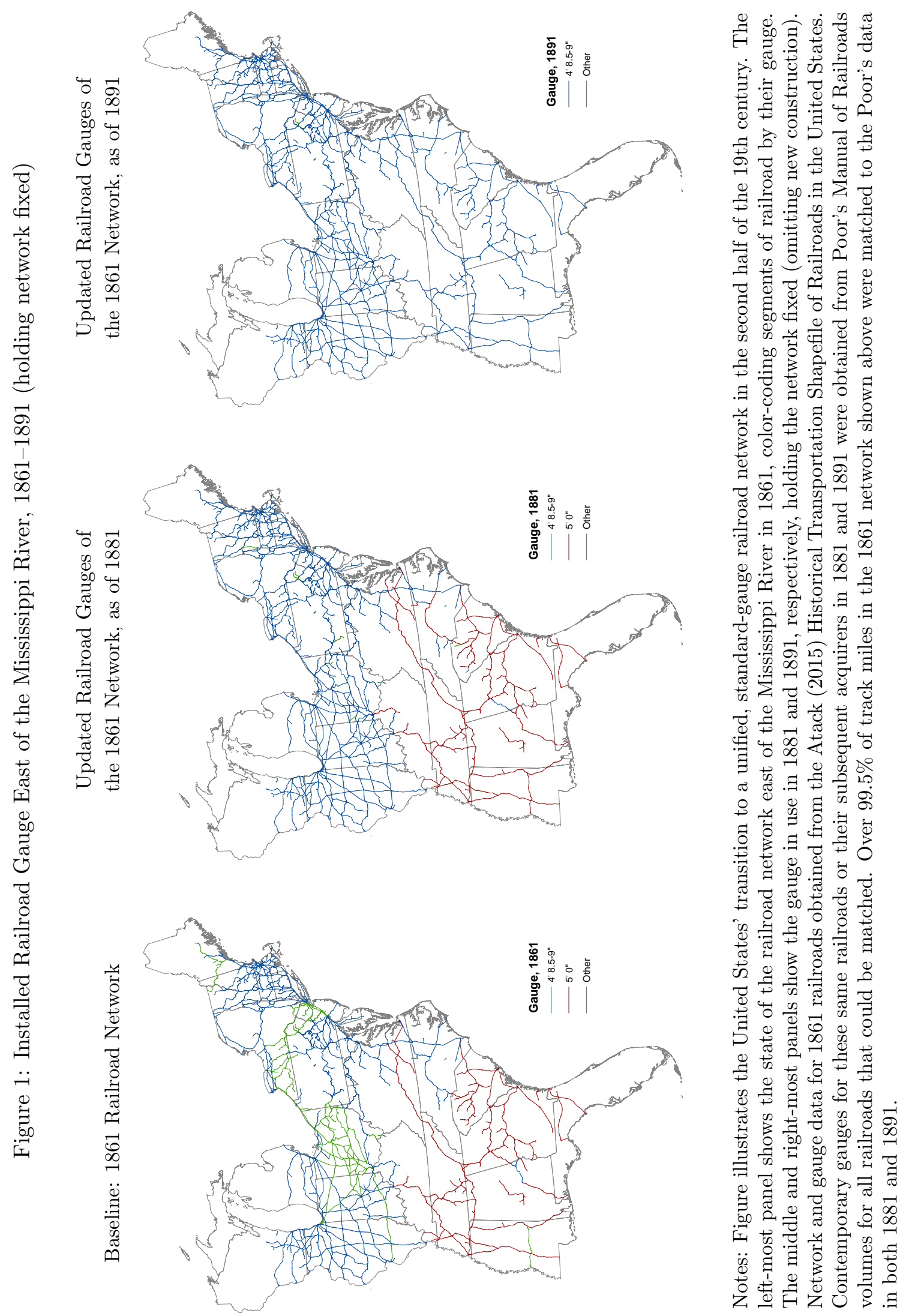


Figure 2: Map of Sampled Origins (North) and Destinations (South)

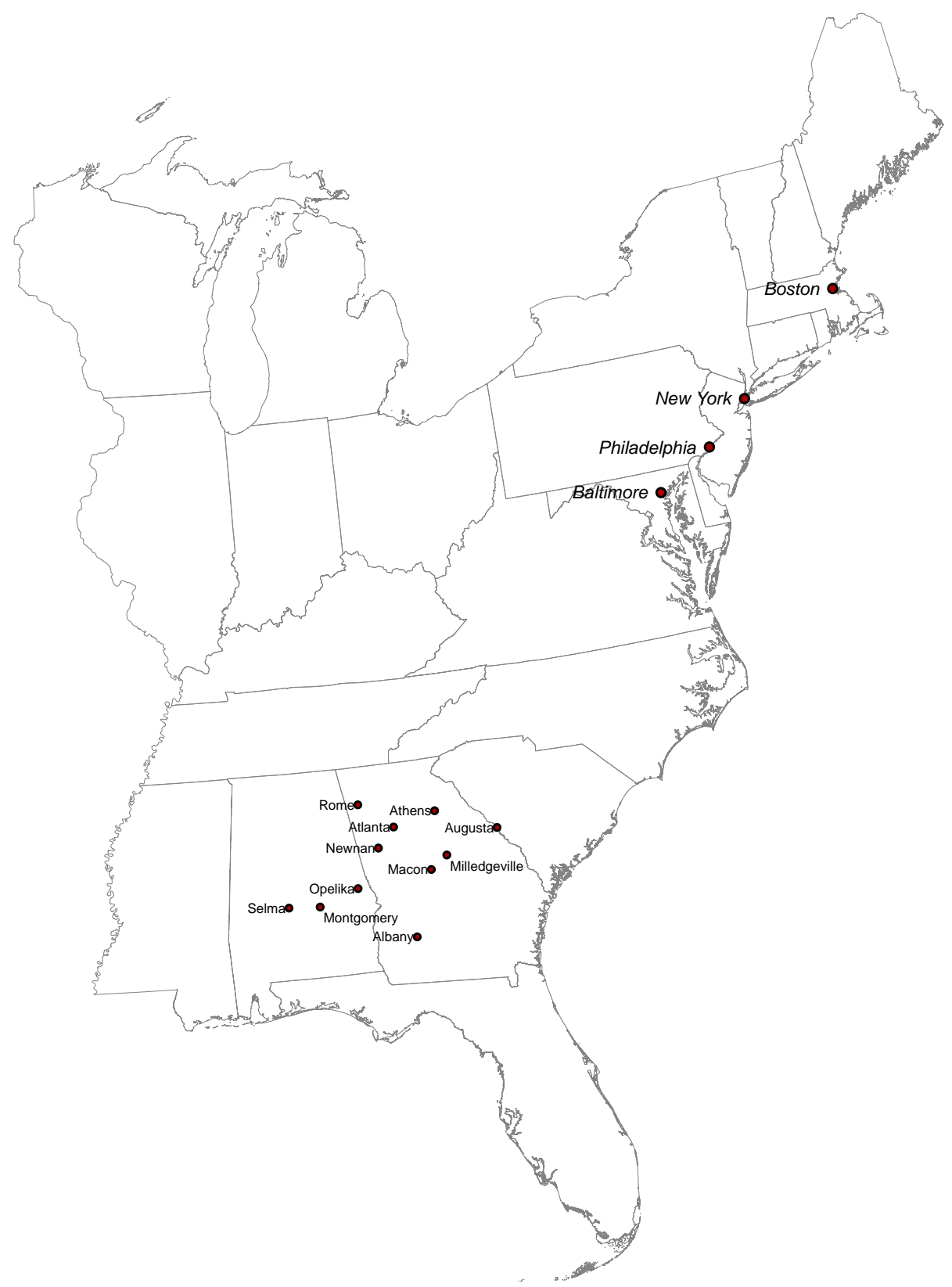

Notes: Figure shows the northern route origins and southern destinations for routes in the sample. These destinations are those for which data was reported by the Southern Railway and Steamship Association both before and after the gauge change. Freight transportation was available by all-rail routes traversing Virginia, Tennessee, and the Carolinas or by a combination of steamship and railroad, via southern port cities such as Charleston, Savannah, Norfolk, and Port Royal. 
Figure 3: Distribution of Cartel Price Changes, pre- vs. post-Gauge Change

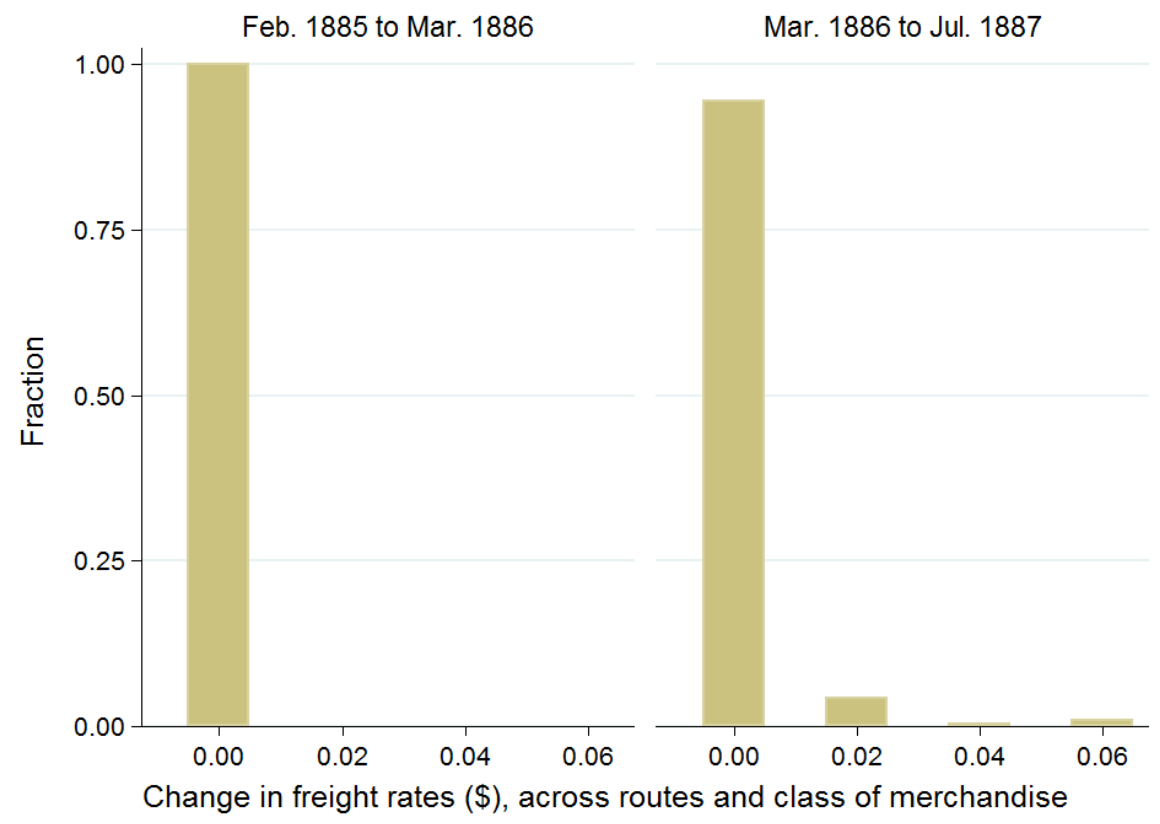

Notes: Figure shows the distribution of cartel price changes across routes and classes of merchandise from February 1885 to March 1886 (left panel) and March 1886 to July 1887 (right panel), for the subset of routes included in the SRSA rate tables. The handful of rate increases in the latter period come entirely from two routes: Philadelphia to Montgomery, and Philadelphia to Selma. Data from SRSA Circular Letters, Volumes 13-24.

Figure 4: Prices, Quantities, and Profits in Competitive Counterfactual
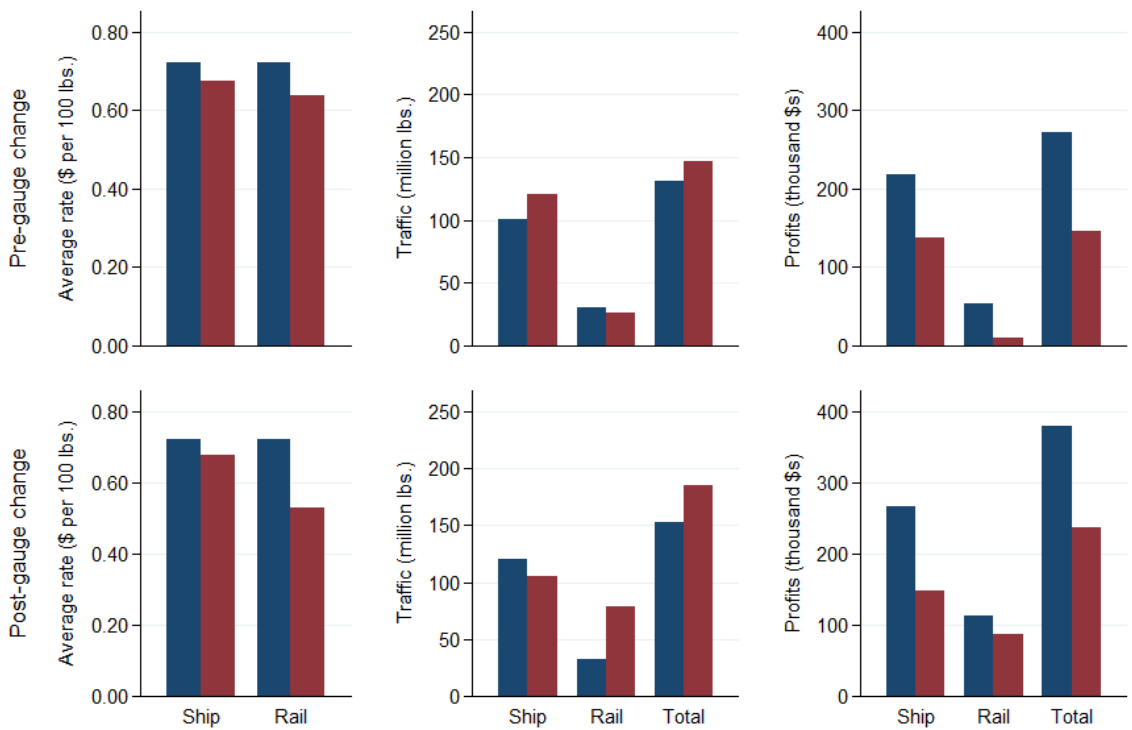

Collusion (as observed)

Competition (counterfactual)

Notes: Figure shows mean prices, total traffic, and est. profits for railroads and steamships, as observed and in a counterfactual in which they compete. The figure is a visual presentation of the data in Table 11. 
Table 1: Approx. Miles of Railroad in each Gauge, by Region, 1881-1889 (Poor's Manual of Railroads)

\begin{tabular}{|c|c|c|c|c|c|}
\hline \multirow[b]{2}{*}{ New England } & \multicolumn{3}{|c|}{ Pre-Gauge Change } & \multicolumn{2}{|c|}{ Post-Gauge Change } \\
\hline & 1881 & 1883 & 1885 & 1887 & 1889 \\
\hline \multicolumn{6}{|l|}{ Miles in gauge: } \\
\hline 4' 8.5-9" & $6,060.2$ & $6,082.6$ & $6,237.8$ & $6,600.3$ & $6,627.6$ \\
\hline 5'0" & 0.0 & 0.0 & 0.0 & 0.0 & 0.0 \\
\hline Other & 191.1 & 201.2 & 180.4 & 184.6 & 116.5 \\
\hline Total Miles & $6,251.3$ & $6,283.8$ & $6,418.2$ & $6,784.9$ & $6,744.1$ \\
\hline Pct. 4' 8.5-9"' & $97 \%$ & $97 \%$ & $97 \%$ & $97 \%$ & $98 \%$ \\
\hline
\end{tabular}

Mid-Atlantic

\begin{tabular}{|c|c|c|c|c|c|}
\hline \multicolumn{6}{|l|}{ Miles in gauge: } \\
\hline 4' 8.5-9"' & $14,855.0$ & $17,590.3$ & $18,923.4$ & $18,648.6$ & $20,210.7$ \\
\hline $5^{\prime} 0 "$ & 0.4 & 0.4 & 0.5 & 0.2 & 0.0 \\
\hline Other & 990.2 & 997.4 & 868.3 & 772.0 & 682.5 \\
\hline Total Miles & $15,845.6$ & $18,588.1$ & $19,792.2$ & $19,420.9$ & $20,893.3$ \\
\hline Pct. 4' 8.5-9"' & $94 \%$ & $95 \%$ & $96 \%$ & $96 \%$ & $97 \%$ \\
\hline
\end{tabular}

Midwest

\begin{tabular}{|c|c|c|c|c|c|}
\hline Miles in gauge: & & & & & \\
\hline 4' 8.5-9" & $34,904.3$ & $38,669.2$ & $37,904.4$ & $42,241.2$ & $45,938.1$ \\
\hline $5^{\prime} 0 "$ & 0.0 & 0.0 & 0.0 & 0.0 & 0.0 \\
\hline Other & $2,342.1$ & $2,800.7$ & $2,591.3$ & $1,318.3$ & $1,028.7$ \\
\hline Total Miles & $37,246.4$ & $41,470.0$ & $40,495.6$ & $43,559.5$ & $46,966.7$ \\
\hline Pct. 4' 8.5-9" & $94 \%$ & $93 \%$ & $94 \%$ & $97 \%$ & $98 \%$ \\
\hline
\end{tabular}

South (focal region)

\begin{tabular}{|c|c|c|c|c|c|}
\hline \multicolumn{6}{|l|}{ Miles in gauge: } \\
\hline 4' 8.5-9" & $4,306.8$ & $4,759.6$ & $6,048.6$ & $21,593.6$ & $25,252.7$ \\
\hline $5^{\prime} 0 "$ & $11,908.1$ & $12,964.5$ & $13,274.2$ & 268.2 & 19.5 \\
\hline Other & $1,042.7$ & $1,592.6$ & $1,371.5$ & $1,734.9$ & $1,521.2$ \\
\hline Total Miles & $17,257.5$ & $19,316.6$ & $20,694.3$ & $23,596.7$ & $26,793.4$ \\
\hline Pct. 4' 8.5-9"' & $25 \%$ & $25 \%$ & $29 \%$ & $92 \%$ & $94 \%$ \\
\hline \multicolumn{6}{|l|}{ Western States } \\
\hline \multicolumn{6}{|l|}{ Miles in gauge: } \\
\hline 4' 8.5-9"' & $26,272.5$ & $33,817.6$ & $36,435.9$ & $47,694.8$ & $54,352.6$ \\
\hline 5' 0" & 135.0 & 135.0 & 0.0 & 0.0 & 0.0 \\
\hline Other & $3,427.4$ & $5,623.2$ & $4,642.0$ & $4,253.6$ & $3,965.9$ \\
\hline Total Miles & $29,834.8$ & $39,575.8$ & $41,078.0$ & $51,948.4$ & $58,318.5$ \\
\hline Pct. 4' 8.5-9" & $88 \%$ & $85 \%$ & $89 \%$ & $92 \%$ & $93 \%$ \\
\hline
\end{tabular}

Notes: Table shows the approximate miles of railroad in the U.S. from 1881 to 1889 in two-year intervals, by region and gauge, confirming the scale of the conversion: 13,000 miles of Southern railroad converted from 5'0" to 4' 9" between 1885 and 1887. Data from Poor's Manual of Railroads, which provides a near-complete, annual enumeration of U.S. railroads. The data are subject to regional classification errors which tend to over-attribute mileage to the Midwest, pulling from the Mid-Atlantic and West, as a result of railroads with principal operations in the Midwest extending into these regions. The table uses the regional definitions of the Poor's Manual; the southern states are Virginia, West Virginia, Kentucky, Tennessee, Mississippi, Alabama, Georgia, Florida, the Carolinas, and Louisiana. 
Table 2: Origins and Destinations for Sampled Routes

\begin{tabular}{|c|c|c|c|}
\hline \multicolumn{2}{|c|}{$\begin{array}{l}\text { Destinations } \\
\quad(\text { south })\end{array}$} & \multicolumn{2}{|l|}{$\begin{array}{l}\text { Origins } \\
\text { (north) }\end{array}$} \\
\hline Albany & GA & Boston & MA \\
\hline Athens & GA & New York & NY \\
\hline Atlanta & GA & Philadelphia & PA \\
\hline Augusta & GA & Baltimore & $\mathrm{MD}$ \\
\hline Macon & GA & & \\
\hline Milledgeville & GA & & \\
\hline Newnan & GA & & \\
\hline Rome & GA & & \\
\hline Montgomery & $\mathrm{AL}$ & & \\
\hline Opelika & $\mathrm{AL}$ & & \\
\hline Selma & $\mathrm{AL}$ & & \\
\hline \multicolumn{4}{|c|}{ A. \& W. Pt. stations (GA) } \\
\hline W. \& A. stat & ons (GA) & & \\
\hline
\end{tabular}

Notes: Table lists the origin and terminus of routes in the sample of Northern merchandise shipments used in the remainder of this paper. These 52 routes ( 4 origins $\mathrm{x} 13$ destinations) are those for which data was reported by the Southern Railway and Steamship Association both before and after the gauge change. "A. \& W. Pt. Stations" refers to stations on the Atlanta and West Point Railroad between East Point and West Point, GA (70 mi), whose traffic was reported collectively; "W. \& A. Stations" refers to stations on the Western and Atlantic Railroad between Chattanooga, TN and Marietta, GA (87 mi). These destinations are geotagged to the centroid of their respective endpoints.

Table 3: Trends in Southern Freight Traffic, by Mode and Route Length (sampled routes only)

\begin{tabular}{|c|c|c|c|c|c|c|c|}
\hline & \multicolumn{3}{|c|}{ Pre-Gauge Change } & \multicolumn{4}{|c|}{ Post-Gauge Change } \\
\hline & 1883-84 & $1884-85$ & $1885-86$ & 1886-87 & $1887-88$ & $1888-89$ & 1889-90 \\
\hline \multicolumn{8}{|c|}{ Panel A. Mean across routes $<25$ th percentile distance } \\
\hline \multirow[t]{2}{*}{ Total traffic (million lbs.) } & 0.75 & 0.69 & 0.70 & 0.74 & 0.83 & 0.87 & 0.83 \\
\hline & $(0.26)$ & $(0.24)$ & $(0.26)$ & $(0.27)$ & $(0.31)$ & $(0.32)$ & $(0.29)$ \\
\hline \multirow[t]{2}{*}{ via rail } & 0.70 & 0.51 & 0.64 & 0.88 & 0.94 & 0.84 & 0.93 \\
\hline & $(0.26)$ & $(0.21)$ & $(0.30)$ & $(0.33)$ & $(0.38)$ & $(0.33)$ & $(0.34)$ \\
\hline \multirow[t]{2}{*}{ via steamship } & 0.80 & 0.88 & 0.76 & 0.60 & 0.72 & 0.91 & 0.72 \\
\hline & $(0.26)$ & $(0.26)$ & $(0.22)$ & $(0.19)$ & $(0.24)$ & $(0.33)$ & $(0.24)$ \\
\hline \multicolumn{8}{|c|}{ Panel B. Mean across routes $>75$ th percentile distance } \\
\hline \multirow[t]{2}{*}{ Total traffic (million lbs.) } & 0.97 & 0.94 & 1.28 & 0.96 & 1.13 & 1.13 & 1.43 \\
\hline & $(0.47)$ & $(0.42)$ & $(0.56)$ & $(0.44)$ & $(0.55)$ & $(0.55)$ & $(0.73)$ \\
\hline \multirow[t]{2}{*}{ via rail } & 0.28 & 0.38 & 0.58 & 0.53 & 0.44 & 0.25 & 0.35 \\
\hline & $(0.17)$ & $(0.24)$ & $(0.36)$ & $(0.41)$ & $(0.34)$ & $(0.17)$ & $(0.23)$ \\
\hline \multirow[t]{2}{*}{ via steamship } & 1.67 & 1.50 & 1.99 & 1.39 & 1.83 & 2.01 & 2.50 \\
\hline & $(0.59)$ & $(0.51)$ & $(0.67)$ & $(0.46)$ & $(0.67)$ & $(0.69)$ & $(0.93)$ \\
\hline
\end{tabular}

Notes: Table reports average merchandise shipments by year on shorter routes $(<25$ th percentile) versus longer routes ( $>75$ th percentile), breaking out the totals by mode. The table illustrates the rapid growth in Southern freight traffic over the 1880s on a set of routes that were serviced throughout the decade. Southern trade growth would be even higher when considering routes that entered service over the decade, as the rail network expanded (Table 1 shows the growth in mileage). Standard errors of the mean shown in parentheses. 
Table 4: Change in All-Rail Traffic

\begin{tabular}{lcccccc}
\hline \hline & $(1)$ & $(2)$ & $(3)$ & $(4)$ & $(5)$ & $(6)$ \\
\hline All-rail x post-change & $2.437^{* * *}$ & $2.429^{* * *}$ & $2.425^{* * *}$ & $2.484^{* * *}$ & $2.466^{* * *}$ & $2.541^{* * *}$ \\
& $(0.460)$ & $(0.455)$ & $(0.455)$ & $(0.466)$ & $(0.559)$ & $(0.582)$ \\
$*$ distance (100 mi) & $-0.322^{* * *}$ & $-0.328^{* * *}$ & $-0.328^{* * *}$ & $-0.334^{* * *}$ & $-0.331^{* * *}$ & $-0.341^{* * *}$ \\
& $(0.059)$ & $(0.059)$ & $(0.059)$ & $(0.060)$ & $(0.073)$ & $(0.075)$ \\
\hline Breakeven distance & 756.5 & 740.5 & 740.1 & 742.8 & 744.1 & 745.6 \\
& $(34.9)$ & $(32.7)$ & $(32.7)$ & $(32.7)$ & $(39.8)$ & $(39.7)$ \\
\hline $\mathrm{N}$ & 1036 & 1036 & 1036 & 1036 & 1036 & 1036 \\
$R^{2}$ & 0.32 & 0.67 & 0.67 & 0.73 & 0.70 & 0.75 \\
Route FE & & $\mathrm{X}$ & $\mathrm{X}$ & & & \\
Mode FE & & & $\mathrm{X}$ & & & \\
Year FE & & & $\mathrm{X}$ & & & $\mathrm{X}$ \\
Route-mode FE & & & & $\mathrm{X}$ & $\mathrm{X}$ & $\mathrm{X}$ \\
Route-yr FE & & & & & & \\
\hline \hline
\end{tabular}

Notes: Table estimates effect of the gauge change on merchandise shipments from North to South. Observations are route-mode-years. The treated group consists of the all-rail mode; the control group, the steamship mode. The "breakeven distance" at which the effects of standardization dissipate to zero is provided below the regression estimates. The dependent variable in all columns is $\log$ pounds of traffic. ${ }^{*}, * *, * * *$ represent significance at the 0.1 , 0.05 , and 0.01 levels, respectively. SEs clustered by route in parentheses.

Table 5: Change in All-Rail Traffic, ACL and PAL

\begin{tabular}{lcccccc}
\hline \hline & $(1)$ & $(2)$ & $(3)$ & $(4)$ & $(5)$ & $(6)$ \\
\hline A.C.L. x post-change & $2.840^{* * *}$ & $2.852^{* * *}$ & $2.851^{* * *}$ & $2.826^{* * *}$ & $2.848^{* * *}$ & $2.809^{* * *}$ \\
& $(0.527)$ & $(0.559)$ & $(0.560)$ & $(0.552)$ & $(0.686)$ & $(0.671)$ \\
$*$ distance (100 mi) & $-0.398^{* * *}$ & $-0.402^{* * *}$ & $-0.402^{* * *}$ & $-0.396^{* * *}$ & $-0.403^{* * *}$ & $-0.396^{* * *}$ \\
& $(0.071)$ & $(0.076)$ & $(0.076)$ & $(0.074)$ & $(0.094)$ & $(0.090)$ \\
P.A.L. x post-change & $1.809^{* * *}$ & $1.743^{* * *}$ & $1.733^{* * *}$ & $1.808^{* * *}$ & $1.748^{* *}$ & $1.829^{* *}$ \\
& $(0.555)$ & $(0.610)$ & $(0.609)$ & $(0.607)$ & $(0.754)$ & $(0.754)$ \\
$*$ distance (100 mi) & $-0.238^{* * *}$ & $-0.244^{* * *}$ & $-0.243^{* * *}$ & $-0.248^{* * *}$ & $-0.247^{* *}$ & $-0.253^{* *}$ \\
& $(0.071)$ & $(0.080)$ & $(0.079)$ & $(0.080)$ & $(0.100)$ & $(0.101)$ \\
\hline Breakeven distance (A.C.L.) & 713.6 & 709.6 & 709.7 & 713.4 & 705.9 & 709.8 \\
& $(32.5)$ & $(32.7)$ & $(32.8)$ & $(34.5)$ & $(39.0)$ & $(41.5)$ \\
Breakeven distance (P.A.L.) & 759.0 & 715.7 & 713.5 & 728.3 & 707.3 & 723.9 \\
& $(53.2)$ & $(58.6)$ & $(58.8)$ & $(55.6)$ & $(70.4)$ & $(66.5)$ \\
\hline N & 1036 & 1036 & 1036 & 1036 & 1036 & 1036 \\
$R^{2}$ & 0.48 & 0.83 & 0.84 & 0.89 & 0.86 & 0.91 \\
Route FE & & $\mathrm{X}$ & $\mathrm{X}$ & & & $\mathrm{X}$ \\
Mode FE & & $\mathrm{X}$ & & & $\mathrm{X}$ \\
Year FE & & $\mathrm{X}$ & & $\mathrm{X}$ & \\
Route-mode FE & & & & & $\mathrm{X}$ \\
Route-yr FE & & & & & & $\mathrm{X}$ \\
\hline \hline
\end{tabular}

Notes: Table estimates effect of the gauge change on merchandise shipments from North to South. Observations are route-mode-years. The treatment group consists of these carriers. The control group remains the steamship mode. The "breakeven distance" at which the effects of standardization dissipate to zero is provided below the regression estimates. The dependent variable in all columns is $\log$ pounds of traffic. ${ }^{*}, * *, * * *$ represent significance at the $0.1,0.05$, and 0.01 levels, respectively. SEs clustered by route in parentheses. 
Table 6: Effects on Traffic Shares

\begin{tabular}{lcc}
\hline \hline & $(1)$ & $(2)$ \\
\hline All-rail x post-change & $2.281^{* * *}$ & $2.400^{* * *}$ \\
& $(0.428)$ & $(0.450)$ \\
$*$ distance $(100 \mathrm{mi})$ & $-0.315^{* * *}$ & $-0.327^{* * *}$ \\
& $(0.056)$ & $(0.058)$ \\
\hline Breakeven distance & 724.6 & 734.4 \\
& $(32.3)$ & $(32.6)$ \\
\hline $\mathrm{N}$ & 676 & 676 \\
$R^{2}$ & 0.12 & 0.45 \\
Route FE & & $\mathrm{X}$ \\
\hline \hline
\end{tabular}

Notes: Table estimates effect of the gauge change on all-rail traffic shares. The dependent variable is the log difference in all-rail and steamship shares within route-years. The "breakeven distance" at which the effects of standardization dissipate to zero is provided below the regression estimates. $*, * *, * * *$ represent significance at the $0.1,0.05$, and 0.01 levels, respectively. SEs clustered by route in parentheses.

Table 7: Effects on Traffic Shares, ACL and PAL

\begin{tabular}{lcc}
\hline \hline & $(1)$ & $(2)$ \\
\hline A.C.L. x post-change & $2.848^{* * *}$ & $2.809^{* * *}$ \\
& $(0.554)$ & $(0.542)$ \\
$*$ distance (100 mi) & $-0.403^{* * *}$ & $-0.396^{* * *}$ \\
& $(0.076)$ & $(0.073)$ \\
P.A.L. x post-change & $1.461^{* *}$ & $1.647^{* * *}$ \\
& $(0.593)$ & $(0.576)$ \\
$*$ distance (100 mi) & $-0.216^{* * *}$ & $-0.232^{* * *}$ \\
& $(0.076)$ & $(0.076)$ \\
\hline Breakeven distance (A.C.L.) & 705.9 & 709.8 \\
& $(31.5)$ & $(33.5)$ \\
Breakeven distance (P.A.L.) & 676.8 & 708.8 \\
& $(73.1)$ & $(57.3)$ \\
\hline N & 676 & 676 \\
$R^{2}$ & 0.45 & 0.77 \\
Route FE & & $\mathrm{X}$ \\
\hline \hline
\end{tabular}

Notes: Table estimates effect of the gauge change on all-rail traffic shares. The dependent variable is the log difference in all-rail and steamship shares within route-years. The "breakeven distance" at which the effects of standardization dissipate to zero is provided below the regression estimates. *, **, *** represent significance at the $0.1,0.05$, and 0.01 levels, respectively. SEs clustered by route in parentheses. 
Table 8: Increasing Effect on Shares over Time

\begin{tabular}{|c|c|c|}
\hline & (1) & $(2)$ \\
\hline \multirow[t]{2}{*}{ All-rail x 1885} & -0.914 & -0.914 \\
\hline & $(0.701)$ & $(0.729)$ \\
\hline \multirow[t]{2}{*}{ * distance $(100 \mathrm{mi})$} & 0.071 & 0.071 \\
\hline & $(0.093)$ & $(0.097)$ \\
\hline \multirow[t]{2}{*}{ All-rail x 1886} & -0.711 & -0.630 \\
\hline & $(0.863)$ & $(0.813)$ \\
\hline \multirow[t]{2}{*}{ * distance $(100 \mathrm{mi})$} & 0.079 & 0.073 \\
\hline & $(0.111)$ & $(0.105)$ \\
\hline \multirow[t]{2}{*}{ All-rail x 1887} & $1.343^{* *}$ & $1.500^{* *}$ \\
\hline & $(0.543)$ & $(0.576)$ \\
\hline \multirow[t]{2}{*}{ * distance $(100 \mathrm{mi})$} & $-0.183^{* *}$ & $-0.199 * *$ \\
\hline & $(0.074)$ & $(0.078)$ \\
\hline \multirow[t]{2}{*}{ All-rail x 1888} & $1.622^{* *}$ & $1.753^{* *}$ \\
\hline & $(0.751)$ & $(0.790)$ \\
\hline \multirow[t]{2}{*}{ * distance $(100 \mathrm{mi})$} & $-0.271^{* * *}$ & $-0.282^{* * *}$ \\
\hline & $(0.098)$ & $(0.103)$ \\
\hline \multirow[t]{2}{*}{ All-rail x 1889} & $1.938^{* *}$ & $2.069 * *$ \\
\hline & $(0.777)$ & $(0.819)$ \\
\hline \multirow[t]{2}{*}{ * distance (100 mi) } & $-0.290 * * *$ & $-0.300 * * *$ \\
\hline & $(0.102)$ & $(0.107)$ \\
\hline \multirow[t]{2}{*}{ All-rail x 1890} & $2.040^{* * *}$ & $2.197^{* * *}$ \\
\hline & $(0.678)$ & $(0.720)$ \\
\hline \multirow[t]{2}{*}{ * distance $(100 \mathrm{mi})$} & $-0.314^{* * *}$ & $-0.331 * * *$ \\
\hline & $(0.093)$ & $(0.098)$ \\
\hline $\mathrm{N}$ & 676 & 676 \\
\hline$R^{2}$ & 0.12 & 0.45 \\
\hline Route FE & & $\mathrm{X}$ \\
\hline
\end{tabular}

Notes: Table estimates the effect of the gauge change on all-rail traffic shares by year, relative to the omitted year of 1884. The dependent variable is the log difference in all-rail and steamship shares within route-years. *, **, *** represent significance at the $0.1,0.05$, and 0.01 levels, respectively. SEs clustered by route in parentheses.

Table 9: Change in Total Traffic/Revenue

\begin{tabular}{lcccc}
\hline \hline & \multicolumn{2}{c}{ Ln(Freight traffic) } & \multicolumn{2}{c}{ Ln(Revenue) } \\
& $(1)$ & $(2)$ & $(3)$ & $(4)$ \\
\hline Post-change & 0.039 & 0.051 & -0.114 & -0.091 \\
& $(0.230)$ & $(0.222)$ & $(0.183)$ & $(0.186)$ \\
$*$ * distance $(100 \mathrm{mi})$ & -0.000 & -0.006 & 0.009 & 0.003 \\
& $(0.031)$ & $(0.028)$ & $(0.023)$ & $(0.022)$ \\
\hline $\mathrm{N}$ & 360 & 360 & 360 & 360 \\
$R^{2}$ & 0.01 & 0.96 & 0.01 & 0.97 \\
Route FE & & $\mathrm{X}$ & & $\mathrm{X}$ \\
\hline
\end{tabular}

Notes: Table estimates the effect of the gauge change on total shipments. Observations are route-years. The dependent variable in Columns (1) to (2) is log pounds of traffic; in Columns (3) to (4), log dollars of revenue. *, **, *** represent significance at the 0.1, 0.05, and 0.01 levels, respectively. SEs clustered by route in parentheses. 
Table 10: Supply and Demand Estimates

\begin{tabular}{|c|c|c|c|}
\hline \multicolumn{2}{|c|}{ Demand Parameters } & \multicolumn{2}{|c|}{ Marginal Costs (\$ per 100 lbs.) } \\
\hline Break in gauge & $\begin{array}{c}-3.42^{* * *} \\
(0.71)\end{array}$ & Break in gauge & $\begin{array}{c}0.079^{* * *} \\
(0.027)\end{array}$ \\
\hline * distance $(100 \mathrm{mi})$ & $\begin{array}{c}0.43^{* * *} \\
(0.09)\end{array}$ & Transshipment & $\begin{array}{c}0.207^{* * *} \\
(0.088)\end{array}$ \\
\hline Rail dummy & $\begin{array}{c}4.54^{* * *} \\
(1.11)\end{array}$ & Distance, rail & $\begin{array}{c}0.044^{* * *} \\
(0.008)\end{array}$ \\
\hline Steam dummy & $\begin{array}{c}6.41^{* * *} \\
(1.13)\end{array}$ & Distance, steam & $\begin{array}{c}0.042^{* * *} \\
(0.009)\end{array}$ \\
\hline Price (\$ per 100 lbs.) & $\begin{array}{c}-8.98^{* * *} \\
(1.54)\end{array}$ & $\begin{array}{l}\mathrm{N} \\
\text { Mean } R^{2}\end{array}$ & $\begin{array}{c}244 \\
0.77\end{array}$ \\
\hline Breakeven distance & $\begin{array}{l}792.7 \\
(95.7)\end{array}$ & & \\
\hline $\mathrm{N}$ & 488 & & \\
\hline$R^{2}$ & 0.62 & & \\
\hline 1st-stage F-stat & 222.5 & & \\
\hline Instrument & Distance & & \\
\hline
\end{tabular}

Notes: Table shows estimates from the joint estimation of demand and supply for freight traffic on the subsample of routes for which prices are available. Demand is estimated over a dataset at the route-mode-year level, with $\mathrm{N}=244$ route-years and $\mathrm{J}=2$ modes. Because cartel policy constrained railroads and steamships serving a given route to the same prices, there are only as many pricing FOCs as there are route-years, hence the halved sample for estimating costs. The price variable is computed as a weighted average of published class rates for the given route, weighting by the share of route traffic in each class in 1880 . *,**, *** represent significance at the $0.1,0.05$, and 0.01 levels, respectively. Bootstrapped SEs are provided in parentheses. 

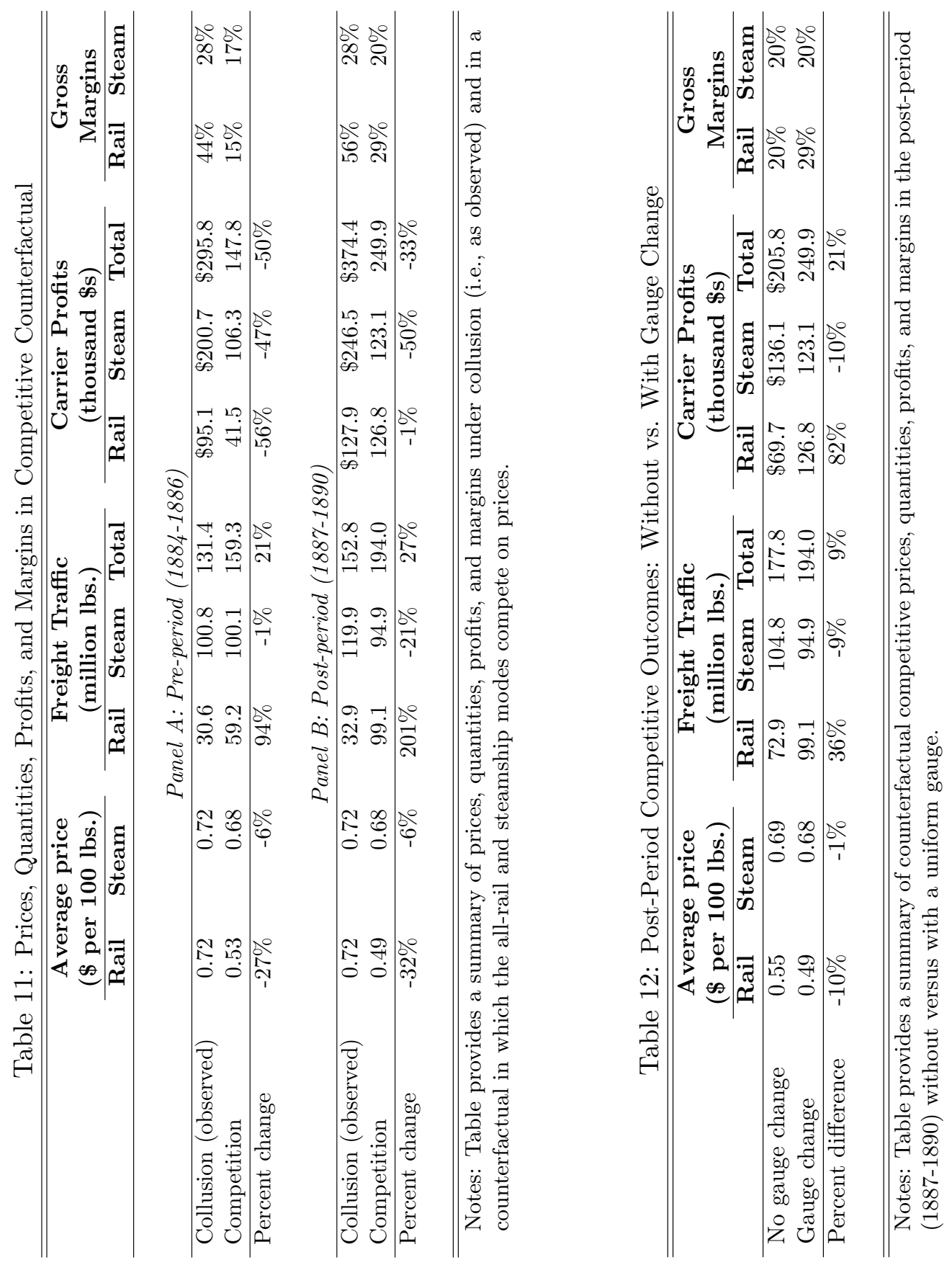
Appendix for Online Publication 


\section{A Data Appendix}

This paper draws on several sources of data, most importantly the SRSA records of freight traffic on apportioned routes. As the paper describes, the SRSA collected daily data on the traffic and revenue of carriers on competed routes, compiled these data into monthly tables, and circulated these tables, as well as annual totals, to cartel members. These tables, as well as other SRSA circulars, were collected into semiannual volumes and have been preserved in original hard copy at the New York Public Library and Yale University archives. ${ }^{1}$

Figure A.1 provides an example table from these records. The table shows pounds and revenue of merchandise shipments from Boston to Augusta, GA for the 1886-87 and 1887-88 fiscal years. The table lists five different paths that freight traveled for this route: three by steamship plus rail, and two entirely by rail. All-rail shipments can be identified as "via A.C.L." or "via P.A.L.", while the steamship line items indicate the intermediate ports where freight was transshipped (here, Savannah and Charleston). Similar tables are available for the remaining destinations, origins, and years, though in most cases a table provides data for one period only.

Figure A.1: Example of Table from SRSA Traffic Reports

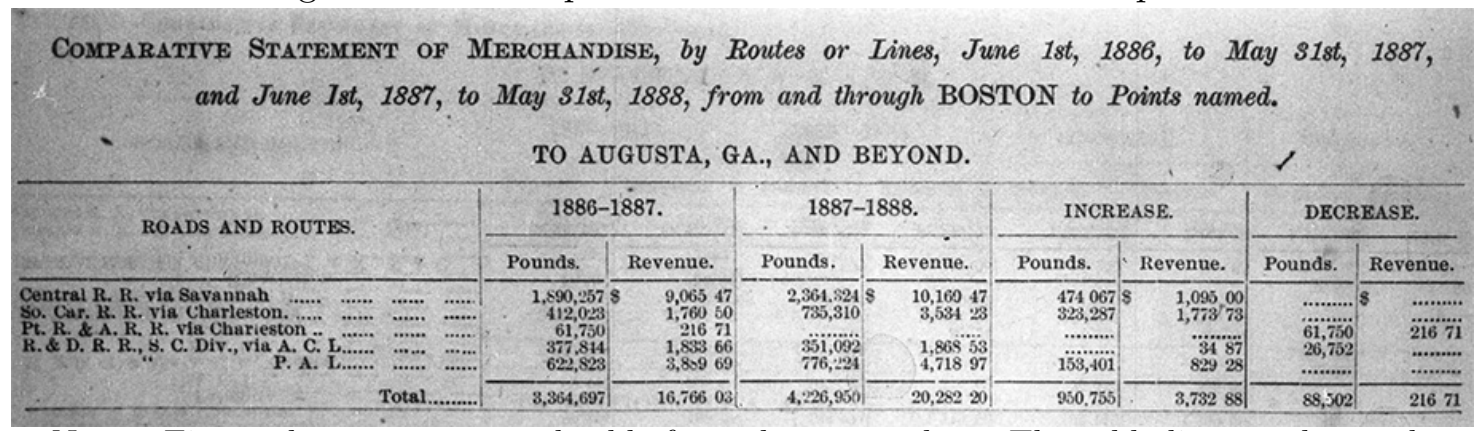

Notes: Figure shows an extracted table from the source data. The table lists total pounds of traffic and revenue from merchandise shipments from Boston to Augusta, GA by carrier, for June 1 to May 31, 1886 and for the same period in 1887. All-rail paths (termed "routes" in the table) can be identified as either A.C.L. or P.A.L.

For the second half of the sample, the cartel operated on a June to May fiscal year and reported annual data accordingly. This accounting period is ideally suited to the purposes of this paper, as the gauge change occurred over May 31 and June 1, 1886 - such that the cartel's annual data provide the cleanest possible comparison. However, until 1886, the cartel operated on a September to August fiscal year. For this earlier period, I therefore collected year-to-date (YTD) traffic in May and August, in order to back out shipments for the June to May period. Concretely: The 1884 fiscal year spanned September 1883 to August 1884, but this paper requires totals from June to May. To obtain them, I transcribed data from three YTD tables in the cartel traffic reports: September 1882 to May 1883 (1), September 1882 to August 1883 (2), and September 1883 to May 1884 (3). I then impute June 1883 to May 1884 traffic as (2)-(1)+(3).

\footnotetext{
${ }^{1} \mathrm{~A}$ subset of the content in these circular letters are also available on microfilm from HBS Baker Library, though the microfilm omits the monthly traffic reports which yield the data in this paper.
} 
To make clear how all-rail freight reached Southern interior cities, Figure A.2 shows maps of the A.C.L. and P.A.L. circa 1885. Both served nearly every route in nearly every year, with a few exceptions: the P.A.L. did not deliver freight to Macon in 1884-86, Athens in 1886, or Albany in any year, and the A.C.L. did not deliver to Albany in 1890 (as inferred from their absence from the respective traffic tables). Additionally, no data is available for Albany in 1887. As a result, the sample reported in tables is reduced from $1,092(=52 \cdot 3 \cdot 7)$ to 1,036 .

Figure A.2: All-Rail Paths connecting North and South ca. 1885

Panel A: Atlantic Coast Line (A.C.L.)

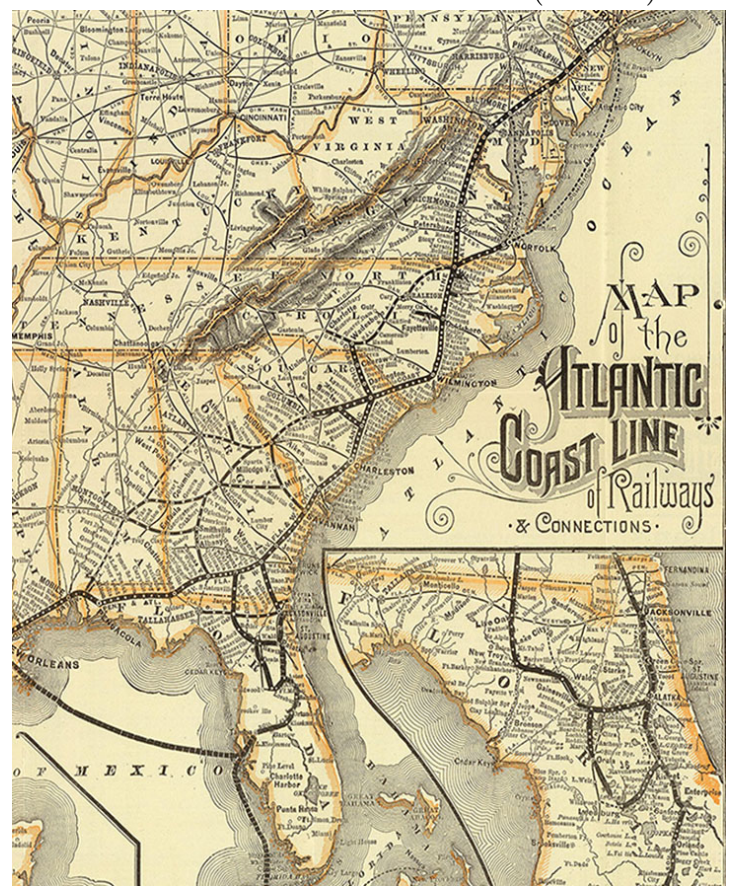

Panel B: Piedmont Air Line (P.A.L.)

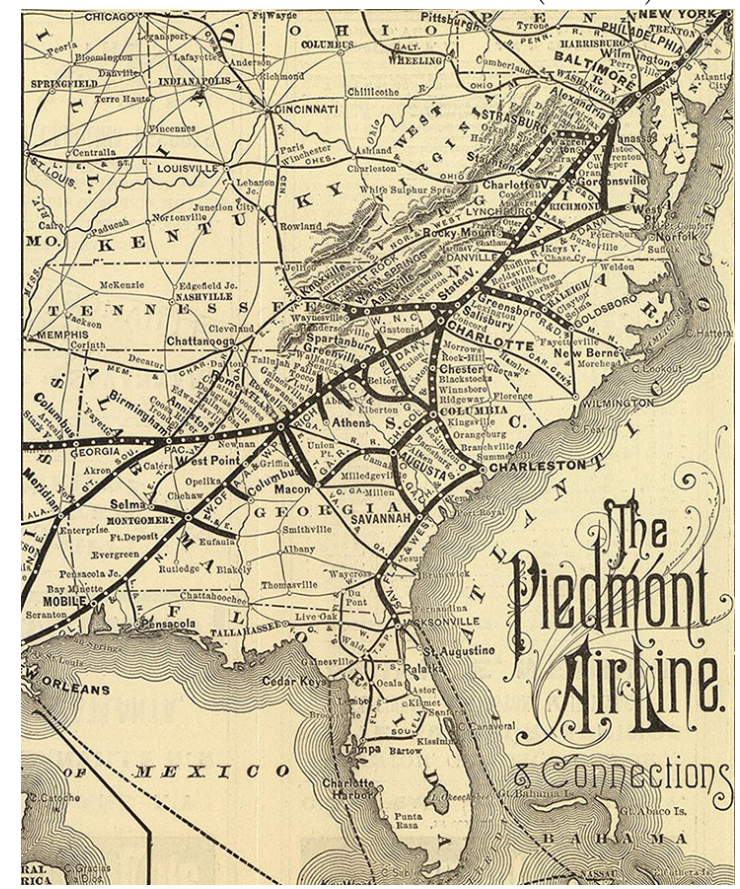

Notes: Figure provides maps of the two all-rail paths between the North and South, as of 1885: the Atlantic Coast Line and Piedmont Air Line. Each was established by mutual agreement among the traversed railroads to facilitate interregional traffic. Maps acquired from the David Rumsey Historical Map Collection.

On a few routes, merchandise shipments between Northern and Southern cities are occasionally indicated to have entered the South from the West, via the Louisville and Nashville or the Cincinnati Southern - crossing the Ohio River at Louisville and Cincinnati, respectively. In these cases, it remains ambiguous whether the active mode was all-rail versus river steamer plus connecting railroad. I thus omit these shipments from the analysis. As Figure A.3 shows, little is lost: the omitted shipments on average comprise $0.8 \%$ of traffic in any given year. 
Figure A.3: Western paths' share of North-South traffic

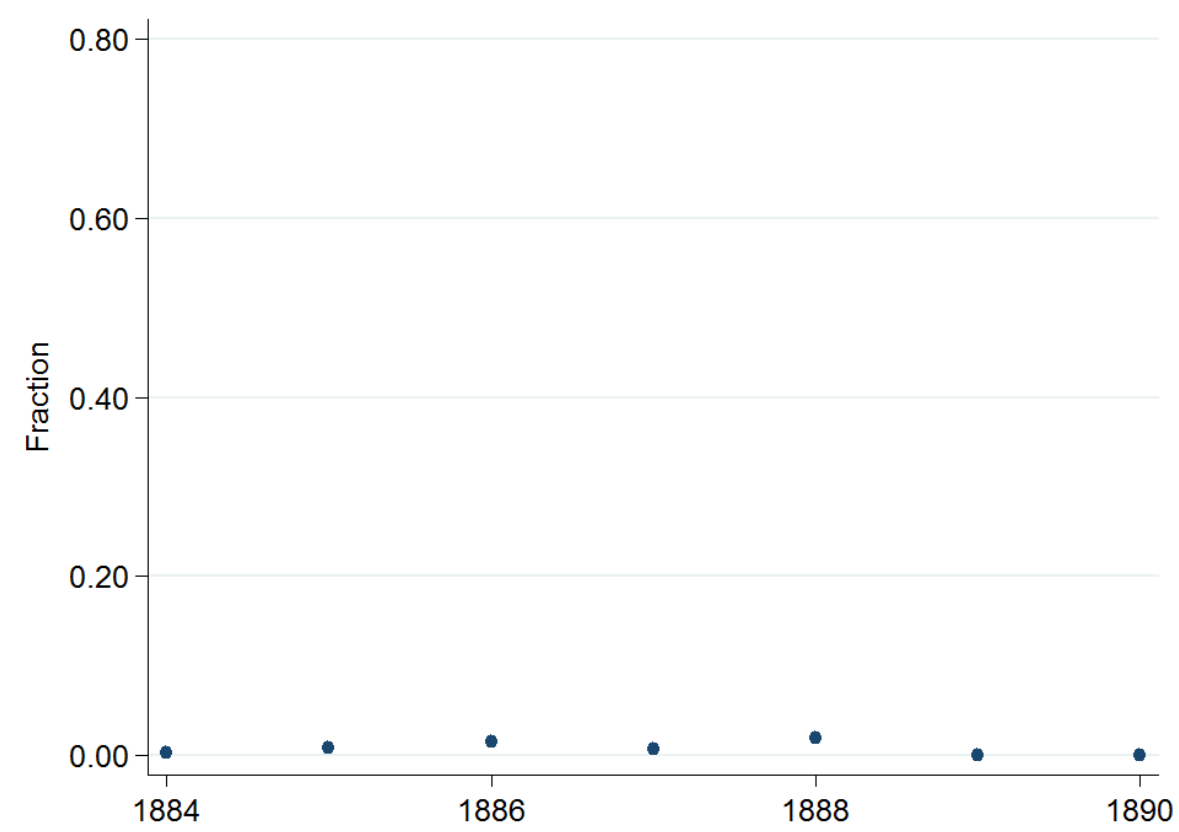

Notes: Figure shows the annual proportion of total traffic on the sampled routes reported to have been by the L. \& N. and the C.S. Railroads, ostensibly after having crossed the Ohio River. Due to ambiguity over the mode of westward travel, this traffic is omitted from all analysis.

To estimate effects that vary with route length, I must measure distances between origin and destination. Throughout the paper, I measure distance as "straight-line" (geodesic) distance, rather than traveled distance, which is not observed. Though traveled distance can in concept be computed for all-rail routes using maps and mapping software, the same cannot be done for steamships, and it is unclear what additional information is generated. Indeed, one early-twentieth century source (Ripley 1913) lists all-rail shipping distances from Boston, New York, Philadelphia, and Baltimore to Atlanta, and as Table A.1 shows, straight-line distance is a roughly fixed proportion (85\%) of the point-to-point track length between origin and destination.

Table A.1: Comparison of Straight-line and Track Distances

\begin{tabular}{llccc}
\hline \hline Origin & Destination & Straight-line (mi.) & All-rail (mi.) & Ratio \\
\hline Boston & Atlanta & 937 & 1089 & 0.86 \\
New York & Atlanta & 747 & 876 & 0.85 \\
Philadelphia & Atlanta & 666 & 786 & 0.85 \\
Baltimore & Atlanta & 577 & 690 & 0.84 \\
\hline \hline
\end{tabular}

Notes: Table compares straight-line (geodesic) distances and all-rail shipping distances between the points shown. Shipping distances from Ripley (1913).

With a limited sample of routes - and particularly, with origins all in the northeast and destinations in Georgia and Alabama - one might be concerned that the sample does not exhibit sufficient variation in distance to identify this source of heterogeneity. Table A.2 lays this concern to rest, 
showing that across the 52 routes in the sample, distance varies from 500 to 1,100 miles, with a 25th-75th percentile spread of over 300 miles.

Table A.2: Descriptive Statistics: Distribution of Route Distances

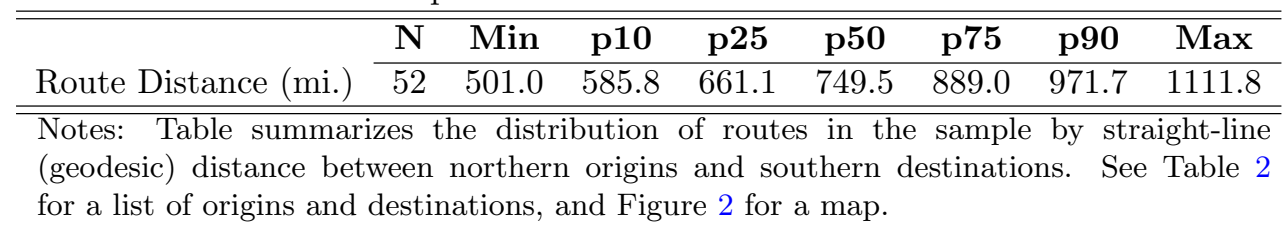

\section{Other Data}

I also collect data from annual volumes of Poor's Manual of Railroads (1868) to confirm the scale of the gauge change. The Poor's Manual was an annual compendium of railroads in the U.S. and Canada that provides railroads' location, mileage, information on their financial performance (when available) - and conveniently, their gauge. These volumes allow me to calculate annual mileage by region and gauge for the universe of U.S. railroads, and thereby observe both the growth of the network and the standardization of gauge across the country.

To do so, I recorded the name, total mileage, and principal gauge of every railroad in five Poor's Manual volumes: 1882, 1883, 1886, 1888, and 1890 (which provide data from 1881, 1883, 1885, 1887, and 1889). ${ }^{2}$ I also recorded the region in which each railroad had principal operations: New England (ME, NH, VT, MA, RI, CT); Middle Atlantic (NY, NJ, PA, DE, MD); Central Northern (OH, IN, IL, MI, WI); South Atlantic (VA, WV, NC, SC, GA, FL); Gulf and Mississippi Valley (KY, TN, AL, MS, LA); Southwestern (MO, AR, TX, KS, CO, NM); Northwestern (WY, NE, IA, MN, Dakota Territory); and Pacific (CA, OR, WA, NV, AZ, UT). In two of the sampled volumes, railroads are sorted alphabetically by these regions; in two other volumes, by state; and in one volume, at the national level. Where available, I use the Poor's Manual-designated region or state as a railroad's location. For the volume with national sorting, I infer each railroad's location from previous or later volumes, or from the address of its principal office (if not otherwise available). There was of course a great deal of new construction and consolidation over this period, but all of it is accounted for in these volumes - indeed, each volume concludes with a table listing all mergers and acquisitions since the first volume in the series was published in 1868.

The collection of the Poor's Manual data proved to be a painstaking process that required significant attention to detail, as many railroads owned subsidiary lines that were listed twice (alone and under the owner), and many railroads leased lines that were listed twice (alone and under the owner). All subsidiary and leased lines were therefore cross-checked against the entered to data to ensure they were not double-counted. The volumes also included railroads under construction, and every

\footnotetext{
${ }^{2}$ Please contact the author at dgross@hbs.edu if you would like to make use of these data. I extended a hearty thanks to the Historical Collections team at HBS Baker Library for providing access to the Poor's Manual volumes, and to Mary Vasile for her help in compiling the data.
} 
effort was made to count only completed mileage - though this count includes railroads which were complete but not yet (or no longer) in operation. In a few cases, a gauge was not provided - when this occurred, I inferred the gauge from previous or later volumes, from separately-listed parents or subsidiaries, or from information obtained through Internet searches. There were also a few railroads which listed multiple gauges, and I count these railroads as standard-gauge roads of one of the listed gauges is standard gauge. Finally, in each volume there are a handful of railroads for which the gauge could not be determined, and these railroads are omitted from all analysis, as the cumulative mileage with unknown gauge in any given year is less than $0.1 \%$ of the network. In Table 1, I sum railroad mileage by year, region, and gauge, consolidating the Poor's regions into five super-regions: New England, Mid-Atlantic, Midwest, South, and West.

I also make use of mapping data from two sources. I use the NHGIS state boundary shapefiles to sketch states east of the Mississippi River, and Atack's (2015) Historical Transportation Shapefiles to map the railroad network. The Atack (2015) railroad shapefile includes railroads constructed between 1826 and 1911; within this file, individual segments are identified by owner and gauge through the Civil War, but this identifying information is not available for later periods. Given the importance of this information to mapping the network by gauge, I restrict attention to set of railroads in operation by 1861. I use these data to illustrate the diversity of gauge in 1861 and then

the standardization that took place through 1881 and 1891, leveraging the Poor's Manual data to identify later gauges of railroads in the Atack (2015) shapefile.

\section{Appendix references not in paper:}

Ripley, William Z. Railway Problems, Boston: Ginn and Company, 1913. 


\section{B Contemporary Accounts of the Gauge Change}

The gauge change received broad coverage in contemporary railroad periodicals and Southern newspapers. The Atlanta Constitution reported on the SRSA's gauge change convention as it was underway (Figure B.1), and the Louisville Courier-Journal reported several weeks later on the planning, preparations, and procedure for converting 13,000 miles of track in one day (Figure B.2). Though not widely covered in the North, the impending gauge change was nevertheless reported in a lengthy article in The Commercial and Financial Chronicle on May 29, where the paper acknowledges that "the matter is hardly attracting the attention it deserves," and the New York Times reported on May 31 that the Louisville and Nashville - the only Southern railroad of real importance to Northern shippers and investors - had completed its changeover that day, with no mention of the other railroads simultaneously converting to standard gauge (Figures B.3 and B.4).

Contemporary accounts were not limited to reporting on the mechanics of the gauge change: some newspapers speculated on the effects it might have, or was already having, on the Southern economy. For example, the Wilmington Morning Star wrote in April 1886 that to date, "very little lumber [goes] North by rail, for the reason that Southern roads [have] a different gauge from the Northern roads," and that "Southern lumber ports are bound to suffer a considerable loss of business" following the gauge change (Figure B.5) - a prediction consistent with this paper's results.

A year after the gauge change, in July 1887, The Railroad Gazette and other railroad journals published a detailed postmortem analysis (Figure B.6) - covering the history of Southern gauge and its "burden [on] both railroads and shippers," the SRSA's gauge change convention in February 1886 and the decision to convert to a 4' 9'" gauge on June 1, the plans and procedures for the day of the conversion and the months leading up to it, the engineering challenges, and even estimates of the aggregate expense of converting the rails and the rolling stock. For those interested, this article is the best source for understanding how 13,000 miles of railroad track could be converted to standard gauge in just 36 hours, and confirmation that it was. 
Figure B.1: Report of the Gauge Change Convention (Atlanta Constitution, February 3, 1886)

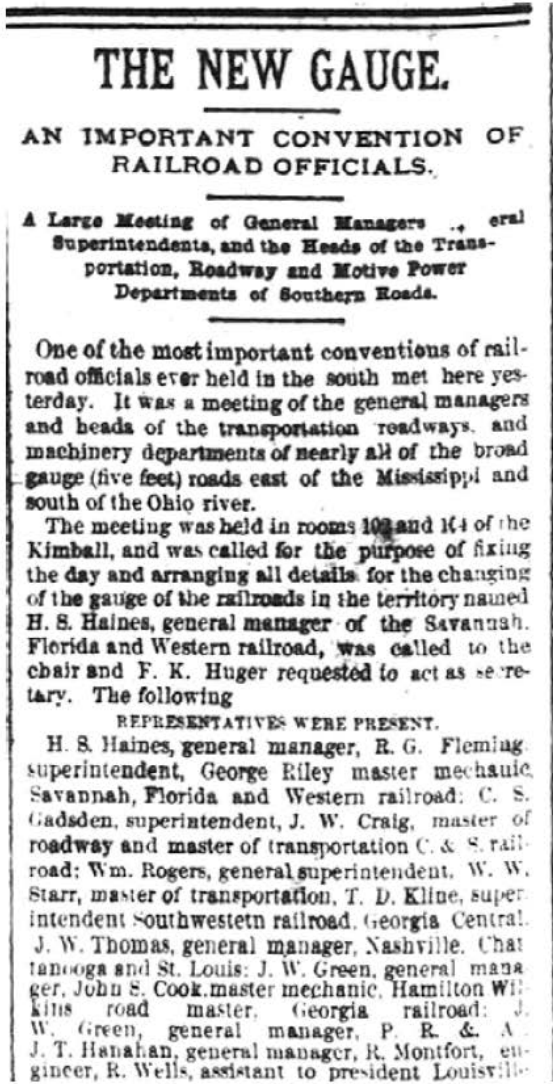

and Nashville; J. B. Beck, gevieral manager, J.H A rerell, master of transportation. D. E. Mas wet general superiutendent Florida railway and Sal gation company south camlins railroad: Cecil (iabbott. general mapager, J. F. Wor wick, mast.mechanif Atlanta and Nest Point, Westera ra: wsy of Alabams. (incinnati. jelma and Mobit gailway: C. II. Hudson, general manager. F. h Huger, superintendent. F. H. Thomas, sup rit endent motjve yower East Temesuee, Yiryinia and Georyia: S. B. Thomas general manager Peytos Randolph, assistant general manager. Ii. H. t, reet superintendent Rlchmond and Danville division cuperintendent Berkeley: Air-Line d rision Ricbmond and Dasville raitrua R. D. Wade, superintendent motive power, 1.7 Eulton, engineer, C. P. Hammond, road maver.
W. Gentry, master mechanic, Rome and Daltons : 1:. Andrews, preeident, Frank Coxe, vice pre-ided I. C. Michee, superintendent, G. II. Gitis, maste: mecbanic, Nestern of North Carolina: Joseph H Sands, general manager, Frank Huger, superinten ent, W. II coe, chic engincer, S. B. Haupt. S! refintendelit M. P., Norfolk and Western, ti. H Talcolt, superiendent. Thoos. Bernard, a sitant et foect, Cariotte, Columbia and August

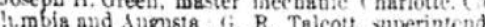

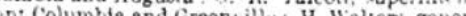

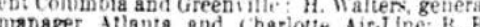

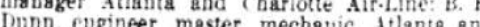

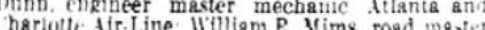
Atlaste and West Point R Coutho, Tod matet

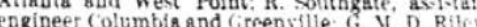
nercer of road was as

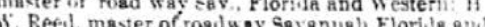
Wheth I Y - age

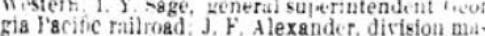

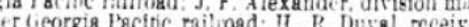
tortula railumay and tarigailon compant If hline master mechan is" Brun-wick will itest.

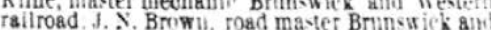
Wertern railmad $R$ a Brióges, rogit master Co

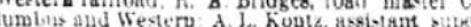
intendent pulman palace cor ompas? J. F. Divine geperal wpetintandent Alla ta an

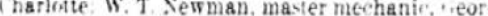
kin Pacific: $K$ A Anderson. sumerintendent A. B

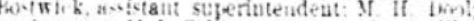

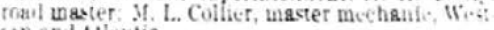
en $x$ d A llatic.
Mr. Haines upon taking the hair briety vated Wo the consention the olow for whith the meet ing bad been rallewl, and annolucel tha: f! wonld

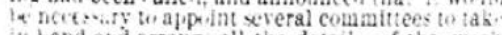
In land atd arrange all the detail of the wo.

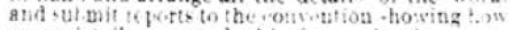
erery detait cotnected with chatize in the axy

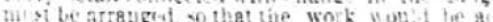
complolied castly and catriuturt

1b

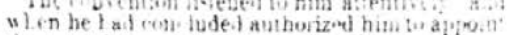

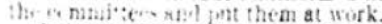

thaiman Haincs theil aprointed the fuitowing rom nilttees:

comiattle on date of bange of gruxe--t: B Thomas, cheirmen J T. Horroban, H H Hudo Wm. Rogers. IL. R. Lural, Henry Walters, R. Fleming T, W. Thomas, J. W. (ireen, J II. Kand Kiline.

cummitke on transportation-J. F. Devine chairman J. B. Averill. D. E. Maxwell, F. K. Intaer leytou Rantioly, A. A. A.tidrels, frauk cose,

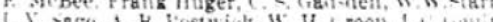

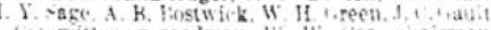

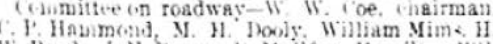
ii. Heade I $\mathrm{X}$ brown $\mathrm{K}$ Muilifot. Hamilen iv

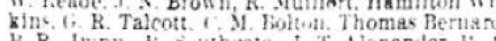

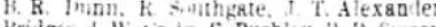

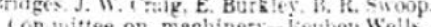

1.

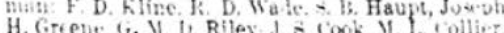

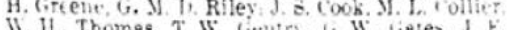
Wurw w. W. T. Nerman.

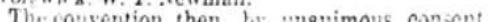
10. cack ard trucks.
the mertiog

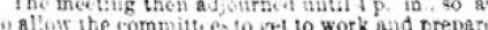
their repert to prevented at he hour for prepart ation. bled. The cummittes made repors, which were read and discinsed.

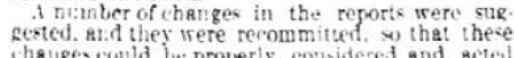
change could be properly entidered and actet Hockes this norsing. 
Figure B.2: Preparations and Procedures for Conversion (Louisville Courier-Journal, March 23, 1886)

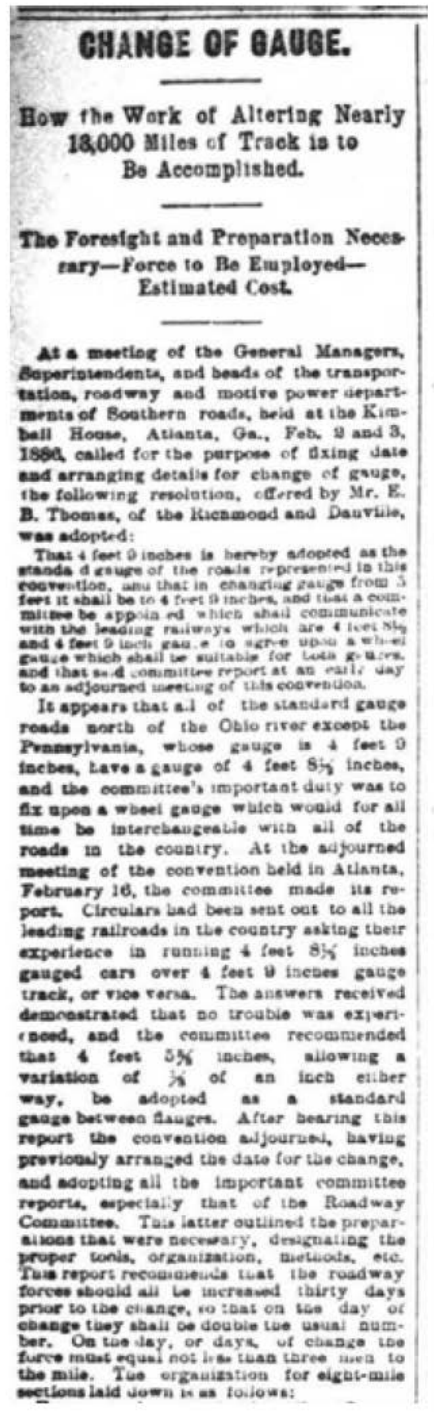

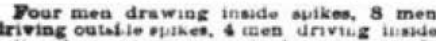

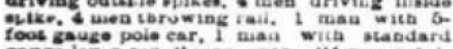

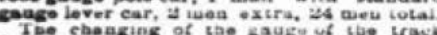

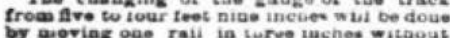

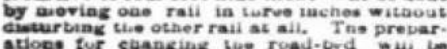

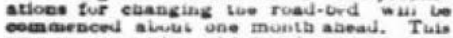

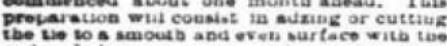

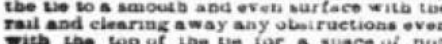
Tith tao wo of has to for syace of nut Doved in. wingat thes the eange is

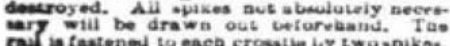

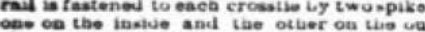

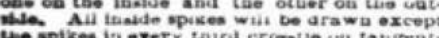

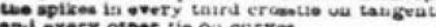

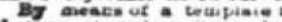

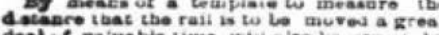

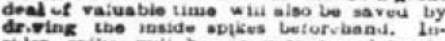
wive spikes wit bo bot with teasplates in

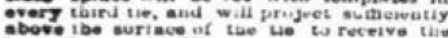

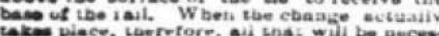

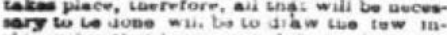

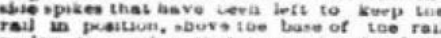

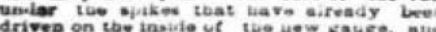

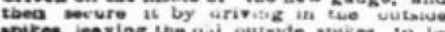
gotkes, leaving the o.d outside ppises to to

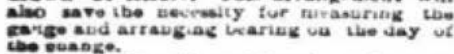

Monday, May 31, and rueeday, Juno 1,

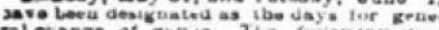

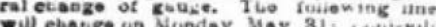

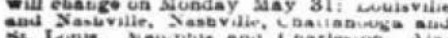

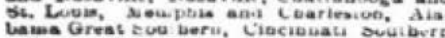

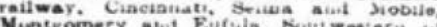
Suatsobery and Euruia, Boutwesiera Railway anu Sivakation conspay. All Juber main lues wit eluange uu luesday.

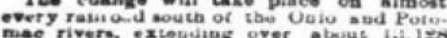

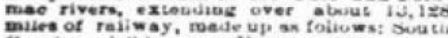

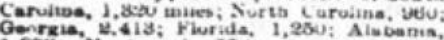

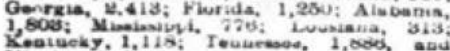

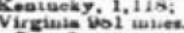
Toe. Sutbera gango bas been an eadlens

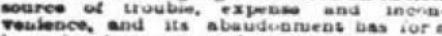
long ian been regarued as a cerianoty, and

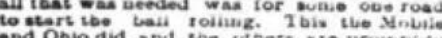

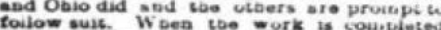

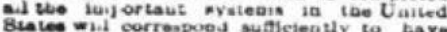
Blateo whil corrospoes suttieleatly to thave
tob rasping gear torouztoot the

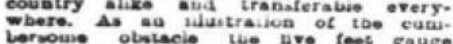

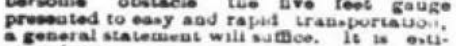

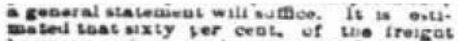

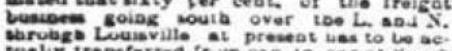

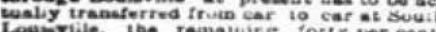

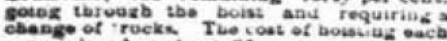
car is placed at about nfty conts for trans.

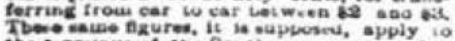

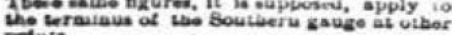
pelate sigantie eadertakiog bas siready lometbougbt on to part of thom to w won

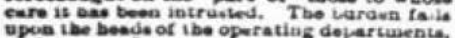

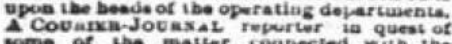

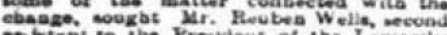

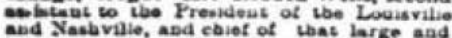

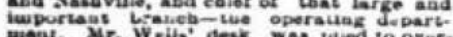
Aow io wit ponated iostruetious to too dif. toreat ibope divisions, ite. whiea bo bad

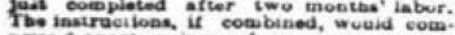
Prino a quarto volvoue of no weau propor.

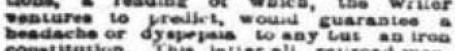

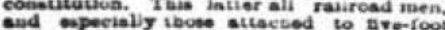

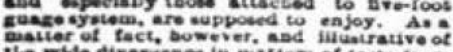
the mide diverseves in natters of laste trod

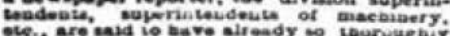

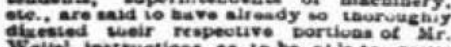

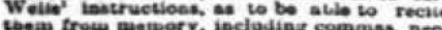

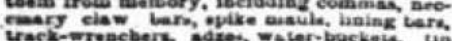

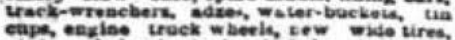

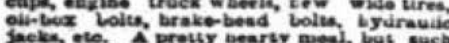

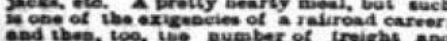

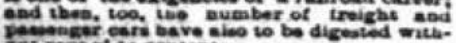

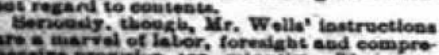

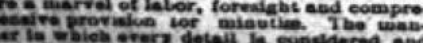

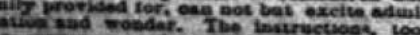

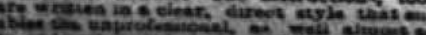
stroeston: for obangling gaugo of rolling;

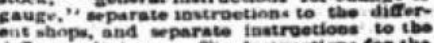

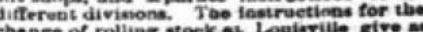

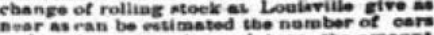

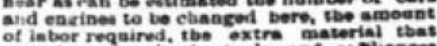

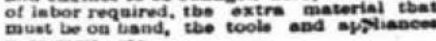

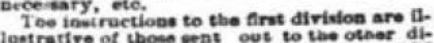

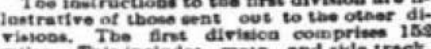

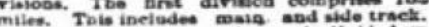

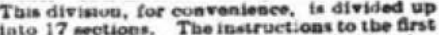

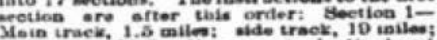
otsi miles, 20.3. Men required, sui bast manik, 14: liaing bark, 8; track caugen, 8 ;

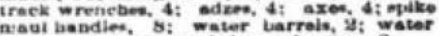
bacsets. 4 i tia eupe, 4 i ieszs of opices, a.

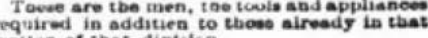
wetuon of taat divtaice

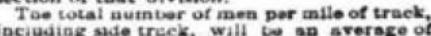
four wea on sections bavive no more than the usual number of earves. and ave men on
cections naving more than the usual number

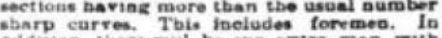
ajdition, wero wil bo ves extra man with

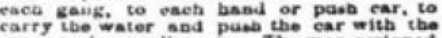

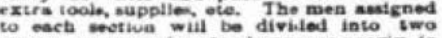
gange. corrmeneling to eliangs as neariy in the middle of tha nettiun, as ung to deetided

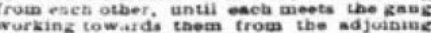
sectioses to to toroman will go with one of tho Rangs: bis stavasurd gauge band car will fol. Grber g-ust. and aaye bis push car of nive toot of the tho kangs is not 10 be coublened to thetr

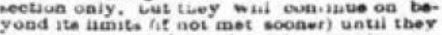
meet two kaug from the otoer section, ro-

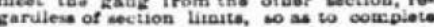

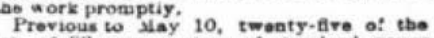
ot of 38 now encines of standard gauge coived, put tozocoer aud tontad. "o tar as that is jirnctickites, and be resuly for corvice

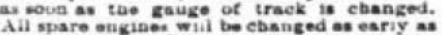
prartueabie. "Doutuing." or having tbe

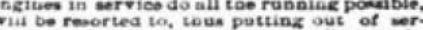

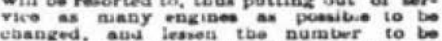
changed the day the trask is changed and

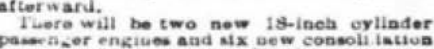

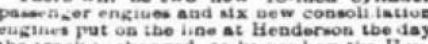
tho track to eliagerd. to bo used ou the Hay.

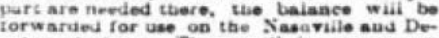

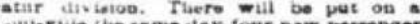

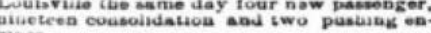

The rolling stoek to be changed at the neverai poincis rpecitied in the instruetious has:

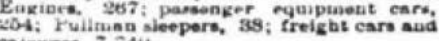

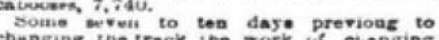

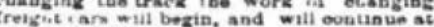
to inalo of 465 per ayy. in groater number if rone cost of the changs of gaugh it. on

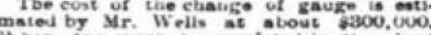
Whe toe work to completed in the chort abor and intelligeuh, compretenaivo tore 
Figure B.3: Report on the Conversion (The Commercial and Financial Chronicle, May 29, 1886)

\section{THE UNIFICATION OF OUR RAILROAD GAUGE.}

On Monday and Tuesday next, according to previous arrangement and agreement, an important work will be undertaken and carried through. This is nothing less than the changing of the guage of all Southern roads whose width of track now is 5 feet, to a standard that
will bring these lines more closely in conformity with the will bring these lines more closely in conformity with

The matter is attracting hardly as much attention as it deserves. It is a task of no little magaitude. Practicoslly it involves the taking up snd relaying of one rail over the entire length of all the rosds (and in some cases a change in the road bed and of course alteration of the rolling stock) in the territory bounded by the Atlantic Ocean on the one side and the Missiseippi and Ohio Rivers on the other, and comprising the Ststes of Virginia, West Virginia, Kentucky, Tennessee, Missis sippi, Alsbama, Georgia, Florida and North snd South Carolina. Some of the newer systems in these States, like the Chesapeake \& Ohio snd its accessories, and the Louis. ville New Orlesns \& Texse, are of the standard Northern gauge, and so is the Southern Line of the Illinots Central, while the Mobile \& Ohio was last year also altered to con. form to this standard. But the vast bulk of the mileage in the Southern States at the present moment has a track width of five feet, snd it is estimated that next week's operations will embrace fully 14,000 to 15,000 miles, from which one can judge of the dimensions of the work. And
as already said, not only will the track have to be changed, but the rolling stock-locomotives and cars-will hare to be adjusted to the new guage (where it has not previously been done) the latter being really the most difficult part of the undertakiag. All the preliminaries, however, have been completed, preparations for the event hav ing been in progress for several months, and much of the equipment having been already altered, so when on the 31 st of Msy and 1st of June the 14,000 or 15,000 miles of track are simul. tsneously changed (some branches snd minor pieces will be changed a day or two earlier), everything will be in readiness, snd the business and operations of the rosds proceed as if nothing had happened, while the means of intercourse between the different sections of the country will have been improved and our transportation interests benefited.

The new gauge will not be precisely the same as the commonly acceped standard, but it will be so nearly so ss to be equivalent to the same thing. It will be 4 feet 9 inches, whereas the prevailing width is 4 feet $8 \frac{1}{2}$ inches. The Pennsylvania, however, has a gange of 4 feet 9 inches, snd the Southern lines have adopted the same figure. In reality, thougb, the difference-half an inch-is so small that the rolling stock of the one can and is being freely used upon the track of the other, so that for all practical purposes the two gauges are identical. Moreover, these after. two gauges embrace together the greater part of the railrosd nileage of the country-the Southern roads with their five foot gauge forming the only important excep. tion. According to the Census Report of 1880 , of the total track in the country at that time (July 1) 66.3 per cent belonged to the roads with $4 \mathrm{ft}$. $8 \frac{1}{2}$ in. gauge, and
11.4 per cent belonged to those of the $4 \mathrm{ft} 9$ in, gauge, $11 \cdot 4$ per cent belonged to those of the $4 \mathrm{ft}$. 9 in. gauge, making together $77 \cdot 7$ per cent, while of the 5 -foot gauge
(almoet exclusively Southern roads and now to be changed) ule. there was 11.4 per cent more, giving in the aggregate the report of the Mobile \& Ohio for the late fiscal yesr. Wher 89 per cent of the total track in the country. The The Mobile \& Ohio was changed to atandard gauge on the remaining 10 per cent was distributed chiefly between 8th of last July, and sn itemized statement in the report roads with the 6-foot gauge, some of which have since places the expenditures on that account up to the close of been changed to the standard, and narrow gauge roads August at $\$ 66,329$, of which $\$ 11,069$ was paid out directly with the 3.foot gauge, the most of which contemplate for labor and $\$ 25,260$ for the necessary materisl. This changing where they have not slresdy changed. It included all the track, engines, cars, tools, bridges, etc. follows, then, that after next week the mileage of the We infer, however, that it does not comprise the whole United States will be substantially of one and the charge involved in the work, for in his remarks we find ame gauge, the exceptions of a wider or narrower Mr. Dancan saying that the total cost, which had been gange being so few merely to emphasize the originally estimated at $\$ 95,777$, would probably be less than $\$ 80,000$. The Mobile \& Obio has 527 miles of main

The step which the Southern rosds have taken is of line and branches, and on the basis of $\$ 80,000$ for the course an important one, both in its immediate effects in whole the cost of effecting the change (including rolling ontailing an exceptional outlay in making the change, and stock and everything else) per mile of road would be a in its ultimate effects in bringing Southern lines in closer little over $\$ 150$. On the same basis, the 14,000 miles communication with Northern snd Western systems. In now to be changed would involve sn outlay of $\$ 2,100,000$, the latter particular the importance of the move can showing that the work is not only one of impurtance, but hardly be overestimated. The free interchange of traffic one also involving in the aggregate a great expense. The which a common standard will permit, we need hardly roads on which this burden of cost will chiefly fall are of asy will be of benefit to all interests concerned. The course the larger systems like the Louisville \& Nashville, ahipper will be saved delays, the railrosd will be able to the Richmond \& Danville, the Cincinnati New Orleans cheapen the cost of handling the traffic, and the mercan. \& Texas Pacific, the East Tennessee, the Norfolk \& Westtile and financial community generally will feel the effects ern, and the Central R.R. of Georgia ; but the minor roads in the increased stimulus that this gives to the develop. all over the South will also have their expenses increased ment of trade snd industry between the different sections. on the same account.

Hitherto the Sonth has been in a measure shut off from It is interesting to note how completely the standard the rest of the country by this lack of uniformity. On gauge of 4tt. 8tin. and 4f. 9:n. has supplanted sill other the north, the Ohio River marted the limit beyond which gauges. Only a few years ago, when hardly enough Southern freight could not go without a transfer of the could be said by the advocates of the 3 foot gauge in contents of the car, or at least a change of trucks, and favor of the narrow guage plan, it Beemed as if a new and on the West the Mississippi River also formed a dividing dangerous rival were sbout to arise. But s short trial ine, for Texas and Arkansas roads are of standard gauge. has served to demonstrate that the advantages claimed for After the change however, this barrier will no longer the narrow guage syatem were largely illusory, and the exist, and traffic can then be moved to the North or West three-foot gauge has mox fallen into pretty genereal without breaking bulk. Aside from the saving of expense disrepute, whila nearly all the companies that that this will involve, good results may bo expected to had built their lines on that guage have become dis. follow from the fact that the equipment of Northern and credited, sod are in the hands of the officers of the law. Western rosds will be placed at the service of Southern The Toledo Cincinnati \& St. Louis was to be the most brilroads, which ray prove of considerable advantage to these, liant exponent of the new theory, "the grandeat narrow especislly during the months when the cutton move. guage enterprise on the Continent," but alas! there never ment is most active. And upon the sections was a road so deeply involved in finsncial and other diffi chemselves the effect of such an interchange culties as this, and when it fnslly succeeds in getting ou in bringing the people closer together, is not to be lightly of the dilemms in which it now tinds itself, the road will be dismissed. It should even he'p to attract attention to the widened to the standard guage. Then there is the Texase South as a feld for the profitable employment of capitsl. \& St. Louis, which also has an extensive narrow guage Tnere has of course been growth in recent years-very Denver \& Rio Grande is the only narrow guage system and Northwest, the South has not gained as much as the character of the country renders a comparison with other
and inducements she offers warrant. The flood of immigration sections out of the question. For short distances and especially has passed her by. It is unnecessary to inquire special kinds of traffic the narrow guage sometimes snswera into the causes of this. It is sufficient to know that the very well, and there sae some pieces of this character that change of gauge will make the union between the sections pay, but on any large or extensive scale, and with ordinore complete, and in connection with the new industrial nary kinds of traffic, experience seems to have demon.

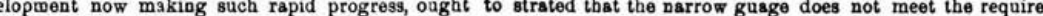
to give greater prominence to that section here. ments called for, and most of the companies of this kin As to the cost of the change on such an extensive body disaster.

of roads, that cannot be stated with any great degree of As to the old brosd guage, that has long since gone out accuracy till after the work has been accomplished. of fashion. The Erie was constructed on that pattera, but Reducing the gauge of track is, of course, a simple was changed to standard in 1878 . Its principal connec. problem, but the adjusting of engines, equipment, tools tion-the Atlantic \& Great Western-was also of six foot and the various paraphernalia connected with the opera' guage, and this was changed in 1880 . We may remark tion of a railrosd, is what constitutes the largest propor- that the Canadian system is likewise of standard guage. tion of the expense. We have no exact dats for There were varying ganges in Canada st firat, but in 1873 estimating the cost of the work, but an approximste a common movement was made towards the adoption of ides of the smount required can be gained by using the standard, and since then that has been generally fol. the figures which Mr. William Butler Dancan gives in lowed. The'Mexican Central (El Paso to City of Mexico) 
Report on the Conversion ( $C F C$, cont'd)

is slso of 4ft. 8 inin. gauge, snd so is the Mexican Railway (Vers Cruz to City of Mexico), though the Mexican National is narrow gauge. Practically, therefore, it may te said that the whole railrosd system of the North American Con. tinent is of standard gauge. And elsewhere this gauge also chielly prevails, that being the usual width in Grest Britain and other Europesn countrieg. In fact the experience of the world seems to have settled in its favor as offering a maximum of service at a minimum of cost.

Not the least aignificant feature about the change now to be made on Southern roads, is that it is undertaken voluntsrily and without any external pressure whatever. In this it is like the adoption of a uniform time standard, effected not so very long ago. The rosds sre yielding simply to the demands of necessity. They find that a gauge at variance with that of the rosds in most other sections of the country is an impediment which interferes greatly with the free operation and full development of their business. So they determine to remove the impedi. ment. But there is no force or compulsion - no law except the natural law of trade, in obedience to which they make the change. They are exercising their own volition en. tirely. Nevertheless, the agreement between them is unanimous. Is there not in that s lesson to those who never weary in calling for legal easctments and Govern. ment intervention to accomplish this or that ? When the necessity for an important stop is clesr and imperativeand who can be a better judge of this than those moet directly concerned-railrosd managers take that step (whether it be a reduction of rates or a change of custom or condition) promptly snd without heaitstion or com plaint. In fact in this way the laws of trade and the in stinct of self preservation effect reforms and improve. ments that all the legislative bodies combined could not sooomplish, as is so evident in the present case. 
Figure B.4: Report on the Conversion (New York Times, May 31, 1886)

\section{CHANGING THE GAUGT.}

WORK ON THE LOUISVILLE AND NASHVILLE COMPLETRD-OTHER SOUTHERN ROADS.

Louisville, Ky., May 30.- The zreat work of ohanging the gauge of the Loulspllle and Nashville Rallway from wide to standard is completed. Eight thousand men were scattered over the divisions of the main stem at daylight this morning, and at sundown the track was standard all along the line, and test trains had been run over the different divisions and $B$ ritches, and reports had been sent in to General Manager Harahan, in thls clty, pronouncing the work complete and everything in good shape. Some of the divisions were completed as early as 9:30 o'clock this morning. and the great bulk of the work was fintshed by noon, everything boing finlahed up in proper shape by the middle of the afternoon. Tho day was propitious, the elements offerink no interference at any point except Memphís, where thunder storms interrupted the work to some extont. But in spite of that the Memphis division was finfohed before noon. No trains were run out last night or to-dny but at midnlght to-night the regular schedule will be resumed and the rolling stock of the Tuurvillo and Nashollil Louisvilo and Nashrille will have onls been treated to a Sunday's rest. The following branches were changed yesterdas: Pensacola and Atlantio Railway, Metumpka branoh; Birmingham Mineral Ratiray, both branches; Owensborough and Nashville, Madisonville branch; Elkton and Guthrie, Glascow branch, Bardstown branch. The following are the roads changed to-day: Maln stem, first and second divlsions, Knoxville Division, Evansville, Henderson and Nashville Division, Memvhls Line, Nashville and Decatur Division, South and North Dlyigion, Mobilo and Division, New-Orleans and Mobile Division, and Pensacola Railroad. 
Figure B.5: Example of Anticipated Effects (Wilmington Morning Star, April 16, 1886)

T TREATENED LOSS, OF
BUSINESS.
Savannah News.
The change of gange on Sonthern
railroads, which, it is expected, will be
made in July next, will hring abont
some important changes in the lum-
ber business in the South. Southern
lumber now reaches the Northern
markets by sea. It is transported
from the mills to the nearest ports,
and sent by sailing veseels to the
Nerthern distributing points.
This way of getting lamber from
the produoer to, the consumer is ra-
ther slow. It has to be handled sev-
eral times-onee at the mills once,
and sometimes twice, at the port of
shipment, generally twice at the port
of its destination, and, finally, once
at the place of consumption. It bas
to be insured against the of
the sea, and frequent handlings often
cause considerable breakage. An-
other drawback to shipments by ses
is the long time required for lumber
to reach the Northern markets after
it has been shipped.
Very little lumber has gone North

by rail for the reason that Southern roads baving a different gauge from the Northern roads, it is rather troublesome and somewhat expense to change the trucks.

Southern lumbermen say, however, that when the gauge of the Sonthern roads is changed they will be able to ship lumber witbout breaking the bulk direct from their mills in Geor. gia, Florida or any other Southern State to any point in the country, and that the difference between the cost of rall and water transportation will be more than overcome by the saving that will be effected in insur. ance, bandling and breaksge.

While mueh of the lumber will contunue to be shipped by sea, there is no doubt that a great deal of it will not seek the seaboard for trans. portation to market when it can be transported as cheaply and much more quickly by rail, and Southern lumber ports are bound to suffer a considerable loss of business. Other kinds of business, however, will doubtless take the place of whatever part of the lumber businese that may be lost to them.

Very little lumber has gone North 
Figure B.6: Technical Summary of the Gauge Change (Railroad Gazette, October 14, 1887)

668

THE RAILROAD GAZETTE.

[OCT. 14, 1887

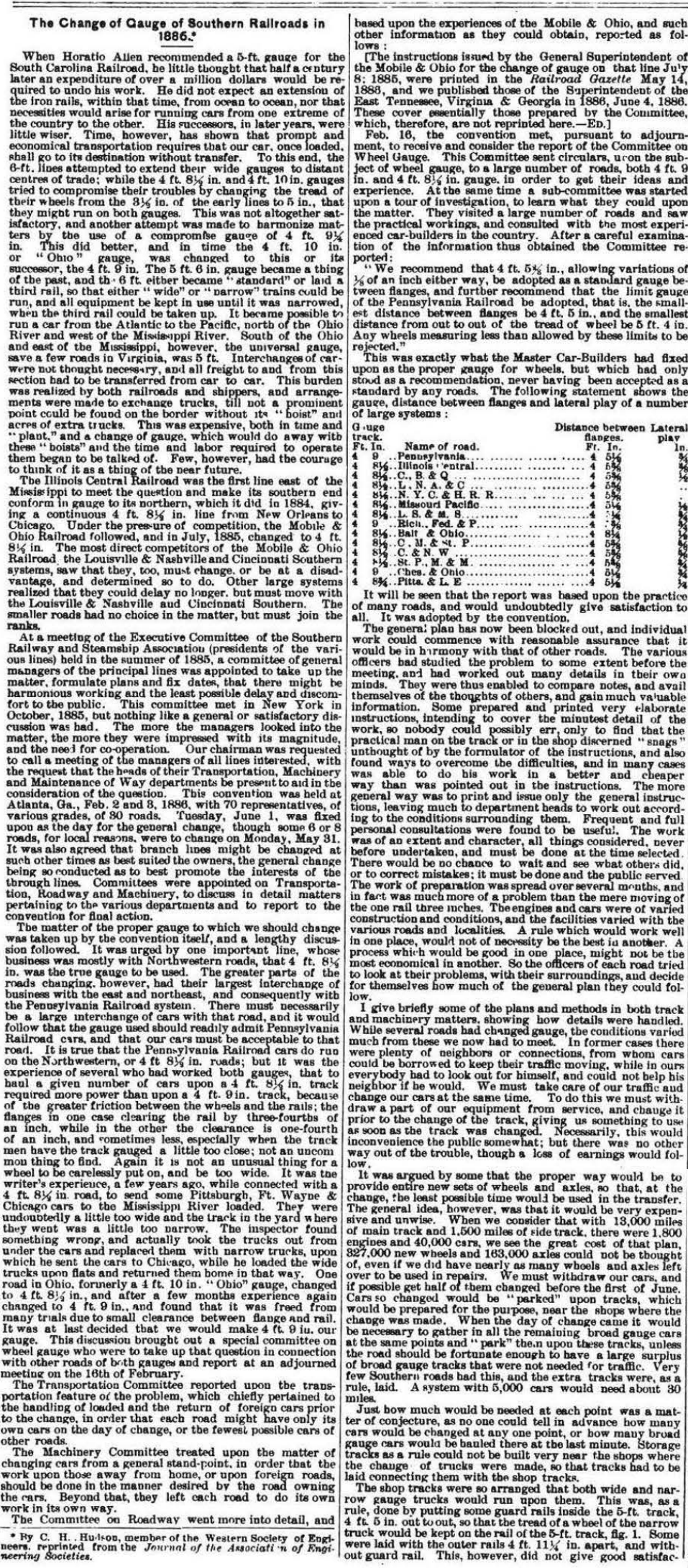

tion, as the bearing surface was so small that a slight imper-
fection in the rail, or a curve that let the wheel run to one side, would cause a wheel to drop in and pive trouble and
delay. The tracks from storage yards to shops were some-
timg.

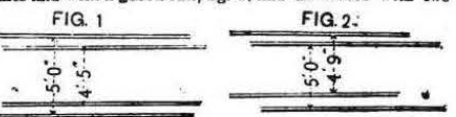
Reparate tracks on the same ties, 'as shown in fig. 2. This last was most satisfactory. Severel ingenious devices were
used to switch front one track to another, all temporary in character and inexpensive. Expensive trogs in some why
were avoided, where two tracks or rails were crossed and cornpound frogs ordinarily used.
In changes beretofore made full sets of bridles for switches had in some cares been provided and "W Warton "switches
thrown out, plain stub switches being put in their places This seemed expensive, and would take up much valuable time on the day of change.
We have various kinds of bridles. The old-fashioned one for the stub switch, that clasped the base of the rail, as
shown in flis. 3 , was cut pear its coutre and had one end
lengthened : each part being at least $2 \mathrm{ft}$, 9 id. long. Three lengthened : each part being at least 2 ft, 9 ia. long. Three
holes were either puncbed or drilled thruugi the bars near
the

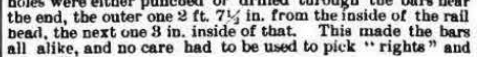

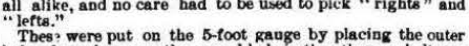
Thes? were put on the 5-foot gauge by placing the outer
bole of one bar over the second bole in the other : a bolt was F FIG.3. FIG.5. FIG.

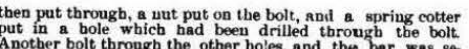
Another bolt through the other holes, and the bar was se-
cure. On the day of change the bolts were easily removed, the bars moved 8 in., the bolts replaced. and our track was
$4 \mathrm{ft} .9$ in. Fig. 4 shows the bars as changed and ready to be put together. Fiz. 5 shows a bar which took hold of the
hange of the switch rail, treated in the same way. Fig. $B$ shows another kind, and the manner of its treatment is
readily seen by the sketch. A hole is drilled 3 in. back from the one through which the original rivet or bolt was put.
With the "Wharton" there was more trouble, as the bar With the "W Warton" there was more trouble, as the bars
could not easily be removed to be prepared for change. It
was found bowever, that a casting could be mude that could

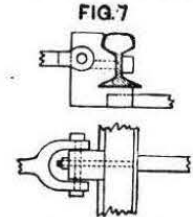

be placed benind the elevated rail, which would hold it in 8
inches securely. a longer bolt being needed. Figk 7 and 8 show this so plainly that po furtber description is needed.
Five each of these boits and castings were needed for each
switteh. The anfety throw bar was simply disconnected to be Cengthened and replaced at leisure.
Croesings were prepared by cutting out at the centre the

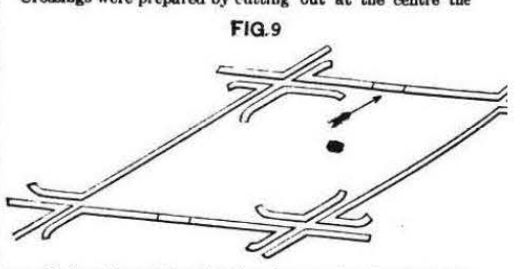
requisite leuxth, and then keeping the peece in place by splice
bars till the day uf change, when the cut pieces were taken
out and one side moved up to proper gauge, see flg. 9 .

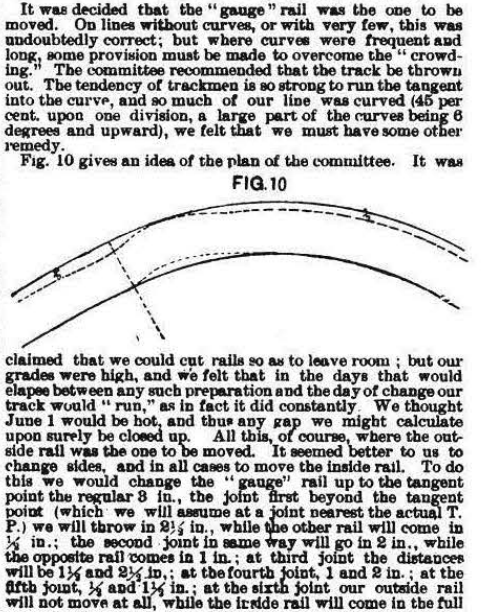


3 in.: we continue to move the inside rail till within six
joints of the next tangent point, when we commence to re verne, the process. In the procees of preparation spikes have

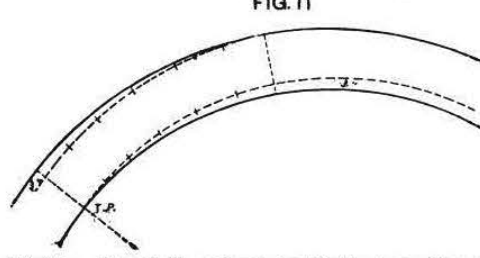

this plan. The outaide or elevated rail is the one usunlly used on which we started, viz: : to move the "gauge" rail. The wiadom of the plan was shown when the dny of change came
and curves changed on this plan were found to be in batter line than those chang
three plans spoken of
In the matter of

In the matter of of locomotives the conditions varied much probabil been the most far-seeing. For twenty years they
had looked forwarid to this change, and had during that tume oo constructer their frames and fire-boxes that, by using new
driving whel contres, the change could be made without changing other parts. Few otber builders had, nutil comparatively recently, given the matter any tbought, and, as a by moving tho frames in, and not unfrequently the tire box peose. Many engines were thrown out of service by the fact of The 5-tt. engines measured between flanges of drivers (and otber wheels as well) 4 ft. $8 \%$ in. As the gauge was

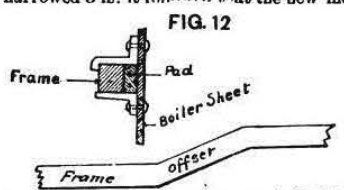

be 4 ft. $5 \%$ in. was the measure convention, with of $1 / x$ in. eitber must be enough
lese than this from a reasosable clearance, or say $4 \mathrm{ft} .5$ in. I think sll our wider frum out to out of "frames. the frames being set out
from the fire-box and a "pad" placed between them ; see Ag. 12. The "pad" could be cut out and the frame set in
against side of the fire box ; but to do it, this frame had to be offset, as shown in fig. 18. This was done bebird the rocker arm and in front of the pedestal or " "jaw" thus render-
ing unnecessery the chsnging of machinery, but enabled us
to get in the boxes and wheels or tires to the proper width without cutting into tho frame.
To get proper informstion about all the engines, accurate measurements were taken of width of fire-box, width be tween frames, from out to out frames. between bubs, be
tween inside of tires, between rims of and wedges, thickness of
hubs, rims of wheels, etc.
Blue print diagrams were 13
FIG. 14 prepared upon which we placed all these measure
ments with the number of head of the machinery de partment could sance at a for each engine. It was expected at the start that new
driving wheel centres would be required for all engines;
but examination of our blne prints showed that upon our
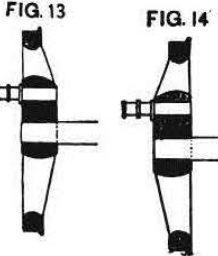

sary. Bome few enfines, notably some of the old Rogers, ing them off and putting on again, with the outeide face in 18 as originally, and fig. 14 as turned. It was found in prac tice that a new crank pin had to be put in. In many cases
we found that we had thick bubs and heavy flanges to both

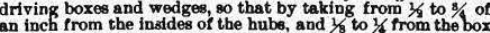
an inch from the insides of the hubs, and 8 to $3 /$ from the bo and wedge flanges, we could gain at least one inch, and
some cases did more. This left not to exceed half an on the inside. neither an unreasonable nor an un usual projection. This change was a trifing one and
done at a cost per engine of about $\$ 180.67$, including new crank pins. A new set nf wheel centres, finished and in place, including pins, which would probably be needed, would
cost $\$ 264.46$. When changes were decided upon, and an enput on at the old gauge, projecting outside the centrme The

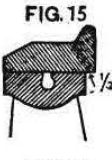

F1G. 17
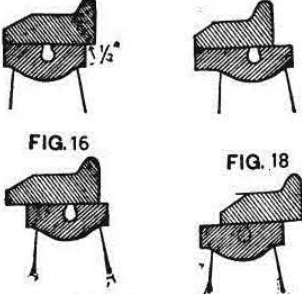

were used in this way without trouble until the day of chang
came; fla. 15, original; fig. 18 , changed. went engines had their wheel centres bullt expresely with would be required with the new gauge: but the rim projected outwardly an inch and a half more than usual, so that the
tire could be placed for the $5 \mathrm{ft}$. gauge and still have its ful tire could be placed for the $5 \mathrm{ft}$. gauge and still have its full
support, Bee flg. 17. When the tire was eventually moved
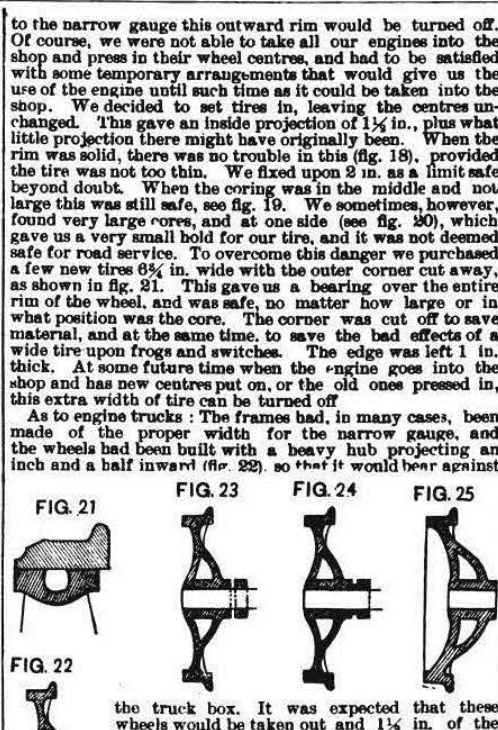

the truck box. It was expected that the
wheels would be taken out and $11 \%$ in. of the

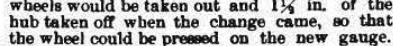
the wheel could be presed on the new gange.
This would have taken too much time, so the wheals, but a cast iron collar or washer $1 \mathrm{~K}$ in thick was placod upon the axle inside each whet day of change came 8 few blows of the hammer upon a cold chisel split this collar of and we were ready to Many of the wheels that were still in use with the long bu back from the face, leaving our cast collar; which was easily split tif as before. (Fig. 24)
With tender wheel 8 , as with our car wheels, the case was

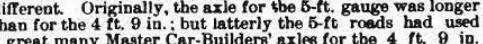

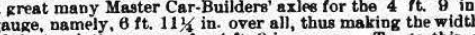
isbed wheel, or rather a wheel with \& greater dish by $11 \%$ in. han previnusly used was needed, so that the tread of the
wheel could be at its proper place; course, many of the wheels with small dish and long axles
still in use. Their treatment, ho came, did not vary from that of the short axles. It had bee
the rule for some years that all axles should be turned bac $11 / 2$ in. furth r than needed; but unfortunately the rule
had not heen cloeely followed, and many were found pot to be sn turned. To make the matter worse, quite a number o
the wheels were found to have been counterbored about in. deep at the back end. and the axle turver up to fit thi the wheel worked loose, but bed frmm thn otandpoint of
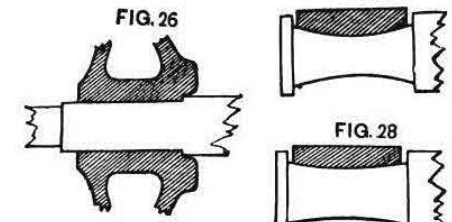

FIG. 28

change of gange. In such cases the wheels had to be started ofr before the axle could be turned back, so that the wheel
could be pusbed on in their proper position. (Fig. 22.) If the work was done where they had a lathe large enough to swing
a pair of wheels, they were preseed off but half an inch, the
wheels gwung in the lathe, the axles turned back 11, in. wheels swung in the lathe, the axles turned back $11 /$ in.
and the wheels then preesed on 2 in. or $11 / 2$ in. inside of their first position. Where no large lathe was in use, the wheels
came entirely off before the axles could be turned back. The
work in the former work in the former case was both the quicker and the
cheaper. Where the large lathes wers used they were either Wheels would easily roll int place, or a raised platform was put before the latbe, with a
inclive up which the wheels were rolled and then taken to the er than to hoist the wheels up, as is usually dono. Inpressing the whels on, where the axles had previousiy been turned
beck, much trouble was at first experienced becanse of the back, much trouble was at first experienced becanse of the
rust that had gatbered upon the turned part behind the wheel. forming a ridge over or upon which the wheel must per cent. of the wheels so presed on. By saturatiog this
surface with coal oil, bowever. it was found that the rust was 作 zorkman would leave a ridge at the starting point of the turning. Frequentiy, a so, uld be a little scant upon one side
that the new turning would when compared with the old surface, and upon the opposite
side a little full. As an indication that these diffeulties were overcome as they appeared, I will say that upon our line
only 202 wheels burst, out of nearly 27,000 pressed on, an excedingly smail percentage.
After the cbange upon the early roads they were troubled
for weeks with hot boxes, caused, as we bylieved, by the for weeks with hot boxes, caused, as we b?lieved, by the
changing of brasses. A brass once fitted to a journal will work upon it without trouble; but when placed upon som
other fournal will probably not fit. If the fournal bad been worn hollow (and it was surprising to see bow many were flg. 27, exargerated of course. The next wheel may bave an
axie worn little or nove, as in fig. 28. Now, if these brasses are exchanged, we have the conditions, as shown in figs. 29
and 30 , and we must expect they will heat. The remedy was simply to keep esch brass upon its own journal. To do
this the brasser were fastened to the axle by a plece of 8 gmall wire, and went with it to the latbe and press. When its
truck was rencher, the brass was there with ite inurnal. Worn
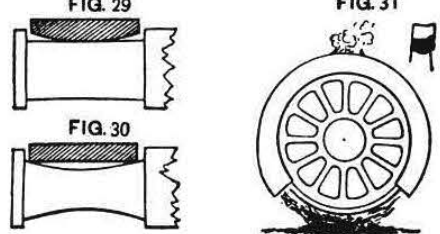

out brasses, of courae, could not be put in, and new ones were the cbange showed the efficacy of the remedy. The manner in which the tires of engines were to be changed,
when the final day came, was a serious question. The old Mobile \& Obio bad used a fire of pine under the whel. Which was covered by a box of sheet iron, so arranged that the flame aperture at the top; If. 81. Many thought this perfect, while others were not satistled, and bexan expernments for
something better. A A device for using gas had been patented, but it was somewhat complicated, as well as expensive, and
did not meet with general favor. A very simple device was son hit apon. A two-inch pipe was bent around in a
circle \& little larger than the outer rim of the wheel. Holes to inch in diameter and 8 or 4
inches apart were drilled throagh the pipe on the
inside of the circle. To this pine was fastemed another inside of the circle. To this pine was fastened another
with a branrb or fork upon it. To one branch or tork was
counected a pas-rine from the reter, while to the other was FIG. 32

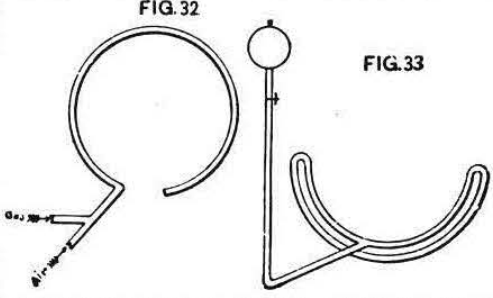

connected a pipe from an airpump. With the ordinary
pressure of city gas upon this pipe it was found that the pressure of city gas upon this pipe it was tound that the and gas might mix properly at the branch or fork, "so we
could get the best combustion and most heat from our "blowpipe, "for such it was. See fig. 32. We were able to beat a
tire, so it could be moved in ten to twenty minules, and the machine may be said to bave been satisfactory. Gas, how.
ever, was not to he bad at all places where it would be neers. ary to change tires, and the item of cost was considerable. un with coal oll (bead-ligbt oil). They were crude and un-
atisfactory at first, but soon succoss was reached. A pipe was bent to ft the lower hall of a wheel pretty closely, aud distant from it. This under part bad boles in in. in diameter
and 3 or 4 in, apart, drilled upon its upper side, or unoer the upper pipe. Connected witt the upper pipe at its centre was
pipe which ran to one side and up to the can containing a pipe which ran to one side and up to the can containing
the kerosene. Betwreen the can and the pipe under the whee was a stop-cock l,y which the flow of oil could be controlled.
To use the device, open the cock and let a small amount of sil fiow: a pply fire to the pipe under the wheel, and the ofi in the upper pipe is converted into gas, which flows out of
the small holes in the lower pypes, takes fire and heats not only the tire. but the upper pipe, thus converting more oil
into gas. We bad here a lot of blue fame jets and the result as with gas, but at less cost. We bad also a machine that was inexpensive and easily handled anywhere. Bnxes
were placed over the upper part of the wheels, that the beat might pass close to the tire. This device was extensively used by our people, and with great satisfaction. Care bad
to be taken that in starting the flre it did not smoke and cover the tire with carbon or " lampblack," which is a non. onductor of beat. Experiments were made with oir forced
tbrough gasoline, and with oil heated in a can to form gas. blow-pipe devire, and no better results were obtained, though With the change of the wheels, the brakes bad to be
inged the same amount, that is, each one get in $11 / 3$ in. his it was thought would either require new bangere, or a hangers could easily be bent without removal. Fig. 34 sbows three hangers after passing through the hending process A
short lever arranged to clasp the hanger just below the point

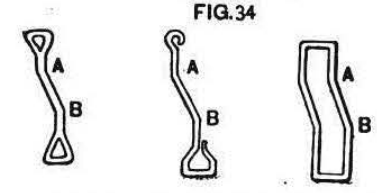

A was the instrument. A forked " shore " is now placed. with the fork against the point $A$, and the other end agains
the car sill; press down on the lever and you bend the bang process and you bave the bend at $B$; the wbole thing taking
ess than two minutes per hanger. A new bolt hole, of course bas been bored in the brake beam $11 / 3$ in. inside the
old bolt. It takes but a short time after this to change the position of the head and shoe.
Before the day of change, a portion of the spikes were rawn from the inside of the rail to be moved, and a spike and the third left. At least every third spike was get for the new gauge, and in some cases every other one. There were
several devices with which to set the splke. A small piece of iron 3 in. wide was common, and answered the purpose well. hand to clasp, while others bad a handle long enough for $a$ man to use it without stooping down. See figs. 35 and 38. 


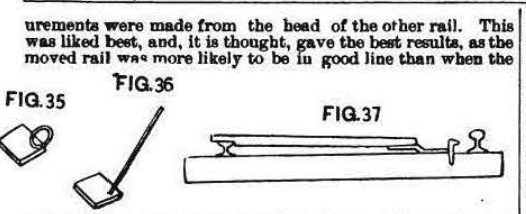

measurements were taken from the flange. It was intender
that great care should be taken in driving the spikes, that they were in the proper place, square with the rail, and left
sticking up about an incb. The ties, of course, were all adzed dowa betore the day of chauge
Hand-spikes were oripinally used to throw the rails, as were linug bars. We found, however, that small cant-
hooks were more easily handied and did better work. The hooks were more easily handied and did better work. The
fint. ware made like fig. 88 , with a spike in the end of a stick, \begin{tabular}{l|l} 
FIG.38 & $\begin{array}{l}\text { while the hook was fastened with } \\
\text { bolt about } 10 \text { or } 12 \text { in. above the } \\
\text { foot. We afterward made them of a }\end{array}$
\end{tabular} $11 /$ in. red, $31 /$ f feet long, thinted at one end, with a ring shruuk on 1 fout
from the bottom. Then the hoo

from the bottom. Then the hook flg. 39, which slipped down over the
top of the main rod. This was
gimple and cheap, and the iron was simple and cheap. and the iron was
to be used for repair purposes when this work was doove. Upon the system with which the writer was connected wo had some branches where we could experiment upon the
moving of the rail. Between Selms and Lauderdale the traffic was light, and at Lauderdale it connected with the
Mobile \& Obio Railroad, which was narrow, and to whicb
all freight had to be transerred, either by hoisting the cars all freight had to be transferred, either by hoigting the cars,
or by bandling through the house. By changing our gauge We would simply change the point of transfer to
Here was a chance to experiment pupon one hundred miles
and cause little trouble to traffic. We could gee the practiand cause little trouble to traffic. We could gee the practiWork. It had been our plan to do it somewbat earlier, hut
floods prevented. Most of the rail was old chair iron, sbort, snd consequently more time was used in making the chance
than would have been required had our work boen on fish
plate rail. Our sections bere were about eight miles long plate rail. Our sections bere were about eigbt miles long,
and we arranged our men on the basis blocked out by the committee, viz.: 24 to 28 men to the esction, consisting of
6 spike pullers, 4 throwing rails, 12 spikers, 2 to push the cars and carry water.
We soon found 5 -ft. cars useless and threw them into the ditch to be picked up at some future time.
The men were spread out so as not to be in each other's way, and, when the organization was understuod and conhours and ten minutes, including a number of switches. We on later work. that after 5 or 6 miles the men began to lag.
We believed we bad the best results when we had sections of about that length. It was arranged tbat two pections, alter.
nately, commenced work together at one point, working from nately. commenced work together at one point, working from
each other and continuing until the forre of anotber section was met, working from the opposite direction.
The foreman in charge was expected to examine the work a good test as to gauge. A work train was started from each end with a small force (20 or 25 men) to run over the changed track. This train, of course, had been changed on a previous
day to be ready for this work. If a force was overtaken by at once spread out to aid in its completion. This done the train ran on. Not until this was done was a traffic train al
lowed to pass over the track. The same rule was followed upon all the work. Upon the final day it was required tha upon all high trestles and in tunnels tha track should be ful
spiked before being left, or a train let over. This took extra precaution on the side of safety. Upon the day of the change of the Alabams Central Di-
vision (Belma to Landerdale), guperintendents of other divisions, with their road masters, supervisors, master me-
chanics and many section foremen, wore sent over to see the organization and work and the preparations that had been
nade. Many of them lent $\mathrm{a}$ helping hand in the work. They saw here in practice what had only been theory before. road between Rorme, Ga, and Selma, Ala., about 200 miles,
was changed, and again men from other divisions were sent to see and aid in the work; so when the final day came the On the last day of May the Memphis \& Charleston, Knoxville \& Obio. avd North Carolina Brapch were changed, and
on June 1 the line from Bristol to Chattanooga and Brunswick. Other roads changed their branch lines a day or two
before the 1 st of June; but the main lines, as a rule, were It was no small maiter to take care of the cars and arrange
a the train service so there should be no bitches. It was not hours prior to the change, and these days were gpent in clear.
ing the road of everything, and taking the cars to the points of rendezvous All scheduled freight trains were abandoned on Upon the East Tenpessee gystem these points were Knoxvill these points all cars must go, loaded or empty, and tbere they
were parked upon the tracks prepared for the purpose. Pas. onger trains were run to points where it had been arranged
to change them, geverally to the general changing point Most of the Bouthern roads have double daily passegerer ser-
vioe : upon all ropads one of thee trains, upon the day of change, was abandoned, and upon some, all. Bome, even,
did not run till next day. We were able to start the day train

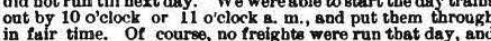
the next day was used in getting the cars which bad been
changed, out of the parks and iuto line. So our freight traf
fic over the entire South was suspended practically three The work of changing was to cummence at $3: 30$ a. m.
but many of the men were in position at an earlier bour and did commence work as soon as the last tran was waver, or an
bour or so before the fixed time. Half-past three $\mathrm{a}$. $\mathrm{m}$., ho ever, can be set dows as the keneral hour of commencement briskly, the men working with much more than "rdinar enthusiasm: but the day was warm, and atter 9 or $10 \mathrm{a}$. $\mathrm{m}$.
it began to lag. All was done, bowerer, hefore the day was it began to lag. A Al was done, bowever, hefore the day was
over, and safe, so that trains could pasa st full speed. The early or late in the day, and were paid that afternoon as soon
as the work was done. Tictrets were given the men, which as the work was done. Tickets were given the men, which
the nearest agent paid, remitting as cash to the treasurer. On some lines it was deemed best to offer prizes to tho
On who got through first. Reports ghowed some very early fin-
ishes; but the facts seem to have been that under such ishes; but the facts seem to have been that under such enfore the change and put tho fero in while changing. They
were thus reported through early, but their work was not done, and they took great chances. It was by most cousid-
ered unwwiee to offer such prizes, preferring to have a little red unwise to offer such prizes, preferring to have a little
more taken and be sure that all was safe. Sucb lines seemed to get their trains in motion with as much promptness as
others This, with freedom from accident, was the end sought.
It was found after the work had been done that there had
been little inaccuracies in driving the gauge spike, to which the rail was thrown, probably from various causee. The proper place, and then the template in the hurry may not or twisted. Whatever was the cause, it was found that fre
quently the line on the moved side was not perfect, and, of quently the line on the moved side was not perfect, and, of
course, many spikes bad to be drawn and the rail lined up and respiked. The more cerefrul the work. had been fone,
the less of this there was to do afterward. With rough track this was least seen. The nearer perfect the more noticeable
it was.
Of course, we all planned to get foreign cars home and have cours ant to us; but when the interchange stopped, we
found we had many foreigu cars, which, of course, hed to be found we had many foreign cars, which, of course, hed to be
changed. This subject had come up in convention and it bad
been voted to charge $\$ 3$ per car when axles did nut need
turning, and 85 where they did. By comparison with the been voted to charge 8 per car when axles did not need
turning, and of where they did. By comparison with the
cost of changing, ss shown in this paper, it will be geen that to our company. at least, thera was no loses at these figures
The following statements will explain the work done upon Georgia systams. formation regarding other roads that fuller statements and comparisons might le made and the sbowings be of greater
value. The figures of the Mobile \& Obio are added, having been compiled from the annual report of that roed.

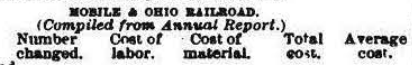

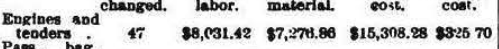

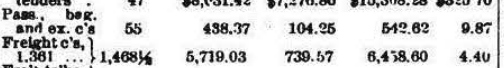

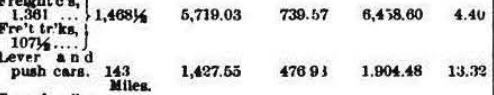

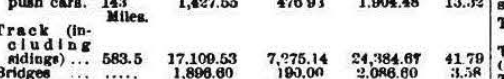

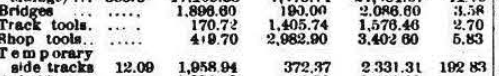

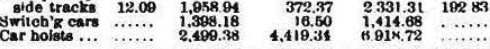

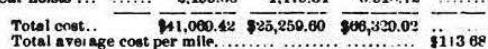

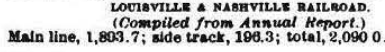
Track

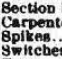

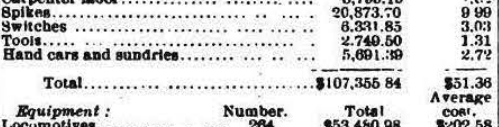

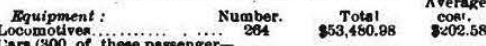

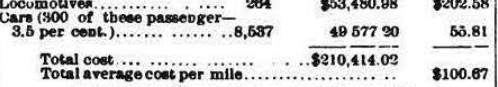

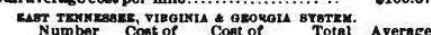
chaoged. Labor. material. cosh coot.

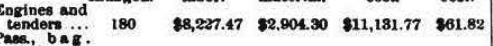

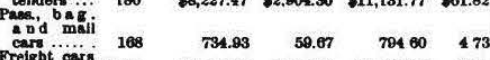

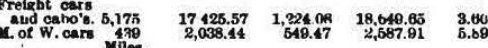

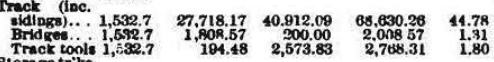

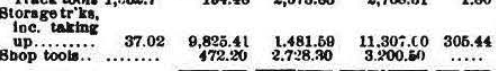

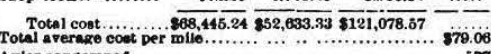
Axles condemped.
Wheels condemned
Wheetla burst New axl 8 used
New wheels unod

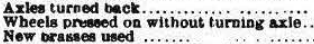

Naw brasses used
Cars narrowed (not including lever or pusi cars)
Engiues narrowed

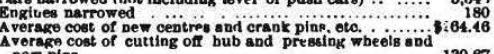

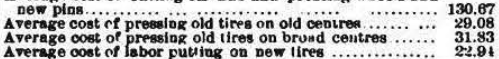
OOKPABATIVE BTATEKENT OY AVRRAG COBT OF VARIOUS TrEMB OF M. \& O. R. R. L. \& N.R. R. v. \&. T. B. K. Averare.

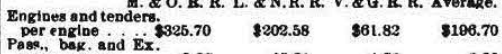

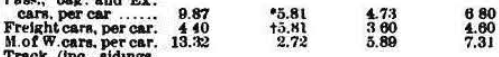

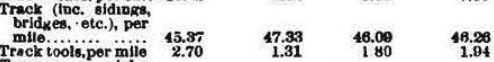

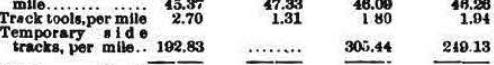

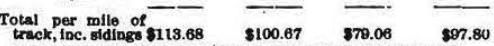

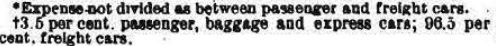

Since the preparation of this paper the general manager of
the Norfolk \& Western Railroad has kindly furnished the fowing items of expense for that line : Average

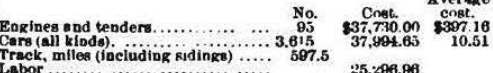

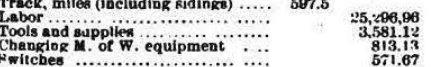

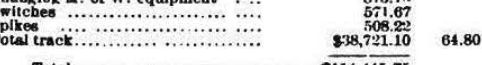

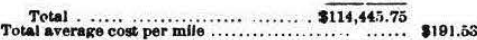
And the superintendent of the Bavannah. Florida \& West-

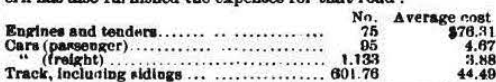
Track, incluning aldiogs ..................601.76
Nothing was said about shop or otber tools, storage tracks COMPARATIVE BTATEMENT OP AVKRAGE COBT OY LABOR OV VABIOU

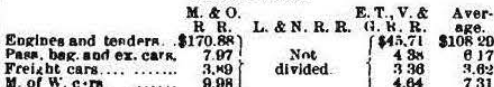

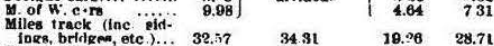

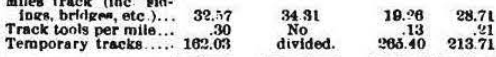

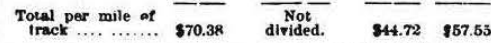

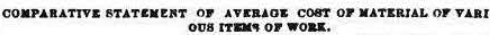

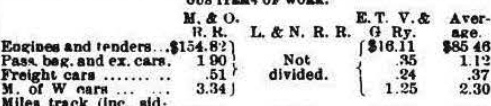

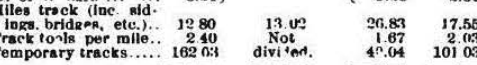

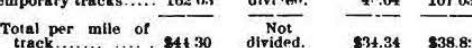

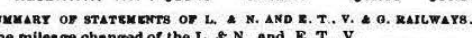

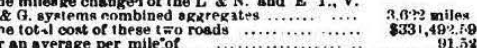

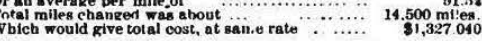
We should really add to this a large sum for the great
unber of new locomotives wbich were purchased to replace old ones that could not be changed, except at large cost, and which, when done, would have boen lifht and undeairable.
Upon the basis of the work done upon the Louisville \& Nashville and East Tennessee, Virkinia \& Georgia systems. we have made the following estimartes. which will perhaps
wonvey a better idea of th9 extent of the work than can be obtained in any other way

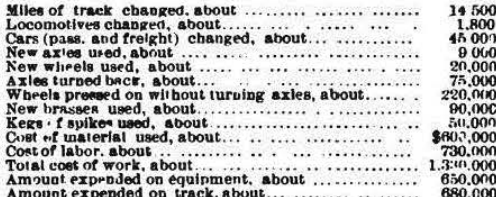

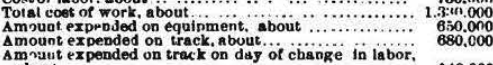
The work was done conomically, and so ablic hardly realized it was in progress. To the casual the orver it was an every-day transaction. It was, however, a
ork of great magnitude, requiring much thought and mechanizal ability. Tbat it was ably handled is evidenced by the uniform success attained, the prompt changing at the
agreed time, and the trifing inconvenience to the public.

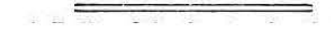

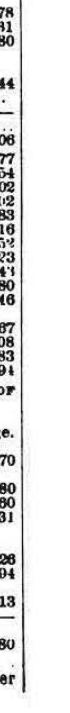




\section{Vertical Structure of Freight Shipping}

Long-distance freight shipment in the 19th century had an inherent vertical character: to get from origin to destination, traffic had to traverse the tracks of multiple, separately-owned connecting lines. Frictions in the vertical transactions required for through shipment were the source of decades of holdup, and led to the formation of numerous innovative contractual relationships, which could be the subject of an entire separate paper - and indeed are the focus of a large contemporary and historical academic literature. For the purposes of this paper, a better understanding of vertical contracting arrangements is both useful context and important to evaluating the model used to estimate demand and supply and simulate competitive conduct.

\section{C.1 How were long-distance shipments priced?}

To fix terms, freight shipments borne by multiple, connecting carriers were known as "through" shipments, typically traveling long distances. Shipments which could be delivered by the originating carrier were "local" shipments. There were two approaches to pricing through shipments: the most primitive method was a combination of local rates, whereby a shipment from point A to point $\mathrm{C}$ would be charged the first carrier's local rate from A to B plus the second carrier's local rate from $\mathrm{B}$ to $\mathrm{C}$, which were independently determined. Given the number of local rates that had to be considered on routes with many connections, and the frequency of rate changes, predicting the cost of shipping under combination rates was a formidable challenge for shippers.

To simplify pricing, railroads began to set joint rates (also/more often termed as "through rates"), which were point-to-point freight rates set jointly by carriers involved in the route, with a negotiated division of revenue. By the dawn of the regulatory era, through rates were by far the most common means of pricing through traffic. However, while there's abundant discussion of the definition and applications of through rates in historical records, there's unfortunately remarkably little coverage of how through rates were set, and how revenue was divided among carriers.

With effort, it was possible to unearth some contemporary references to the issue, which consistently point to prorating of through revenue according to the distance of each carrier's leg in the journey. Proportions were determined by the "constructive mileage" of each leg, which is derived from true distances but allows adjustments (Haney 1924). For example, in Congressional testimony in 1874, the P.A.L. general manager claimed to prorate through revenue with the water lines with which it connects (U.S. Congress 1874, p. 401), with ocean steamships prorating 3 miles for every 1 railroad mile. In the same Congressional record, a representative of the Green Line (a fast freight line, see next subsection) stated that all railroads in the organization received the same rate per mile from through revenue (p. 786). Division pro rata thus appears to have been the norm.

Joint pricing was not the only means of contracting around vertical transfers of shipments. Trackage rights were also common, which gave an originating carrier rights to travel freely over a connecting carrier's tracks. An alternative was vertical integration via merger or acquisition, which was also occurring at a rapid pace during and after the Reconstruction era.

\section{C.2 Who owned/controlled the rolling stock?}

Vertical transfers of rolling stock were an entirely different contracting problem that was resolved in a distinct way. While not as important to the paper as the process determining rates, it is useful 
to understand how rolling stock was transferred across railroads, and who maintained ownership and control, as freight traveled the tracks of multiple carriers along its route.

The root of the problem is that, to send shipments over long distances on the same car, originating railroads had to (i) send their rolling stock across connecting lines, and (ii) get it back. Conversely, intermediate railroads had to host the rolling stock of their connections. The moral hazard problems arise in several places: not only does the originating carrier have to relinquish control over its rolling stock, but it also retains liability for damage or loss of its shipments on connections. Moreover, different railroads might have different quality cars and different maintenance practices, and a lowquality or poorly-maintained car could damage the tracks it traveled. As a result, until the 1860s, freight had to be unloaded, unregistered, reregistered, and reloaded every time one line ended and another began, imposing enormous costs and delays on through traffic.

To address these issues, railroads around the country formed "fast freight lines" in the 1860s and 1870 s, which were joint ventures between connecting railroads which pooled their freight cars into a shared rolling stock. The largest of these in the South was the Green Line fast-freight company, established in 1868. Under the agreement, members of the Green Line submitted rolling stock to the common pool in proportion to their total track mileage, and members were paid 1.5 cents per car-mile when other carriers used their cars. Ordinary maintenance was performed by the railroad operating the car and charged to its owner, but if a railroad damaged another carrier's car, it would be responsible for repairing or replacing it - though enforcement of this latter provision was inherently challenged by the difficulty of determining the party at fault. ${ }^{3,4}$

\section{C.3 What was the vertical structure in the South?}

Though these contracting innovations were being developed around the country during Reconstruction, the key question for this paper is ultimately what vertical contracting arrangements were in place in the South around the time of the gauge change, to evaluate whether the model of industry conduct is appropriate. The fundamental issues are (i) whether SRSA freight rates were for endto-end North-South freight traffic, (ii) whether they applied to both railroads and steamships, and (iii) whether they were determined in coordination with Northern carriers (which comprised half of each all-rail route) and how revenue from each shipment was divided. If the answer to any of these questions is in the negative, or if revenue division was endogenous, the model of the market could require nonstandard features such as bargaining or a vertical dimension.

Details of the SRSA's vertical contracting arrangements are thin at best. What is clear from SRSA records is that the cartel rates were through rates, from origin to destination, and that these rates applied to all lines in the cartel. However, the records say nothing about how through revenue was divided among carriers down the line, nor about what role Northern railroads played in pricesetting, and other sources have not yielded any insight. My understanding from cartel documents and later accounts is that the SRSA fundamentally controlled prices on shipments into and out of the South - in part due to its outsize influence over these routes, and in part because Southern traffic was relatively unimportant to Northern carriers in volume and value - and it is thus appropriate to model the SRSA as a price-setter. ${ }^{5}$ Revenue from each shipment was likely distributed pro rata,

\footnotetext{
${ }^{3}$ When asked by Congress "How do you know whether it is the fault of the road or ... the car?" a Green Line agent responded that the issue was an ongoing source of contention (U.S. Congress 1874, p. 788).

${ }^{4}$ For more information on the Green Line, see the following sources: Sindall (1886, pp. 680-861), Joubert (1949, pp. 31-40), Taylor and Neu (1956, pp. 67-76), and Puffert (2009, p. 134).

${ }^{5}$ Total railroad tonnage in the New England, Mid-Atlantic, and Great Lakes regions was over 10x that in the South in 1880, and the difference in ton-miles even greater (U.S. Department of Interior 1883).
} 
following industry norms, such that revenue division is orthogonal to prices and would not enter or affect the cartel's profit-maximization problem.

\section{Appendix references not in paper:}

Haney, Lewis H. The Business of Railway Transportation, New York: Ronald Press Company, 1924.

U.S. Congress. Reports of the Select Committee on Transportation Routes to the Seaboard, Washington: Government Printing Office, 1874. 


\section{Sensitivity Checks}

\section{D.1 Sensitivity Checks: Dropping Origins}

The tables in this section evaluate the sensitivity of the main results in Tables 4 and 6 to dropping observations with a given origin.

Table D.1: Change in All-Rail Traffic, omitting Boston

\begin{tabular}{lcccccc}
\hline \hline & $(1)$ & $(2)$ & $(3)$ & $(4)$ & $(5)$ & $(6)$ \\
\hline All-rail x post-change & $3.342^{* * *}$ & $3.362^{* * *}$ & $3.363^{* * *}$ & $3.412^{* * *}$ & $3.368^{* * *}$ & $3.455^{* * *}$ \\
& $(0.827)$ & $(0.780)$ & $(0.782)$ & $(0.801)$ & $(0.955)$ & $(0.983)$ \\
$*$ distance (100 mi) & $-0.460^{* * *}$ & $-0.470^{* * *}$ & $-0.470^{* * *}$ & $-0.474^{* * *}$ & $-0.469^{* * *}$ & $-0.478^{* * *}$ \\
& $(0.122)$ & $(0.115)$ & $(0.115)$ & $(0.118)$ & $(0.141)$ & $(0.144)$ \\
\hline Breakeven distance & 727.1 & 715.7 & 715.8 & 720.3 & 717.7 & 722.9 \\
& $(31.3)$ & $(27.3)$ & $(27.4)$ & $(28.9)$ & $(33.4)$ & $(35.5)$ \\
\hline $\mathrm{N}$ & 777 & 777 & 777 & 777 & 777 & 777 \\
$R^{2}$ & 0.34 & 0.69 & 0.69 & 0.72 & 0.71 & 0.75 \\
Route FE & & $\mathrm{X}$ & $\mathrm{X}$ & & & \\
Mode FE & & & $\mathrm{X}$ & & & \\
Year FE & & & $\mathrm{X}$ & & & $\mathrm{X}$ \\
Route-mode FE & & & & $\mathrm{X}$ & $\mathrm{X}$ & $\mathrm{X}$ \\
Route-yr FE & & & & & & \\
\hline \hline
\end{tabular}

Notes: This table is a robustness check on the results in Table 4, omitting observations with an origin of Boston. *, **, *** represent significance at the 0.1, 0.05, and 0.01 levels, respectively. SEs clustered by route in parentheses.

Table D.2: Share of Traffic, omitting Boston

\begin{tabular}{lcc}
\hline \hline & $(1)$ & $(2)$ \\
\hline All-rail x post-change & $3.369^{* * *}$ & $3.471^{* * *}$ \\
& $(0.691)$ & $(0.734)$ \\
$*$ distance (100 mi) & $-0.481^{* * *}$ & $-0.487^{* * *}$ \\
& $(0.102)$ & $(0.107)$ \\
\hline Breakeven distance & 701.0 & 712.1 \\
& $(23.4)$ & $(26.0)$ \\
\hline $\mathrm{N}$ & 507 & 507 \\
$R^{2}$ & 0.29 & 0.48 \\
Route FE & $\mathrm{X}$ \\
\hline \hline Notes: This table is a robustness check on the results in \\
Table 6, omitting observations with an origin of Boston. ${ }^{*}$, \\
**, ${ }^{* * *}$ represent significance at the $0.1,0.05$, and 0.01 levels, \\
respectively. SEs clustered by route in parentheses.
\end{tabular}


Table D.3: Change in All-Rail Traffic, omitting New York

\begin{tabular}{lcccccc}
\hline \hline & $(1)$ & $(2)$ & $(3)$ & $(4)$ & $(5)$ & $(6)$ \\
\hline All-rail x post-change & $2.314^{* * *}$ & $2.313^{* * *}$ & $2.310^{* * *}$ & $2.367^{* * *}$ & $2.358^{* * *}$ & $2.430^{* * *}$ \\
& $(0.460)$ & $(0.449)$ & $(0.449)$ & $(0.469)$ & $(0.548)$ & $(0.590)$ \\
\multirow{2}{*}{$*$ distance (100 mi) } & $-0.301^{* * *}$ & $-0.308^{* * *}$ & $-0.307^{* * *}$ & $-0.314^{* * *}$ & $-0.313^{* * *}$ & $-0.321^{* * *}$ \\
& $(0.057)$ & $(0.057)$ & $(0.057)$ & $(0.060)$ & $(0.070)$ & $(0.075)$ \\
\hline Breakeven distance & 767.7 & 752.0 & 751.5 & 754.5 & 754.0 & 755.8 \\
& $(41.0)$ & $(39.1)$ & $(39.1)$ & $(39.5)$ & $(46.7)$ & $(47.9)$ \\
\hline $\mathrm{N}$ & 777 & 777 & 777 & 777 & 777 & 777 \\
$R^{2}$ & 0.28 & 0.67 & 0.67 & 0.71 & 0.70 & 0.73 \\
Route FE & & $\mathrm{X}$ & $\mathrm{X}$ & & & \\
Mode FE & & & $\mathrm{X}$ & & & \\
Year FE & & & $\mathrm{X}$ & & & $\mathrm{X}$ \\
Route-mode FE & & & & $\mathrm{X}$ & $\mathrm{X}$ & $\mathrm{X}$ \\
Route-yr FE & & & & & & \\
\hline \hline
\end{tabular}

Notes: This table is a robustness check on the results in Table 4, omitting observations with an origin of New York. ${ }^{*}, * *, * * *$ represent significance at the $0.1,0.05$, and 0.01 levels, respectively. SEs clustered by route in parentheses.

Table D.4: Share of Traffic, omitting New York

\begin{tabular}{lcc}
\hline \hline & $(1)$ & $(2)$ \\
\hline All-rail x post-change & $2.155^{* * *}$ & $2.275^{* * *}$ \\
& $(0.424)$ & $(0.452)$ \\
$*$ distance (100 mi) & $-0.293^{* * *}$ & $-0.305^{* * *}$ \\
& $(0.055)$ & $(0.057)$ \\
\hline Breakeven distance & 735.6 & 746.8 \\
& $(38.7)$ & $(39.8)$ \\
\hline $\mathrm{N}$ & 507 & 507 \\
$R^{2}$ & 0.14 & 0.37 \\
Route FE & & $\mathrm{X}$ \\
\hline \hline
\end{tabular}

Notes: This table is a robustness check on the results in Table 6 , omitting observations with an origin of New York. *, **, *** represent significance at the $0.1,0.05$, and 0.01 levels, respectively. SEs clustered by route in parentheses. 
Table D.5: Change in All-Rail Traffic, omitting Philadelphia

\begin{tabular}{|c|c|c|c|c|c|c|}
\hline & (1) & (2) & (3) & (4) & (5) & (6) \\
\hline All-rail x post-change & $\begin{array}{c}2.487^{* * *} \\
(0.489)\end{array}$ & $\begin{array}{c}2.466^{* * *} \\
(0.485)\end{array}$ & $\begin{array}{c}2.458^{* * *} \\
(0.484)\end{array}$ & $\begin{array}{c}2.502^{* * *} \\
(0.495)\end{array}$ & $\begin{array}{c}2.472^{* * *} \\
(0.585)\end{array}$ & $\begin{array}{c}2.519^{* * *} \\
(0.606)\end{array}$ \\
\hline * distance $(100 \mathrm{mi})$ & $\begin{array}{c}-0.323^{* * *} \\
(0.060)\end{array}$ & $\begin{array}{c}-0.327^{* * *} \\
(0.061)\end{array}$ & $\begin{array}{c}-0.327^{* * *} \\
(0.061)\end{array}$ & $\begin{array}{c}-0.332^{* * *} \\
(0.062)\end{array}$ & $\begin{array}{c}-0.327^{* * *} \\
(0.074)\end{array}$ & $\begin{array}{c}-0.334^{* * *} \\
(0.076)\end{array}$ \\
\hline Breakeven distance & $\begin{array}{l}770.6 \\
(37.3)\end{array}$ & $\begin{array}{l}753.6 \\
(35.4)\end{array}$ & $\begin{array}{l}752.7 \\
(35.4)\end{array}$ & $\begin{array}{l}754.0 \\
(35.0)\end{array}$ & $\begin{array}{l}755.9 \\
(43.3)\end{array}$ & $\begin{array}{l}754.8 \\
(42.3)\end{array}$ \\
\hline $\mathrm{N}$ & 777 & 777 & 777 & 777 & 777 & 777 \\
\hline$R^{2}$ & 0.34 & 0.68 & 0.68 & 0.74 & 0.70 & 0.77 \\
\hline Route FE & & $\mathrm{X}$ & $\mathrm{X}$ & & & \\
\hline Mode FE & & & $\mathrm{X}$ & & & \\
\hline Year FE & & & $\mathrm{X}$ & & & \\
\hline Route-mode FE & & & & $\mathrm{X}$ & & $\mathrm{X}$ \\
\hline Route-yr FE & & & & & $\mathrm{X}$ & $\mathrm{X}$ \\
\hline
\end{tabular}

Notes: This table is a robustness check on the results in Table 4, omitting observations with an origin of Philadelphia. ${ }^{*},{ }^{* *},{ }^{* * *}$ represent significance at the $0.1,0.05$, and 0.01 levels, respectively. SEs clustered by route in parentheses.

Table D.6: Share of Traffic, omitting Philadelphia

\begin{tabular}{lcc}
\hline \hline & $(1)$ & $(2)$ \\
\hline All-rail x post-change & $2.320^{* * *}$ & $2.396^{* * *}$ \\
& $(0.455)$ & $(0.472)$ \\
$*$ distance (100 mi) & $-0.313^{* * *}$ & $-0.321^{* * *}$ \\
& $(0.057)$ & $(0.059)$ \\
\hline Breakeven distance & 740.3 & 746.2 \\
& $(35.2)$ & $(34.7)$ \\
\hline $\mathrm{N}$ & 507 & 507 \\
$R^{2}$ & 0.13 & 0.50 \\
Route FE & $\mathrm{X}$ \\
\hline \hline Notes: This table is a robustness check on the results in Table \\
6, omitting observations with an origin of Philadelphia. ${ }^{*}$, \\
** $^{* * *}$ represent significance at the 0.1, 0.05, and 0.01 levels, \\
respectively. SEs clustered by route in parentheses.
\end{tabular}


Table D.7: Change in All-Rail Traffic, omitting Baltimore

\begin{tabular}{lcccccc}
\hline \hline & $(1)$ & $(2)$ & $(3)$ & $(4)$ & $(5)$ & $(6)$ \\
\hline All-rail x post-change & $2.133^{* * *}$ & $2.108^{* * *}$ & $2.102^{* * *}$ & $2.196^{* * *}$ & $2.203^{* * *}$ & $2.325^{* *}$ \\
& $(0.653)$ & $(0.644)$ & $(0.645)$ & $(0.676)$ & $(0.807)$ & $(0.870)$ \\
$*$ distance (100 mi) & $-0.289^{* * *}$ & $-0.293^{* * *}$ & $-0.292^{* * *}$ & $-0.304^{* * *}$ & $-0.302^{* * *}$ & $-0.318^{* * *}$ \\
& $(0.075)$ & $(0.076)$ & $(0.076)$ & $(0.079)$ & $(0.095)$ & $(0.101)$ \\
\hline Breakeven distance & 737.9 & 719.5 & 718.8 & 723.3 & 728.6 & 731.9 \\
& $(55.3)$ & $(54.0)$ & $(54.2)$ & $(53.4)$ & $(63.6)$ & $(63.1)$ \\
\hline $\mathrm{N}$ & 777 & 777 & 777 & 777 & 777 & 777 \\
$R^{2}$ & 0.34 & 0.68 & 0.68 & 0.73 & 0.71 & 0.76 \\
Route FE & & $\mathrm{X}$ & $\mathrm{X}$ & & & \\
Mode FE & & & $\mathrm{X}$ & & & \\
Year FE & & & $\mathrm{X}$ & & & $\mathrm{X}$ \\
Route-mode FE & & & & $\mathrm{X}$ & $\mathrm{X}$ & $\mathrm{X}$ \\
Route-yr FE & & & & & & \\
\hline \hline
\end{tabular}

Notes: This table is a robustness check on the results in Table 4, omitting observations with an origin of Baltimore. ${ }^{*},{ }^{* *}, * * *$ represent significance at the $0.1,0.05$, and 0.01 levels, respectively. SEs clustered by route in parentheses.

Table D.8: Share of Traffic, omitting Baltimore

\begin{tabular}{lcc}
\hline \hline & $(1)$ & $(2)$ \\
\hline All-rail x post-change & $1.905^{* * *}$ & $2.088^{* * *}$ \\
& $(0.611)$ & $(0.658)$ \\
$*$ distance (100 mi) & $-0.273^{* * *}$ & $-0.293^{* * *}$ \\
& $(0.071)$ & $(0.076)$ \\
\hline Breakeven distance & 697.7 & 712.5 \\
& $(58.2)$ & $(55.8)$ \\
\hline $\mathrm{N}$ & 507 & 507 \\
$R^{2}$ & 0.03 & 0.36 \\
Route FE & & $\mathrm{X}$ \\
\hline \hline
\end{tabular}

Notes: This table is a robustness check on the results in Table 6 , omitting observations with an origin of Baltimore. *, **, *** represent significance at the $0.1,0.05$, and 0.01 levels, respectively. SEs clustered by route in parentheses. 


\section{D.2 Sensitivity Checks: Dropping Destinations}

The tables in this section evaluate the sensitivity of the main results in Tables 4 and 6 to dropping observations with a given destination.

Table D.9: Change in All-Rail Traffic, omitting Albany

\begin{tabular}{lcccccc}
\hline \hline & $(1)$ & $(2)$ & $(3)$ & $(4)$ & $(5)$ & $(6)$ \\
\hline All-rail x post-change & $2.298^{* * *}$ & $2.288^{* * *}$ & $2.281^{* * *}$ & $2.328^{* * *}$ & $2.348^{* * *}$ & $2.405^{* * *}$ \\
& $(0.458)$ & $(0.449)$ & $(0.448)$ & $(0.462)$ & $(0.542)$ & $(0.569)$ \\
$*$ distance (100 mi) & $-0.311^{* * *}$ & $-0.316^{* * *}$ & $-0.316^{* * *}$ & $-0.319^{* * *}$ & $-0.322^{* * *}$ & $-0.327^{* * *}$ \\
& $(0.058)$ & $(0.058)$ & $(0.058)$ & $(0.059)$ & $(0.070)$ & $(0.072)$ \\
\hline Breakeven distance & 738.8 & 723.5 & 722.8 & 728.9 & 728.7 & 735.8 \\
& $(34.9)$ & $(33.0)$ & $(33.0)$ & $(34.1)$ & $(39.1)$ & $(41.3)$ \\
\hline $\mathrm{N}$ & 992 & 992 & 992 & 992 & 992 & 992 \\
$R^{2}$ & 0.32 & 0.66 & 0.66 & 0.72 & 0.69 & 0.74 \\
Route FE & & $\mathrm{X}$ & $\mathrm{X}$ & & & \\
Mode FE & & & $\mathrm{X}$ & & & \\
Year FE & & & $\mathrm{X}$ & & & $\mathrm{X}$ \\
Route-mode FE & & & & $\mathrm{X}$ & $\mathrm{X}$ & $\mathrm{X}$ \\
Route-yr FE & & & & & & \\
\hline \hline
\end{tabular}

Notes: This table is a robustness check on the results in Table 4, omitting observations with a destination of Albany. ${ }^{*},{ }^{* *},{ }^{* * *}$ represent significance at the 0.1, 0.05, and 0.01 levels, respectively. SEs clustered by route in parentheses.

Table D.10: Share of Traffic, omitting Albany

\begin{tabular}{lcc}
\hline \hline & $(1)$ & $(2)$ \\
\hline All-rail x post-change & $2.200^{* * *}$ & $2.306^{* * *}$ \\
& $(0.427)$ & $(0.449)$ \\
$*$ distance $(100 \mathrm{mi})$ & $-0.309^{* * *}$ & $-0.317^{* * *}$ \\
& $(0.055)$ & $(0.057)$ \\
\hline Breakeven distance & 712.5 & 726.8 \\
& $(32.7)$ & $(34.0)$ \\
\hline $\mathrm{N}$ & 656 & 656 \\
$R^{2}$ & 0.11 & 0.44 \\
Route FE & & $\mathrm{X}$ \\
\hline \hline
\end{tabular}

Notes: This table is a robustness check on the results in Table 6 , omitting observations with a destination of Albany. *, **, *** represent significance at the $0.1,0.05$, and 0.01 levels, respectively. SEs clustered by route in parentheses. 
Table D.11: Change in All-Rail Traffic, omitting Athens

\begin{tabular}{lcccccc}
\hline \hline & $(1)$ & $(2)$ & $(3)$ & $(4)$ & $(5)$ & $(6)$ \\
\hline All-rail x post-change & $2.199^{* * *}$ & $2.178^{* * *}$ & $2.179^{* * *}$ & $2.247^{* * *}$ & $2.210^{* * *}$ & $2.304^{* * *}$ \\
& $(0.461)$ & $(0.450)$ & $(0.452)$ & $(0.468)$ & $(0.555)$ & $(0.589)$ \\
\multirow{2}{*}{ distance (100 mi) } & $-0.301^{* * *}$ & $-0.305^{* * *}$ & $-0.306^{* * *}$ & $-0.313^{* * *}$ & $-0.308^{* * *}$ & $-0.319^{* * *}$ \\
& $(0.058)$ & $(0.058)$ & $(0.058)$ & $(0.060)$ & $(0.072)$ & $(0.075)$ \\
\hline Breakeven distance & 731.0 & 713.2 & 713.1 & 717.9 & 716.6 & 721.4 \\
& $(38.3)$ & $(36.1)$ & $(36.1)$ & $(36.4)$ & $(43.6)$ & $(44.3)$ \\
\hline $\mathrm{N}$ & 956 & 956 & 956 & 956 & 956 & 956 \\
$R^{2}$ & 0.33 & 0.69 & 0.69 & 0.74 & 0.71 & 0.77 \\
Route FE & & $\mathrm{X}$ & $\mathrm{X}$ & & & $\mathrm{X}$ \\
Mode FE & & $\mathrm{X}$ & & & $\mathrm{X}$ \\
Year FE & & $\mathrm{X}$ & & $\mathrm{X}$ & $\mathrm{X}$ \\
Route-mode FE & & & & & $\mathrm{X}$ \\
Route-yr FE & & & & & & \\
\hline \hline
\end{tabular}

Notes: This table is a robustness check on the results in Table 4, omitting observations with a destination of Athens. ${ }^{*}, * *, * * *$ represent significance at the $0.1,0.05$, and 0.01 levels, respectively. SEs clustered by route in parentheses.

Table D.12: Share of Traffic, omitting Athens

\begin{tabular}{lcc}
\hline \hline & $(1)$ & $(2)$ \\
\hline All-rail x post-change & $2.034^{* * *}$ & $2.193^{* * *}$ \\
& $(0.426)$ & $(0.464)$ \\
$*$ distance (100 mi) & $-0.293^{* * *}$ & $-0.308^{* * *}$ \\
& $(0.055)$ & $(0.059)$ \\
\hline Breakeven distance & 695.3 & 711.9 \\
& $(36.4)$ & $(36.9)$ \\
\hline $\mathrm{N}$ & 624 & 624 \\
$R^{2}$ & 0.11 & 0.46 \\
Route FE & $\mathrm{X}$ \\
\hline \hline Notes: This table is a robustness check on the results in Table \\
6, omitting observations with a destination of Athens. *, $*$,, \\
*** represent significance at the 0.1, 0.05, and 0.01 levels, \\
respectively. SEs clustered by route in parentheses.
\end{tabular}


Table D.13: Change in All-Rail Traffic, omitting Atlanta

\begin{tabular}{|c|c|c|c|c|c|c|}
\hline & (1) & (2) & (3) & (4) & $(5)$ & (6) \\
\hline All-rail x post-change & $\begin{array}{c}2.637^{* * *} \\
(0.475)\end{array}$ & $\begin{array}{c}2.587^{* * *} \\
(0.467)\end{array}$ & $\begin{array}{c}2.583^{* * *} \\
(0.468)\end{array}$ & $\begin{array}{c}2.646^{* * *} \\
(0.478)\end{array}$ & $\begin{array}{c}2.632^{* * *} \\
(0.574)\end{array}$ & $\begin{array}{c}2.712^{* * *} \\
(0.597)\end{array}$ \\
\hline * distance $(100 \mathrm{mi})$ & $\begin{array}{c}-0.339^{* * *} \\
(0.061)\end{array}$ & $\begin{array}{c}-0.342^{* * *} \\
(0.061)\end{array}$ & $\begin{array}{c}-0.342^{* * *} \\
(0.061)\end{array}$ & $\begin{array}{c}-0.349^{* * *} \\
(0.062)\end{array}$ & $\begin{array}{c}-0.346^{* * *} \\
(0.076)\end{array}$ & $\begin{array}{c}-0.356^{* * *} \\
(0.077)\end{array}$ \\
\hline Breakeven distance & $\begin{array}{l}776.8 \\
(35.3)\end{array}$ & $\begin{array}{l}756.2 \\
(33.1)\end{array}$ & $\begin{array}{l}755.8 \\
(33.1)\end{array}$ & $\begin{array}{l}758.3 \\
(33.0)\end{array}$ & $\begin{array}{l}760.2 \\
(40.3)\end{array}$ & $\begin{array}{l}761.6 \\
(40.0)\end{array}$ \\
\hline $\mathrm{N}$ & 952 & 952 & 952 & 952 & 952 & 952 \\
\hline$R^{2}$ & 0.35 & 0.65 & 0.65 & 0.72 & 0.68 & 0.75 \\
\hline Route FE & & $\mathrm{X}$ & $\mathrm{X}$ & & & \\
\hline Mode FE & & & $\mathrm{X}$ & & & \\
\hline Year FE & & & $\mathrm{X}$ & & & \\
\hline Route-mode FE & & & & $\mathrm{X}$ & & $\mathrm{X}$ \\
\hline Route-yr FE & & & & & $\mathrm{X}$ & $\mathrm{X}$ \\
\hline
\end{tabular}

Notes: This table is a robustness check on the results in Table 4, omitting observations with a destination of Atlanta. ${ }^{*}, * *, * * *$ represent significance at the 0.1, 0.05, and 0.01 levels, respectively. SEs clustered by route in parentheses.

Table D.14: Share of Traffic, omitting Atlanta

\begin{tabular}{lcc}
\hline \hline & $(1)$ & $(2)$ \\
\hline All-rail x post-change & $2.429^{* * *}$ & $2.562^{* * *}$ \\
& $(0.438)$ & $(0.462)$ \\
& $-0.328^{* * *}$ & $-0.341^{* * *}$ \\
& $(0.057)$ & $(0.059)$ \\
\hline Breakeven distance (100 mi) & 741.2 & 751.0 \\
& $(32.4)$ & $(32.8)$ \\
\hline $\mathrm{N}$ & 620 & 620 \\
$R^{2}$ & 0.12 & 0.47 \\
Route FE & & $\mathrm{X}$ \\
\hline Notes: This table is a robustness check on the results in Table \\
6, omitting observations with a destination of Atlanta. *, **, \\
*** represent significance at the 0.1, 0.05, and 0.01 levels, \\
respectively. SEs clustered by route in parentheses.
\end{tabular}


Table D.15: Change in All-Rail Traffic, omitting Augusta

\begin{tabular}{|c|c|c|c|c|c|c|}
\hline & (1) & (2) & (3) & (4) & $(5)$ & (6) \\
\hline All-rail x post-change & $\begin{array}{c}2.634^{* * *} \\
(0.529)\end{array}$ & $\begin{array}{c}2.532^{* * *} \\
(0.513)\end{array}$ & $\begin{array}{c}2.527^{* * *} \\
(0.514)\end{array}$ & $\begin{array}{c}2.594^{* * * *} \\
(0.528)\end{array}$ & $\begin{array}{c}2.576^{* * *} \\
(0.631)\end{array}$ & $\begin{array}{c}2.658^{* * *} \\
(0.659)\end{array}$ \\
\hline * distance $(100 \mathrm{mi})$ & $\begin{array}{c}-0.341^{* * *} \\
(0.066)\end{array}$ & $\begin{array}{c}-0.337^{* * *} \\
(0.065)\end{array}$ & $\begin{array}{c}-0.337^{* * *} \\
(0.065)\end{array}$ & $\begin{array}{c}-0.344^{* * *} \\
(0.066)\end{array}$ & $\begin{array}{c}-0.341^{* * *} \\
(0.080)\end{array}$ & $\begin{array}{c}-0.352^{* * *} \\
(0.082)\end{array}$ \\
\hline Breakeven distance & $\begin{array}{l}772.1 \\
(35.8)\end{array}$ & $\begin{array}{l}750.8 \\
(34.6)\end{array}$ & $\begin{array}{l}750.3 \\
(34.6)\end{array}$ & $\begin{array}{l}753.0 \\
(34.6)\end{array}$ & $\begin{array}{l}754.6 \\
(41.9)\end{array}$ & $\begin{array}{l}756.1 \\
(41.8)\end{array}$ \\
\hline $\mathrm{N}$ & 952 & 952 & 952 & 952 & 952 & 952 \\
\hline$R^{2}$ & 0.33 & 0.64 & 0.64 & 0.70 & 0.66 & 0.72 \\
\hline Route FE & & $\mathrm{X}$ & $\mathrm{X}$ & & & \\
\hline Mode FE & & & $\mathrm{X}$ & & & \\
\hline Year FE & & & $\mathrm{X}$ & & & \\
\hline Route-mode FE & & & & $\mathrm{X}$ & & $\mathrm{X}$ \\
\hline Route-yr FE & & & & & $\mathrm{X}$ & $\mathrm{X}$ \\
\hline
\end{tabular}

Notes: This table is a robustness check on the results in Table 4, omitting observations with a destination of Augusta. ${ }^{*},{ }^{* *},{ }^{* * *}$ represent significance at the 0.1, 0.05, and 0.01 levels, respectively. SEs clustered by route in parentheses.

Table D.16: Share of Traffic, omitting Augusta

\begin{tabular}{lcc}
\hline \hline & $(1)$ & $(2)$ \\
\hline All-rail x post-change & $2.358^{* * *}$ & $2.490^{* * *}$ \\
& $(0.485)$ & $(0.514)$ \\
$*$ distance (100 mi) & $-0.321^{* * *}$ & $-0.334^{* * *}$ \\
& $(0.061)$ & $(0.064)$ \\
\hline Breakeven distance & 734.5 & 744.3 \\
& $(34.7)$ & $(35.0)$ \\
\hline $\mathrm{N}$ & 620 & 620 \\
$R^{2}$ & 0.10 & 0.42 \\
Route FE & & $\mathrm{X}$ \\
\hline \hline
\end{tabular}

Notes: This table is a robustness check on the results in Table 6 , omitting observations with a destination of Augusta. *, **, *** represent significance at the $0.1,0.05$, and 0.01 levels, respectively. SEs clustered by route in parentheses. 
Table D.17: Change in All-Rail Traffic, omitting Macon

\begin{tabular}{lcccccc}
\hline \hline & $(1)$ & $(2)$ & $(3)$ & $(4)$ & $(5)$ & $(6)$ \\
\hline All-rail x post-change & $2.353^{* * *}$ & $2.354^{* * *}$ & $2.351^{* * *}$ & $2.362^{* * *}$ & $2.340^{* * *}$ & $2.348^{* * *}$ \\
& $(0.471)$ & $(0.481)$ & $(0.482)$ & $(0.487)$ & $(0.588)$ & $(0.598)$ \\
\multirow{2}{*}{ distance (100 mi) } & $-0.318^{* * *}$ & $-0.319^{* * *}$ & $-0.319^{* * *}$ & $-0.322^{* * *}$ & $-0.317^{* * *}$ & $-0.321^{* * *}$ \\
& $(0.060)$ & $(0.062)$ & $(0.062)$ & $(0.063)$ & $(0.077)$ & $(0.077)$ \\
\hline Breakeven distance & 740.2 & 738.5 & 737.9 & 734.0 & 739.1 & 731.5 \\
& $(36.3)$ & $(36.3)$ & $(36.3)$ & $(35.8)$ & $(44.8)$ & $(43.6)$ \\
\hline $\mathrm{N}$ & 964 & 964 & 964 & 964 & 964 & 964 \\
$R^{2}$ & 0.30 & 0.66 & 0.66 & 0.71 & 0.68 & 0.74 \\
Route FE & & $\mathrm{X}$ & $\mathrm{X}$ & & & \\
Mode FE & & $\mathrm{X}$ & & & $\mathrm{X}$ \\
Year FE & & $\mathrm{X}$ & & $\mathrm{X}$ & $\mathrm{X}$ \\
Route-mode FE & & & & $\mathrm{X}$ & \\
Route-yr FE & & & & & & $\mathrm{X}$ \\
\hline \hline
\end{tabular}

Notes: This table is a robustness check on the results in Table 4, omitting observations with a destination of Macon. *, **,*** represent significance at the 0.1, 0.05, and 0.01 levels, respectively. SEs clustered by route in parentheses.

Table D.18: Share of Traffic, omitting Macon

\begin{tabular}{lcc}
\hline \hline & $(1)$ & $(2)$ \\
\hline All-rail x post-change & $2.253^{* * *}$ & $2.244^{* * *}$ \\
& $(0.454)$ & $(0.462)$ \\
$*$ distance (100 mi) & $-0.309^{* * *}$ & $-0.311^{* * *}$ \\
& $(0.059)$ & $(0.059)$ \\
\hline Breakeven distance & 729.8 & 721.8 \\
& $(35.5)$ & $(35.6)$ \\
\hline $\mathrm{N}$ & 632 & 632 \\
$R^{2}$ & 0.12 & 0.43 \\
Route FE & $\mathrm{X}$ \\
\hline \hline Notes: This table is a robustness check on the results in Table \\
6, omitting observations with a destination of Macon. **, ${ }^{* *}$, \\
*** represent significance at the 0.1, 0.05, and 0.01 levels, \\
respectively. SEs clustered by route in parentheses.
\end{tabular}


Table D.19: Change in All-Rail Traffic, omitting Milledgeville

\begin{tabular}{lcccccc}
\hline & $(1)$ & $(2)$ & $(3)$ & $(4)$ & $(5)$ & $(6)$ \\
\hline All-rail x post-change & $2.218^{* * *}$ & $2.231^{* * *}$ & $2.228^{* * *}$ & $2.296^{* * *}$ & $2.271^{* * *}$ & $2.358^{* * *}$ \\
& $(0.478)$ & $(0.479)$ & $(0.480)$ & $(0.493)$ & $(0.590)$ & $(0.617)$ \\
\multirow{2}{*}{$*$ distance (100 mi) } & $-0.297^{* * *}$ & $-0.305^{* * *}$ & $-0.305^{* * *}$ & $-0.313^{* * *}$ & $-0.309^{* * *}$ & $-0.320^{* * *}$ \\
& $(0.061)$ & $(0.062)$ & $(0.062)$ & $(0.063)$ & $(0.076)$ & $(0.078)$ \\
\hline Breakeven distance & 745.9 & 730.4 & 730.1 & 733.6 & 734.6 & 736.9 \\
& $(39.9)$ & $(37.7)$ & $(37.7)$ & $(37.6)$ & $(45.6)$ & $(45.6)$ \\
\hline $\mathrm{N}$ & 952 & 952 & 952 & 952 & 952 & 952 \\
$R^{2}$ & 0.32 & 0.66 & 0.66 & 0.72 & 0.69 & 0.74 \\
Route FE & & $\mathrm{X}$ & $\mathrm{X}$ & & & \\
Mode FE & & & $\mathrm{X}$ & & & \\
Year FE & & & $\mathrm{X}$ & & & $\mathrm{X}$ \\
Route-mode FE & & & & $\mathrm{X}$ & $\mathrm{X}$ & $\mathrm{X}$ \\
Route-yr FE & & & & & & \\
\hline
\end{tabular}

Notes: This table is a robustness check on the results in Table 4, omitting observations with a destination of Milledgeville. ${ }^{*},{ }^{* *},{ }^{* * *}$ represent significance at the $0.1,0.05$, and 0.01 levels, respectively. SEs clustered by route in parentheses.

Table D.20: Share of Traffic, omitting Milledgeville

\begin{tabular}{lcc}
\hline \hline & $(1)$ & $(2)$ \\
\hline All-rail x post-change & $2.047^{* * *}$ & $2.193^{* * *}$ \\
& $(0.444)$ & $(0.473)$ \\
$*$ distance $(100 \mathrm{mi})$ & $-0.289^{* * *}$ & $-0.303^{* * *}$ \\
& $(0.057)$ & $(0.060)$ \\
\hline Breakeven distance & 709.2 & 722.6 \\
& $(37.5)$ & $(37.9)$ \\
\hline $\mathrm{N}$ & 620 & 620 \\
$R^{2}$ & 0.12 & 0.45 \\
Route FE & & $\mathrm{X}$ \\
\hline \hline
\end{tabular}

Notes: This table is a robustness check on the results in Table 6 , omitting observations with a destination of Milledgeville. $*, * *, * * *$ represent significance at the $0.1,0.05$, and 0.01 levels, respectively. SEs clustered by route in parentheses. 
Table D.21: Change in All-Rail Traffic, omitting Montgomery

\begin{tabular}{lcccccc}
\hline \hline & $(1)$ & $(2)$ & $(3)$ & $(4)$ & $(5)$ & $(6)$ \\
\hline All-rail x post-change & $2.343^{* * *}$ & $2.366^{* * *}$ & $2.362^{* * *}$ & $2.428^{* * *}$ & $2.407^{* * *}$ & $2.496^{* * *}$ \\
& $(0.489)$ & $(0.481)$ & $(0.482)$ & $(0.493)$ & $(0.596)$ & $(0.619)$ \\
$*$ distance (100 mi) & $-0.303^{* * *}$ & $-0.314^{* * *}$ & $-0.314^{* * *}$ & $-0.321^{* * *}$ & $-0.318^{* * *}$ & $-0.329^{* * *}$ \\
& $(0.064)$ & $(0.064)$ & $(0.064)$ & $(0.064)$ & $(0.079)$ & $(0.081)$ \\
\hline Breakeven distance & 774.1 & 753.8 & 753.4 & 755.8 & 757.2 & 757.8 \\
& $(39.2)$ & $(35.7)$ & $(35.7)$ & $(35.4)$ & $(43.6)$ & $(42.7)$ \\
\hline $\mathrm{N}$ & 952 & 952 & 952 & 952 & 952 & 952 \\
$R^{2}$ & 0.30 & 0.68 & 0.68 & 0.73 & 0.70 & 0.76 \\
Route FE & & $\mathrm{X}$ & $\mathrm{X}$ & & & \\
Mode FE & & $\mathrm{X}$ & & & $\mathrm{X}$ \\
Year FE & & $\mathrm{X}$ & & $\mathrm{X}$ & $\mathrm{X}$ \\
Route-mode FE & & & & $\mathrm{X}$ & \\
Route-yr FE & & & & & & \\
\hline \hline
\end{tabular}

Notes: This table is a robustness check on the results in Table 4, omitting observations with a destination of Montgomery. ${ }^{*},{ }^{* *},{ }^{* * *}$ represent significance at the $0.1,0.05$, and 0.01 levels, respectively. SEs clustered by route in parentheses.

Table D.22: Share of Traffic, omitting Montgomery

\begin{tabular}{lcc}
\hline \hline & $(1)$ & $(2)$ \\
\hline All-rail x post-change & $2.230^{* * *}$ & $2.350^{* * *}$ \\
& $(0.455)$ & $(0.475)$ \\
$*$ distance (100 mi) & $-0.303^{* * *}$ & $-0.315^{* * *}$ \\
& $(0.060)$ & $(0.062)$ \\
\hline Breakeven distance & 736.2 & 746.7 \\
& $(34.6)$ & $(34.9)$ \\
\hline $\mathrm{N}$ & 620 & 620 \\
$R^{2}$ & 0.10 & 0.45 \\
Route FE & & $\mathrm{X}$ \\
\hline \hline
\end{tabular}

Notes: This table is a robustness check on the results in Table 6 , omitting observations with a destination of Montgomery. $*, * *, * * *$ represent significance at the $0.1,0.05$, and 0.01 levels, respectively. SEs clustered by route in parentheses. 
Table D.23: Change in All-Rail Traffic, omitting Newnan

\begin{tabular}{|c|c|c|c|c|c|c|}
\hline & (1) & (2) & (3) & (4) & $(5)$ & (6) \\
\hline All-rail x post-change & $\begin{array}{c}2.590^{* * *} \\
(0.469)\end{array}$ & $\begin{array}{c}2.598^{* * *} \\
(0.467)\end{array}$ & $\begin{array}{c}2.595^{* * *} \\
(0.468)\end{array}$ & $\begin{array}{c}2.655^{* * *} \\
(0.479)\end{array}$ & $\begin{array}{c}2.640^{* * *} \\
(0.576)\end{array}$ & $\begin{array}{c}2.718^{* * *} \\
(0.600)\end{array}$ \\
\hline * distance $(100 \mathrm{mi})$ & $\begin{array}{c}-0.346^{* * *} \\
(0.059)\end{array}$ & $\begin{array}{c}-0.353^{* * *} \\
(0.060)\end{array}$ & $\begin{array}{c}-0.353^{* * *} \\
(0.060)\end{array}$ & $\begin{array}{c}-0.360^{* * *} \\
(0.060)\end{array}$ & $\begin{array}{c}-0.357^{* * *} \\
(0.074)\end{array}$ & $\begin{array}{c}-0.367^{* * *} \\
(0.076)\end{array}$ \\
\hline Breakeven distance & $\begin{array}{l}748.9 \\
(34.4)\end{array}$ & $\begin{array}{l}735.3 \\
(32.5)\end{array}$ & $\begin{array}{l}735.0 \\
(32.5)\end{array}$ & $\begin{array}{l}737.6 \\
(32.5)\end{array}$ & $\begin{array}{l}739.0 \\
(39.4)\end{array}$ & $\begin{array}{l}740.6 \\
(39.4)\end{array}$ \\
\hline $\mathrm{N}$ & 952 & 952 & 952 & 952 & 952 & 952 \\
\hline$R^{2}$ & 0.33 & 0.67 & 0.67 & 0.73 & 0.69 & 0.76 \\
\hline Route FE & & $\mathrm{X}$ & $\mathrm{X}$ & & & \\
\hline Mode FE & & & $\mathrm{X}$ & & & \\
\hline Year FE & & & $\mathrm{X}$ & & & \\
\hline Route-mode FE & & & & $\mathrm{X}$ & & $\mathrm{X}$ \\
\hline Route-yr FE & & & & & $\mathrm{X}$ & $\mathrm{X}$ \\
\hline
\end{tabular}

Notes: This table is a robustness check on the results in Table 4, omitting observations with a destination of Newnan. ${ }^{*},{ }^{* *},{ }^{* * *}$ represent significance at the $0.1,0.05$, and 0.01 levels, respectively. SEs clustered by route in parentheses.

Table D.24: Share of Traffic, omitting Newnan

\begin{tabular}{lcc}
\hline \hline & $(1)$ & $(2)$ \\
\hline All-rail x post-change & $2.448^{* * *}$ & $2.572^{* * *}$ \\
& $(0.440)$ & $(0.464)$ \\
$*$ distance (100 mi) & $-0.340^{* * *}$ & $-0.353^{* * *}$ \\
& $(0.056)$ & $(0.058)$ \\
\hline Breakeven distance & 719.2 & 728.8 \\
& $(32.0)$ & $(32.5)$ \\
\hline $\mathrm{N}$ & 620 & 620 \\
$R^{2}$ & 0.12 & 0.47 \\
Route FE & $\mathrm{X}$ \\
\hline \hline Notes: This table is a robustness check on the results in Table \\
6, omitting observations with a destination of Newnan. * ${ }^{* *}$, \\
*** represent significance at the 0.1, 0.05, and 0.01 levels, \\
respectively. SEs clustered by route in parentheses.
\end{tabular}


Table D.25: Change in All-Rail Traffic, omitting Opelika

\begin{tabular}{lcccccc}
\hline \hline & $(1)$ & $(2)$ & $(3)$ & $(4)$ & $(5)$ & $(6)$ \\
\hline All-rail x post-change & $2.440^{* * *}$ & $2.443^{* * *}$ & $2.438^{* * *}$ & $2.498^{* * *}$ & $2.485^{* * *}$ & $2.559^{* * *}$ \\
& $(0.481)$ & $(0.477)$ & $(0.477)$ & $(0.486)$ & $(0.589)$ & $(0.608)$ \\
\multirow{2}{*}{$*$ distance (100 mi) } & $-0.328^{* * *}$ & $-0.336^{* * *}$ & $-0.335^{* * *}$ & $-0.342^{* * *}$ & $-0.340^{* * *}$ & $-0.349^{* * *}$ \\
& $(0.063)$ & $(0.063)$ & $(0.063)$ & $(0.064)$ & $(0.078)$ & $(0.079)$ \\
\hline Breakeven distance & 743.1 & 727.1 & 726.7 & 729.7 & 730.8 & 732.8 \\
& $(35.3)$ & $(32.7)$ & $(32.7)$ & $(32.9)$ & $(39.7)$ & $(39.9)$ \\
\hline $\mathrm{N}$ & 952 & 952 & 952 & 952 & 952 & 952 \\
$R^{2}$ & 0.32 & 0.68 & 0.68 & 0.74 & 0.71 & 0.76 \\
Route FE & & $\mathrm{X}$ & $\mathrm{X}$ & & & \\
Mode FE & & & $\mathrm{X}$ & & & \\
Year FE & & & $\mathrm{X}$ & & & $\mathrm{X}$ \\
Route-mode FE & & & & $\mathrm{X}$ & $\mathrm{X}$ & $\mathrm{X}$ \\
Route-yr FE & & & & & & \\
\hline \hline
\end{tabular}

Notes: This table is a robustness check on the results in Table 4, omitting observations with a destination of Opelika. ${ }^{*}, * *, * * *$ represent significance at the $0.1,0.05$, and 0.01 levels, respectively. SEs clustered by route in parentheses.

Table D.26: Share of Traffic, omitting Opelika

\begin{tabular}{lcc}
\hline \hline & $(1)$ & $(2)$ \\
\hline All-rail x post-change & $2.291^{* * *}$ & $2.414^{* * *}$ \\
& $(0.451)$ & $(0.470)$ \\
$*$ distance $(100 \mathrm{mi})$ & $-0.323^{* * *}$ & $-0.335^{* * *}$ \\
& $(0.060)$ & $(0.061)$ \\
\hline Breakeven distance & 709.9 & 720.1 \\
& $(32.0)$ & $(32.5)$ \\
\hline $\mathrm{N}$ & 620 & 620 \\
$R^{2}$ & 0.13 & 0.46 \\
Route FE & & $\mathrm{X}$ \\
\hline \hline Notes: This table is a robustness check on the results in Table \\
6, omitting observations with a destination of Opelika. **, \\
*** represent significance at the 0.1, 0.05, and 0.01 levels, \\
respectively. SEs clustered by route in parentheses.
\end{tabular}


Table D.27: Change in All-Rail Traffic, omitting Rome

\begin{tabular}{lcccccc}
\hline & $(1)$ & $(2)$ & $(3)$ & $(4)$ & $(5)$ & $(6)$ \\
\hline All-rail x post-change & $2.835^{* * *}$ & $2.828^{* * *}$ & $2.823^{* * *}$ & $2.898^{* * *}$ & $2.863^{* * *}$ & $2.958^{* * *}$ \\
& $(0.438)$ & $(0.426)$ & $(0.427)$ & $(0.436)$ & $(0.524)$ & $(0.548)$ \\
\multirow{2}{*}{$*$ distance (100 mi) } & $-0.364^{* * *}$ & $-0.370^{* * *}$ & $-0.370^{* * *}$ & $-0.378^{* * *}$ & $-0.373^{* * *}$ & $-0.385^{* * *}$ \\
& $(0.058)$ & $(0.058)$ & $(0.058)$ & $(0.059)$ & $(0.072)$ & $(0.074)$ \\
\hline Breakeven distance & 779.2 & 763.9 & 763.4 & 765.9 & 767.4 & 768.4 \\
& $(30.6)$ & $(27.9)$ & $(27.8)$ & $(27.4)$ & $(34.4)$ & $(33.5)$ \\
\hline $\mathrm{N}$ & 952 & 952 & 952 & 952 & 952 & 952 \\
$R^{2}$ & 0.30 & 0.68 & 0.68 & 0.73 & 0.70 & 0.75 \\
Route FE & & $\mathrm{X}$ & $\mathrm{X}$ & & & \\
Mode FE & & & $\mathrm{X}$ & & & \\
Year FE & & & $\mathrm{X}$ & & & $\mathrm{X}$ \\
Route-mode FE & & & & $\mathrm{X}$ & $\mathrm{X}$ & $\mathrm{X}$ \\
Route-yr FE & & & & & & \\
\hline
\end{tabular}

Notes: This table is a robustness check on the results in Table 4, omitting observations with a destination of Rome. ${ }^{*},{ }^{* *}, * * *$ represent significance at the $0.1,0.05$, and 0.01 levels, respectively. SEs clustered by route in parentheses.

Table D.28: Share of Traffic, omitting Rome

\begin{tabular}{lcc}
\hline \hline & $(1)$ & $(2)$ \\
\hline All-rail x post-change & $2.658^{* * *}$ & $2.817^{* * *}$ \\
& $(0.402)$ & $(0.419)$ \\
$*$ distance (100 mi) & $-0.355^{* * *}$ & $-0.371^{* * *}$ \\
& $(0.055)$ & $(0.056)$ \\
\hline Breakeven distance & 748.7 & 759.2 \\
& $(27.0)$ & $(26.7)$ \\
\hline $\mathrm{N}$ & 620 & 620 \\
$R^{2}$ & 0.13 & 0.43 \\
Route FE & $\mathrm{X}$ \\
\hline \hline Notes: This table is a robustness check on the results in Table \\
6, omitting observations with a destination of Rome. ${ }^{*}, * *$, \\
*** represent significance at the $0.1,0.05$, and 0.01 levels, \\
respectively. SEs clustered by route in parentheses.
\end{tabular}


Table D.29: Change in All-Rail Traffic, omitting Selma

\begin{tabular}{lcccccc}
\hline \hline & $(1)$ & $(2)$ & $(3)$ & $(4)$ & $(5)$ & $(6)$ \\
\hline All-rail x post-change & $2.378^{* * *}$ & $2.405^{* * *}$ & $2.403^{* * *}$ & $2.469^{* * *}$ & $2.438^{* * *}$ & $2.529^{* * *}$ \\
& $(0.504)$ & $(0.497)$ & $(0.498)$ & $(0.508)$ & $(0.613)$ & $(0.635)$ \\
$*$ distance (100 mi) & $-0.310^{* * *}$ & $-0.321^{* * *}$ & $-0.321^{* * *}$ & $-0.329^{* * *}$ & $-0.324^{* * *}$ & $-0.336^{* * *}$ \\
& $(0.067)$ & $(0.067)$ & $(0.067)$ & $(0.067)$ & $(0.082)$ & $(0.084)$ \\
\hline Breakeven distance & 766.9 & 748.3 & 747.8 & 750.2 & 752.2 & 752.9 \\
& $(38.7)$ & $(35.2)$ & $(35.2)$ & $(34.9)$ & $(43.1)$ & $(42.3)$ \\
\hline $\mathrm{N}$ & 952 & 952 & 952 & 952 & 952 & 952 \\
$R^{2}$ & 0.29 & 0.67 & 0.67 & 0.72 & 0.69 & 0.75 \\
Route FE & & $\mathrm{X}$ & $\mathrm{X}$ & & & \\
Mode FE & & & $\mathrm{X}$ & & & \\
Year FE & & & $\mathrm{X}$ & & & $\mathrm{X}$ \\
Route-mode FE & & & & $\mathrm{X}$ & $\mathrm{X}$ & $\mathrm{X}$ \\
Route-yr FE & & & & & & \\
\hline
\end{tabular}

Notes: This table is a robustness check on the results in Table 4, omitting observations with a destination of Selma. *, **, *** represent significance at the 0.1, 0.05, and 0.01 levels, respectively. SEs clustered by route in parentheses.

Table D.30: Share of Traffic, omitting Selma

\begin{tabular}{lcc}
\hline \hline & $(1)$ & $(2)$ \\
\hline All-rail x post-change & $2.264^{* * *}$ & $2.385^{* * *}$ \\
& $(0.469)$ & $(0.489)$ \\
$*$ distance (100 mi) & $-0.310^{* * *}$ & $-0.322^{* * *}$ \\
& $(0.063)$ & $(0.064)$ \\
\hline Breakeven distance & 731.4 & 741.7 \\
& $(34.1)$ & $(34.4)$ \\
\hline $\mathrm{N}$ & 620 & 620 \\
$R^{2}$ & 0.09 & 0.43 \\
Route FE & & $\mathrm{X}$ \\
\hline Notes: This table is a robustness check on the results in Table \\
6, omitting observations with a destination of Selma. ${ }^{*},{ }^{* *}$, \\
*** represent significance at the 0.1, 0.05, and 0.01 levels, \\
respectively. SEs clustered by route in parentheses.
\end{tabular}


Table D.31: Change in All-Rail Traffic, omitting A. \& W. Pt.

\begin{tabular}{lcccccc}
\hline \hline & $(1)$ & $(2)$ & $(3)$ & $(4)$ & $(5)$ & $(6)$ \\
\hline All-rail x post-change & $2.442^{* * *}$ & $2.447^{* * *}$ & $2.441^{* * *}$ & $2.500^{* * *}$ & $2.489^{* * *}$ & $2.560^{* * *}$ \\
& $(0.488)$ & $(0.482)$ & $(0.482)$ & $(0.492)$ & $(0.597)$ & $(0.616)$ \\
$*$ distance (100 mi) & $-0.319^{* * *}$ & $-0.326^{* * *}$ & $-0.326^{* * *}$ & $-0.332^{* * *}$ & $-0.331^{* * *}$ & $-0.340^{* * *}$ \\
& $(0.063)$ & $(0.063)$ & $(0.063)$ & $(0.063)$ & $(0.078)$ & $(0.079)$ \\
\hline Breakeven distance & 766.1 & 749.4 & 748.9 & 751.9 & 752.3 & 754.1 \\
& $(37.8)$ & $(35.2)$ & $(35.2)$ & $(35.2)$ & $(42.7)$ & $(42.6)$ \\
\hline $\mathrm{N}$ & 952 & 952 & 952 & 952 & 952 & 952 \\
$R^{2}$ & 0.33 & 0.69 & 0.69 & 0.74 & 0.71 & 0.76 \\
Route FE & & $\mathrm{X}$ & $\mathrm{X}$ & & & \\
Mode FE & & $\mathrm{X}$ & & & $\mathrm{X}$ \\
Year FE & & $\mathrm{X}$ & & $\mathrm{X}$ & $\mathrm{X}$ \\
Route-mode FE & & & & $\mathrm{X}$ & \\
Route-yr FE & & & & & & \\
\hline \hline
\end{tabular}

Notes: This table is a robustness check on the results in Table 4, omitting observations with a destination of A. \& W. Pt.. *, **, *** represent significance at the $0.1,0.05$, and 0.01 levels, respectively. SEs clustered by route in parentheses.

Table D.32: Share of Traffic, omitting A. \& W. Pt.

\begin{tabular}{lcc}
\hline \hline & $(1)$ & $(2)$ \\
\hline All-rail x post-change & $2.287^{* * *}$ & $2.410^{* * *}$ \\
& $(0.453)$ & $(0.476)$ \\
$*$ distance (100 mi) & $-0.312^{* * *}$ & $-0.325^{* * *}$ \\
& $(0.059)$ & $(0.061)$ \\
\hline Breakeven distance & 732.7 & 742.5 \\
& $(34.6)$ & $(35.1)$ \\
\hline $\mathrm{N}$ & 620 & 620 \\
$R^{2}$ & 0.13 & 0.45 \\
Route FE & & $\mathrm{X}$ \\
\hline \hline Notes: This table is a robustness check on the results in Table \\
6, omitting observations with a destination of A. \& W. Pt.. \\
$*, * *, * * *$ represent significance at the 0.1, 0.05, and 0.01 \\
levels, respectively. SEs clustered by route in parentheses.
\end{tabular}


Table D.33: Change in All-Rail Traffic, omitting W. \& A.

\begin{tabular}{|c|c|c|c|c|c|c|}
\hline & (1) & (2) & (3) & (4) & (5) & (6) \\
\hline All-rail x post-change & $\begin{array}{c}2.298^{* * *} \\
(0.485)\end{array}$ & $\begin{array}{c}2.300^{* * *} \\
(0.480)\end{array}$ & $\begin{array}{c}2.294^{* * *} \\
(0.480)\end{array}$ & $\begin{array}{c}2.354^{* * *} \\
(0.491)\end{array}$ & $\begin{array}{c}2.342^{* * *} \\
(0.593)\end{array}$ & $\begin{array}{c}2.416^{* * *} \\
(0.616)\end{array}$ \\
\hline * distance $(100 \mathrm{mi})$ & $\begin{array}{c}-0.307^{* * * *} \\
(0.062)\end{array}$ & $\begin{array}{c}-0.314^{* * *} \\
(0.062)\end{array}$ & $\begin{array}{c}-0.314^{* * *} \\
(0.062)\end{array}$ & $\begin{array}{c}-0.321^{* * *} \\
(0.063)\end{array}$ & $\begin{array}{c}-0.318^{* * *} \\
(0.077)\end{array}$ & $\begin{array}{c}-0.328^{* * *} \\
(0.078)\end{array}$ \\
\hline Breakeven distance & $\begin{array}{l}748.1 \\
(39.4)\end{array}$ & $\begin{array}{l}731.8 \\
(37.0)\end{array}$ & $\begin{array}{l}731.1 \\
(37.0)\end{array}$ & $\begin{array}{l}734.2 \\
(37.0)\end{array}$ & $\begin{array}{l}735.8 \\
(44.7)\end{array}$ & $\begin{array}{l}737.5 \\
(44.9)\end{array}$ \\
\hline $\mathrm{N}$ & 952 & 952 & 952 & 952 & 952 & 952 \\
\hline$R^{2}$ & 0.33 & 0.68 & 0.68 & 0.74 & 0.71 & 0.76 \\
\hline Route FE & & $\mathrm{X}$ & $\mathrm{X}$ & & & \\
\hline Mode FE & & & $\mathrm{X}$ & & & \\
\hline Year FE & & & $\mathrm{X}$ & & & \\
\hline Route-mode FE & & & & $\mathrm{X}$ & & $\mathrm{X}$ \\
\hline Route-yr FE & & & & & $\mathrm{X}$ & $\mathrm{X}$ \\
\hline
\end{tabular}

Notes: This table is a robustness check on the results in Table 4, omitting observations with a destination of W. \& A.. ${ }^{*},{ }^{* *},{ }^{* * *}$ represent significance at the $0.1,0.05$, and 0.01 levels, respectively. SEs clustered by route in parentheses.

Table D.34: Share of Traffic, omitting W. \& A.

\begin{tabular}{lcc}
\hline \hline & $(1)$ & $(2)$ \\
\hline All-rail x post-change & $2.143^{* * *}$ & $2.253^{* * *}$ \\
& $(0.453)$ & $(0.471)$ \\
$*$ distance (100 mi) & $-0.300^{* * *}$ & $-0.311^{* * *}$ \\
& $(0.059)$ & $(0.060)$ \\
\hline Breakeven distance & 713.6 & 723.6 \\
& $(36.8)$ & $(37.2)$ \\
\hline $\mathrm{N}$ & 620 & 620 \\
$R^{2}$ & 0.10 & 0.44 \\
Route FE & & $\mathrm{X}$ \\
\hline \hline
\end{tabular}

Notes: This table is a robustness check on the results in Table 6 , omitting observations with a destination of W. \& A.. *, $* *, * * *$ represent significance at the $0.1,0.05$, and 0.01 levels, respectively. SEs clustered by route in parentheses. 


\section{D.3 Sensitivity Checks: Dropping Years}

The tables in this section evaluate the sensitivity of the main results in Tables 4 and 6 to dropping observations in a given year.

Table D.35: Change in All-Rail Traffic, omitting 1884

\begin{tabular}{lcccccc}
\hline \hline & $(1)$ & $(2)$ & $(3)$ & $(4)$ & $(5)$ & $(6)$ \\
\hline All-rail x post-change & $2.730^{* * *}$ & $2.712^{* * *}$ & $2.704^{* * *}$ & $2.777^{* * *}$ & $2.746^{* * *}$ & $2.837^{* * *}$ \\
& $(0.567)$ & $(0.560)$ & $(0.558)$ & $(0.573)$ & $(0.683)$ & $(0.707)$ \\
$*$ distance (100 mi) & $-0.350^{* * *}$ & $-0.355^{* * *}$ & $-0.354^{* * *}$ & $-0.363^{* * *}$ & $-0.357^{* * *}$ & $-0.368^{* * *}$ \\
& $(0.072)$ & $(0.072)$ & $(0.072)$ & $(0.073)$ & $(0.088)$ & $(0.090)$ \\
\hline Breakeven distance & 780.5 & 764.2 & 763.5 & 765.5 & 769.7 & 770.1 \\
& $(37.8)$ & $(36.0)$ & $(35.9)$ & $(35.8)$ & $(44.4)$ & $(43.7)$ \\
\hline $\mathrm{N}$ & 888 & 888 & 888 & 888 & 888 & 888 \\
$R^{2}$ & 0.32 & 0.67 & 0.67 & 0.73 & 0.69 & 0.75 \\
Route FE & & $\mathrm{X}$ & $\mathrm{X}$ & & & \\
Mode FE & & & $\mathrm{X}$ & & & \\
Year FE & & & $\mathrm{X}$ & & & $\mathrm{X}$ \\
Route-mode FE & & & & $\mathrm{X}$ & $\mathrm{X}$ & $\mathrm{X}$ \\
Route-yr FE & & & & & & \\
\hline \hline
\end{tabular}

Notes: This table is a robustness check on the results in Table 4, omitting observations in 1884. *,**, *** represent significance at the $0.1,0.05$, and 0.01 levels, respectively. SEs clustered by route in parentheses.

Table D.36: Share of Traffic, omitting 1884

\begin{tabular}{lcc}
\hline \hline & $(1)$ & $(2)$ \\
\hline All-rail x post-change & $2.563^{* * *}$ & $2.685^{* * *}$ \\
& $(0.532)$ & $(0.545)$ \\
$*$ distance $(100 \mathrm{mi})$ & $-0.341^{* * *}$ & $-0.354^{* * *}$ \\
& $(0.069)$ & $(0.069)$ \\
\hline Breakeven distance & 751.8 & 758.9 \\
& $(35.9)$ & $(35.6)$ \\
\hline $\mathrm{N}$ & 580 & 580 \\
$R^{2}$ & 0.12 & 0.45 \\
Route FE & & $\mathrm{X}$ \\
\hline
\end{tabular}

Notes: This table is a robustness check on the results in Table 6 , omitting observations in $1884 . *, * *, * * *$ represent significance at the $0.1,0.05$, and 0.01 levels, respectively. SEs clustered by route in parentheses. 
Table D.37: Change in All-Rail Traffic, omitting 1885

\begin{tabular}{|c|c|c|c|c|c|c|}
\hline & (1) & $(2)$ & $(3)$ & (4) & $(5)$ & $(6)$ \\
\hline All-rail x post-change & $\begin{array}{c}2.291^{* * *} \\
(0.455)\end{array}$ & $\begin{array}{c}2.274^{* * *} \\
(0.447)\end{array}$ & $\begin{array}{c}2.272^{* * *} \\
(0.448)\end{array}$ & $\begin{array}{c}2.330^{* * *} \\
(0.465)\end{array}$ & $\begin{array}{c}2.277^{* * *} \\
(0.537)\end{array}$ & $\begin{array}{c}2.354^{* * *} \\
(0.572)\end{array}$ \\
\hline * distance $(100 \mathrm{mi})$ & $\begin{array}{c}-0.318^{* * *} \\
(0.056)\end{array}$ & $\begin{array}{c}-0.323^{* * *} \\
(0.056)\end{array}$ & $\begin{array}{c}-0.323^{* * *} \\
(0.057)\end{array}$ & $\begin{array}{c}-0.330 * * * \\
(0.058)\end{array}$ & $\begin{array}{c}-0.321^{* * *} \\
(0.068)\end{array}$ & $\begin{array}{c}-0.331^{* * *} \\
(0.071)\end{array}$ \\
\hline Breakeven distance & $\begin{array}{l}721.3 \\
(35.6)\end{array}$ & $\begin{array}{l}704.3 \\
(34.0)\end{array}$ & $\begin{array}{l}704.0 \\
(34.0)\end{array}$ & $\begin{array}{l}706.3 \\
(34.2)\end{array}$ & $\begin{array}{l}710.3 \\
(41.6)\end{array}$ & $\begin{array}{l}711.8 \\
(42.1)\end{array}$ \\
\hline $\mathrm{N}$ & 888 & 888 & 888 & 888 & 888 & 888 \\
\hline$R^{2}$ & 0.32 & 0.67 & 0.67 & 0.73 & 0.70 & 0.75 \\
\hline Route FE & & $\mathrm{X}$ & $\mathrm{X}$ & & & \\
\hline Mode FE & & & $\mathrm{X}$ & & & \\
\hline Year FE & & & $\mathrm{X}$ & & & \\
\hline Route-mode FE & & & & $\mathrm{X}$ & & $\mathrm{X}$ \\
\hline Route-yr FE & & & & & $\mathrm{X}$ & $\mathrm{X}$ \\
\hline
\end{tabular}

Table D.38: Share of Traffic, omitting 1885

\begin{tabular}{lcc}
\hline \hline & $(1)$ & $(2)$ \\
\hline All-rail x post-change & $2.084^{* * *}$ & $2.182^{* * *}$ \\
& $(0.411)$ & $(0.445)$ \\
$*$ distance (100 mi) & $-0.303^{* * *}$ & $-0.314^{* * *}$ \\
& $(0.052)$ & $(0.055)$ \\
\hline Breakeven distance & 687.1 & 694.8 \\
& $(35.3)$ & $(36.1)$ \\
\hline $\mathrm{N}$ & 580 & 580 \\
$R^{2}$ & 0.13 & 0.47 \\
Route FE & & $\mathrm{X}$ \\
\hline \hline
\end{tabular}

Notes: This table is a robustness check on the results in Table 6 , omitting observations in $1885 . *{ }^{*} * *, * * *$ represent significance at the $0.1,0.05$, and 0.01 levels, respectively. SEs clustered by route in parentheses. 
Table D.39: Change in All-Rail Traffic, omitting 1886

\begin{tabular}{|c|c|c|c|c|c|c|}
\hline & (1) & (2) & (3) & (4) & $(5)$ & (6) \\
\hline All-rail x post-change & $\begin{array}{c}2.297^{* * *} \\
(0.484)\end{array}$ & $\begin{array}{c}2.286^{* * *} \\
(0.494)\end{array}$ & $\begin{array}{c}2.287^{* * *} \\
(0.495)\end{array}$ & $\begin{array}{c}2.338^{* * *} \\
(0.508)\end{array}$ & $\begin{array}{c}2.375^{* * *} \\
(0.621)\end{array}$ & $\begin{array}{c}2.450^{* * *} \\
(0.651)\end{array}$ \\
\hline * distance $(100 \mathrm{mi})$ & $\begin{array}{c}-0.300^{* * *} \\
(0.065)\end{array}$ & $\begin{array}{c}-0.305^{* * * *} \\
(0.067)\end{array}$ & $\begin{array}{c}-0.305^{* * *} \\
(0.067)\end{array}$ & $\begin{array}{c}-0.310^{* * *} \\
(0.068)\end{array}$ & $\begin{array}{c}-0.317^{* * * *} \\
(0.084)\end{array}$ & $\begin{array}{c}-0.325^{* * *} \\
(0.087)\end{array}$ \\
\hline Breakeven distance & $\begin{array}{l}765.9 \\
(39.4)\end{array}$ & $\begin{array}{l}749.4 \\
(37.2)\end{array}$ & $\begin{array}{l}749.3 \\
(37.2)\end{array}$ & $\begin{array}{l}753.5 \\
(37.9)\end{array}$ & $\begin{array}{c}749.4 \\
(43.0)\end{array}$ & $\begin{array}{l}753.3 \\
(44.3)\end{array}$ \\
\hline $\mathrm{N}$ & 892 & 892 & 892 & 892 & 892 & 892 \\
\hline$R^{2}$ & 0.32 & 0.67 & 0.67 & 0.73 & 0.69 & 0.75 \\
\hline Route FE & & $\mathrm{X}$ & $\mathrm{X}$ & & & \\
\hline Mode FE & & & $\mathrm{X}$ & & & \\
\hline Year FE & & & $\mathrm{X}$ & & & \\
\hline Route-mode FE & & & & $\mathrm{X}$ & & $\mathrm{X}$ \\
\hline Route-yr FE & & & & & $\mathrm{X}$ & $\mathrm{X}$ \\
\hline
\end{tabular}

Table D.40: Share of Traffic, omitting 1886

\begin{tabular}{lcc}
\hline \hline & $(1)$ & $(2)$ \\
\hline All-rail x post-change & $2.197^{* * *}$ & $2.329^{* * *}$ \\
& $(0.480)$ & $(0.512)$ \\
$*$ distance (100 mi) & $-0.300^{* * *}$ & $-0.312^{* * *}$ \\
& $(0.065)$ & $(0.068)$ \\
\hline Breakeven distance & 731.4 & 745.5 \\
& $(34.3)$ & $(36.3)$ \\
\hline $\mathrm{N}$ & 584 & 584 \\
$R^{2}$ & 0.13 & 0.46 \\
Route FE & & $\mathrm{X}$ \\
\hline \hline
\end{tabular}

Notes: This table is a robustness check on the results in Table 6, omitting observations in $1886 .{ }^{*},{ }^{* *}, * * *$ represent significance at the $0.1,0.05$, and 0.01 levels, respectively. SEs clustered by route in parentheses. 
Table D.41: Change in All-Rail Traffic, omitting 1887

\begin{tabular}{|c|c|c|c|c|c|c|}
\hline & $(1)$ & $(2)$ & $(3)$ & $(4)$ & $(5)$ & $(6)$ \\
\hline All-rail x post-change & $\begin{array}{c}2.561^{* * *} \\
(0.512)\end{array}$ & $\begin{array}{c}2.571^{* * *} \\
(0.515)\end{array}$ & $\begin{array}{c}2.566^{* * *} \\
(0.516)\end{array}$ & $\begin{array}{c}2.623^{* * *} \\
(0.534)\end{array}$ & $\begin{array}{c}2.595^{* * *} \\
(0.631)\end{array}$ & $\begin{array}{c}2.669^{* * *} \\
(0.664)\end{array}$ \\
\hline * distance $(100 \mathrm{mi})$ & $\begin{array}{c}-0.346^{* * *} \\
(0.065)\end{array}$ & $\begin{array}{c}-0.356^{* * *} \\
(0.066)\end{array}$ & $\begin{array}{c}-0.356^{* * *} \\
(0.066)\end{array}$ & $\begin{array}{c}-0.361^{* * *} \\
(0.068)\end{array}$ & $\begin{array}{c}-0.358^{* * *} \\
(0.081)\end{array}$ & $\begin{array}{c}-0.366^{* * *} \\
(0.085)\end{array}$ \\
\hline Breakeven distance & $\begin{array}{l}740.7 \\
(35.9)\end{array}$ & $\begin{array}{l}721.9 \\
(33.7)\end{array}$ & $\begin{array}{l}721.7 \\
(33.7) \\
\end{array}$ & $\begin{array}{l}726.1 \\
(34.5)\end{array}$ & $\begin{array}{l}724.8 \\
(40.6)\end{array}$ & $\begin{array}{l}728.6 \\
(41.8) \\
\end{array}$ \\
\hline $\mathrm{N}$ & 892 & 892 & 892 & 892 & 892 & 892 \\
\hline$R^{2}$ & 0.32 & 0.68 & 0.68 & 0.73 & 0.70 & 0.76 \\
\hline $\begin{array}{l}\text { Route FE } \\
\text { Mode FE } \\
\text { Year FE }\end{array}$ & & $\mathrm{X}$ & $\begin{array}{l}X \\
X \\
X\end{array}$ & & & \\
\hline Route-mode FE & & & & $\mathrm{X}$ & & $\mathrm{X}$ \\
\hline Route-yr FE & & & & & $\mathrm{X}$ & $\mathrm{X}$ \\
\hline
\end{tabular}

Table D.42: Share of Traffic, omitting 1887

\begin{tabular}{lcc}
\hline \hline & $(1)$ & $(2)$ \\
\hline All-rail x post-change & $2.406^{* * *}$ & $2.533^{* * *}$ \\
& $(0.489)$ & $(0.522)$ \\
$*$ distance (100 mi) & $-0.341^{* * *}$ & $-0.353^{* * *}$ \\
& $(0.063)$ & $(0.066)$ \\
\hline Breakeven distance & 705.5 & 717.0 \\
& $(33.9)$ & $(34.7)$ \\
\hline $\mathrm{N}$ & 580 & 580 \\
$R^{2}$ & 0.12 & 0.45 \\
Route FE & & $\mathrm{X}$ \\
\hline \hline
\end{tabular}

Notes: This table is a robustness check on the results in Table 6, omitting observations in $1887 .{ }^{*},{ }^{* *}, * * *$ represent significance at the $0.1,0.05$, and 0.01 levels, respectively. SEs clustered by route in parentheses. 
Table D.43: Change in All-Rail Traffic, omitting 1888

\begin{tabular}{|c|c|c|c|c|c|c|}
\hline & $(1)$ & $(2)$ & $(3)$ & $(4)$ & $(5)$ & $(6)$ \\
\hline All-rail x post-change & $\begin{array}{c}2.483^{* * *} \\
(0.471)\end{array}$ & $\begin{array}{c}2.477^{* * * *} \\
(0.461)\end{array}$ & $\begin{array}{c}2.473^{* * *} \\
(0.462)\end{array}$ & $\begin{array}{c}2.532^{* * *} \\
(0.473)\end{array}$ & $\begin{array}{c}2.496^{* * *} \\
(0.563)\end{array}$ & $\begin{array}{c}2.567^{* * * *} \\
(0.588)\end{array}$ \\
\hline * distance (100 mi) & $\begin{array}{c}-0.321^{* * *} \\
(0.062) \\
\end{array}$ & $\begin{array}{c}-0.327^{* * *} \\
(0.062) \\
\end{array}$ & $\begin{array}{c}-0.327^{* * *} \\
(0.063) \\
\end{array}$ & $\begin{array}{c}-0.334^{* * *} \\
(0.063) \\
\end{array}$ & $\begin{array}{c}-0.328^{* * *} \\
(0.076) \\
\end{array}$ & $\begin{array}{c}-0.338^{* * *} \\
(0.078) \\
\end{array}$ \\
\hline Breakeven distance & $\begin{array}{l}774.2 \\
(36.8)\end{array}$ & $\begin{array}{l}757.6 \\
(33.7) \\
\end{array}$ & $\begin{array}{l}757.1 \\
(33.7)\end{array}$ & $\begin{array}{r}758.4 \\
(33.6) \\
\end{array}$ & $\begin{array}{l}761.3 \\
(41.7) \\
\end{array}$ & $\begin{array}{r}759.8 \\
(41.2) \\
\end{array}$ \\
\hline $\mathrm{N}$ & 884 & 884 & 884 & 884 & 884 & 884 \\
\hline$R^{2}$ & 0.31 & 0.67 & 0.67 & 0.73 & 0.70 & 0.75 \\
\hline $\begin{array}{l}\text { Route FE } \\
\text { Mode FE } \\
\text { Year FE }\end{array}$ & & $\mathrm{X}$ & $\begin{array}{l}X \\
X \\
X\end{array}$ & & & \\
\hline Route-mode FE & & & & $\mathrm{X}$ & & $\mathrm{X}$ \\
\hline Route-yr FE & & & & & $\mathrm{X}$ & $\mathrm{X}$ \\
\hline
\end{tabular}

Table D.44: Share of Traffic, omitting 1888

\begin{tabular}{lcc}
\hline \hline & $(1)$ & $(2)$ \\
\hline All-rail x post-change & $2.318^{* * *}$ & $2.440^{* * *}$ \\
& $(0.433)$ & $(0.457)$ \\
$*$ distance (100 mi) & $-0.312^{* * *}$ & $-0.325^{* * *}$ \\
& $(0.059)$ & $(0.061)$ \\
\hline Breakeven distance & 742.2 & 749.9 \\
& $(32.4)$ & $(33.2)$ \\
\hline $\mathrm{N}$ & 576 & 576 \\
$R^{2}$ & 0.11 & 0.43 \\
Route FE & & $\mathrm{X}$ \\
\hline \hline
\end{tabular}

Notes: This table is a robustness check on the results in Table 6 , omitting observations in $1888 .{ }^{*}, * *, * * *$ represent significance at the $0.1,0.05$, and 0.01 levels, respectively. SEs clustered by route in parentheses. 
Table D.45: Change in All-Rail Traffic, omitting 1889

\begin{tabular}{|c|c|c|c|c|c|c|}
\hline & (1) & $(2)$ & $(3)$ & (4) & $(5)$ & $(6)$ \\
\hline All-rail x post-change & $\begin{array}{c}2.353^{* * *} \\
(0.423)\end{array}$ & $\begin{array}{c}2.352^{* * *} \\
(0.423)\end{array}$ & $\begin{array}{c}2.348^{* * *} \\
(0.422)\end{array}$ & $\begin{array}{c}2.405^{* * *} \\
(0.434)\end{array}$ & $\begin{array}{c}2.389^{* * *} \\
(0.520)\end{array}$ & $\begin{array}{c}2.454^{* * *} \\
(0.541)\end{array}$ \\
\hline * distance $(100 \mathrm{mi})$ & $\begin{array}{c}-0.310^{* * *} \\
(0.054)\end{array}$ & $\begin{array}{c}-0.317^{* * *} \\
(0.055)\end{array}$ & $\begin{array}{c}-0.317^{* * *} \\
(0.055)\end{array}$ & $\begin{array}{c}-0.324^{* * *} \\
(0.055)\end{array}$ & $\begin{array}{c}-0.322^{* * *} \\
(0.068)\end{array}$ & $\begin{array}{c}-0.331^{* * *} \\
(0.068)\end{array}$ \\
\hline Breakeven distance & $\begin{array}{l}757.7 \\
(34.5) \\
\end{array}$ & $\begin{array}{l}741.1 \\
(32.3)\end{array}$ & $\begin{array}{l}740.6 \\
(32.3)\end{array}$ & $\begin{array}{l}741.7 \\
(32.1)\end{array}$ & $\begin{array}{l}742.5 \\
(38.7) \\
\end{array}$ & $\begin{array}{l}740.8 \\
(38.5)\end{array}$ \\
\hline $\mathrm{N}$ & 884 & 884 & 884 & 884 & 884 & 884 \\
\hline$R^{2}$ & 0.31 & 0.67 & 0.67 & 0.73 & 0.70 & 0.76 \\
\hline $\begin{array}{l}\text { Route FE } \\
\text { Mode FE } \\
\text { Year FE }\end{array}$ & & $\mathrm{X}$ & $\begin{array}{l}X \\
X \\
X\end{array}$ & & & \\
\hline Route-mode FE & & & & $\mathrm{X}$ & & $\mathrm{X}$ \\
\hline Route-yr FE & & & & & $\mathrm{X}$ & $\mathrm{X}$ \\
\hline
\end{tabular}

Table D.46: Share of Traffic, omitting 1889

\begin{tabular}{lcc}
\hline \hline & $(1)$ & $(2)$ \\
\hline All-rail x post-change & $2.214^{* * *}$ & $2.327^{* * *}$ \\
& $(0.397)$ & $(0.417)$ \\
$*$ distance (100 mi) & $-0.306^{* * *}$ & $-0.319^{* * *}$ \\
& $(0.052)$ & $(0.053)$ \\
\hline Breakeven distance & 722.5 & 730.3 \\
& $(31.0)$ & $(31.4)$ \\
\hline $\mathrm{N}$ & 576 & 576 \\
$R^{2}$ & 0.11 & 0.44 \\
Route FE & & $\mathrm{X}$ \\
\hline \hline
\end{tabular}

Notes: This table is a robustness check on the results in Table 6 , omitting observations in $1889 .{ }^{*},{ }^{* *}, * * *$ represent significance at the $0.1,0.05$, and 0.01 levels, respectively. SEs clustered by route in parentheses. 
Table D.47: Change in All-Rail Traffic, omitting 1890

\begin{tabular}{|c|c|c|c|c|c|c|}
\hline & (1) & (2) & (3) & (4) & (5) & (6) \\
\hline All-rail x post-change & $\begin{array}{c}2.351^{* * *} \\
(0.497)\end{array}$ & $\begin{array}{c}2.329^{* * *} \\
(0.488)\end{array}$ & $\begin{array}{c}2.326^{* * *} \\
(0.489)\end{array}$ & $\begin{array}{c}2.387^{* * *} \\
(0.502)\end{array}$ & $\begin{array}{c}2.380^{* * *} \\
(0.593)\end{array}$ & $\begin{array}{c}2.455^{* * *} \\
(0.622)\end{array}$ \\
\hline * distance $(100 \mathrm{mi})$ & $\begin{array}{c}-0.311^{* * *} \\
(0.064)\end{array}$ & $\begin{array}{c}-0.312^{* * *} \\
(0.063)\end{array}$ & $\begin{array}{c}-0.312^{* * *} \\
(0.063)\end{array}$ & $\begin{array}{c}-0.319^{* * *} \\
(0.064)\end{array}$ & $\begin{array}{c}-0.317^{* * *} \\
(0.077)\end{array}$ & $\begin{array}{c}-0.326^{* * *} \\
(0.080)\end{array}$ \\
\hline Breakeven distance & $\begin{array}{l}755.0 \\
(37.0)\end{array}$ & $\begin{array}{l}745.7 \\
(36.5)\end{array}$ & $\begin{array}{l}744.9 \\
(36.6)\end{array}$ & $\begin{array}{l}748.1 \\
(36.5)\end{array}$ & $\begin{array}{l}750.2 \\
(43.7)\end{array}$ & $\begin{array}{l}753.9 \\
(44.2)\end{array}$ \\
\hline $\mathrm{N}$ & 888 & 888 & 888 & 888 & 888 & 888 \\
\hline$R^{2}$ & 0.32 & 0.67 & 0.67 & 0.73 & 0.69 & 0.75 \\
\hline Route FE & & $\mathrm{X}$ & $\mathrm{X}$ & & & \\
\hline Mode FE & & & $\mathrm{X}$ & & & \\
\hline Year FE & & & $\mathrm{X}$ & & & \\
\hline Route-mode FE & & & & $\mathrm{X}$ & & $\mathrm{X}$ \\
\hline Route-yr FE & & & & & $\mathrm{X}$ & $\mathrm{X}$ \\
\hline
\end{tabular}

Table D.48: Share of Traffic, omitting 1890

\begin{tabular}{lcc}
\hline \hline & $(1)$ & $(2)$ \\
\hline All-rail x post-change & $2.185^{* * *}$ & $2.310^{* * *}$ \\
& $(0.454)$ & $(0.480)$ \\
$*$ distance $(100 \mathrm{mi})$ & $-0.299^{* * *}$ & $-0.311^{* * *}$ \\
& $(0.059)$ & $(0.061)$ \\
\hline Breakeven distance & 730.2 & 743.2 \\
& $(36.3)$ & $(36.6)$ \\
\hline $\mathrm{N}$ & 580 & 580 \\
$R^{2}$ & 0.10 & 0.45 \\
Route FE & & $\mathrm{X}$ \\
\hline
\end{tabular}

Notes: This table is a robustness check on the results in Table 6 , omitting observations in $1890 .{ }^{*},{ }^{* *}, * * *$ represent significance at the $0.1,0.05$, and 0.01 levels, respectively. SEs clustered by route in parentheses. 


\section{E International Railway Agreements}

This appendix provides more background on the persistence of breaks in gauge around the world today, accompanying the discussion in Section 6 on what these results might teach us regarding the value of standardizing railway gauge in the present. Though countries in North America and Western Europe have adopted a common standard, gauge breaks are prevalent in underdeveloped regions, including most of Asia, Africa, and South America.

To focus attention, I invoke two examples: Asia and the European periphery. Table E.1 shows the principal gauges currently used in countries in South and Southeast Asia. This diversity precluded an agreement to unify domestic railways into a transcontinental railway network for over 50 years, and the problem of incompatibility was never fully resolved: when the Trans-Asian Railway Network Agreement (UNTC 2006) was ratified in 2006, they skirted the issue, instead opting to continue using adapters at border crossings, which were enumerated in the agreement itself.

Similarly, when European countries agreed to unify their railway networks in 1991, no uniform standard was specified. Though much of Western Europe was on standard gauge, breaks persisted in various places. Table E.2 lists the interchange stations enumerated in the European Agreement on Important International Combined Transport Lines (UNTC 1991, p. 38), as well as the means of interchange at each station - which are (shockingly) the same technologies that were in use 100 years prior. These breaks are present mostly along the eastern periphery, though there are also two junctions where French and Spanish tracks of incompatible gauge meet.

To make the problem more concrete, Figures E.1 and E.2 illustrate the diversity in gauge in Asia and around the world. The former figure is taken from supporting documentation for the TransAsian Railway Network Agreement and maps the major lines in Asia, color-coding by gauge. The latter figure is from Wikipedia and shows a map of the world which color-codes countries by their principal gauge. Both figures make it visually obvious just how much of a problem breaks in gauge continue to be in less developed parts of the world: sending a rail car from Europe to Southeast Asia requires at least two interchanges, and from parts of Russia, three. 
Figure E.1: World Map, Color-coding Countries by Principal Gauge

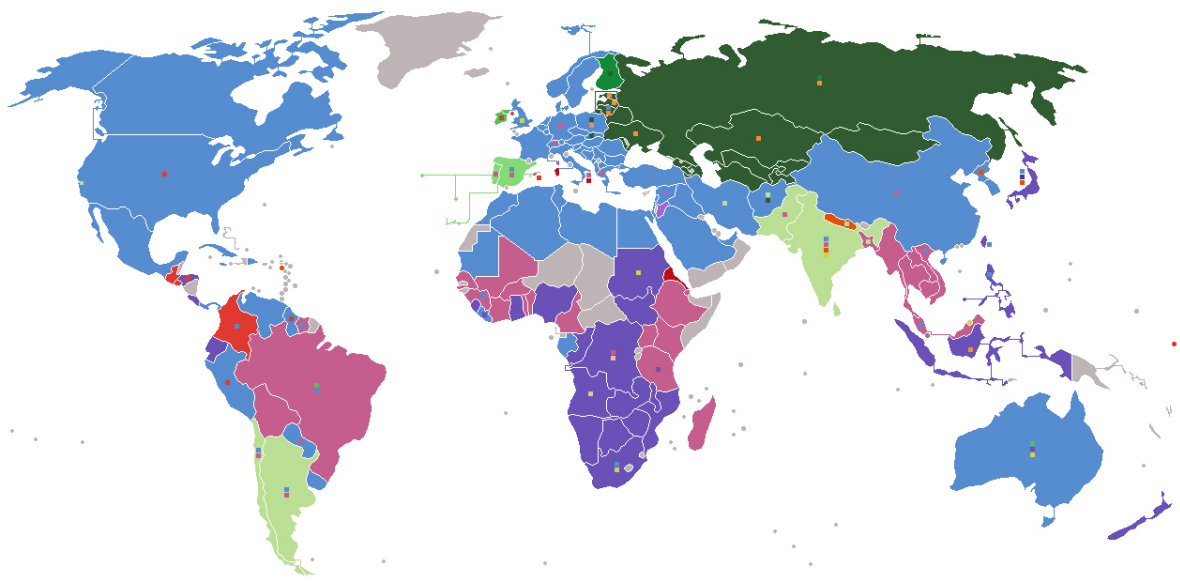

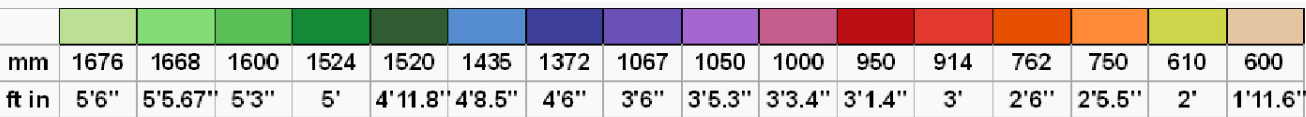

Notes: Map illustrates the principal gauge of individual countries around the world, color-coding each country by gauge, thereby making the prevalence of breaks visually apparent. Figure obtained from Wikipedia, available at https://upload.wikimedia. org/wikipedia/commons/1/1f/Rail_gauge_world.jpg.

Figure E.2: Map of Principal Lines in Asia, Color-coded by Gauge (2006)

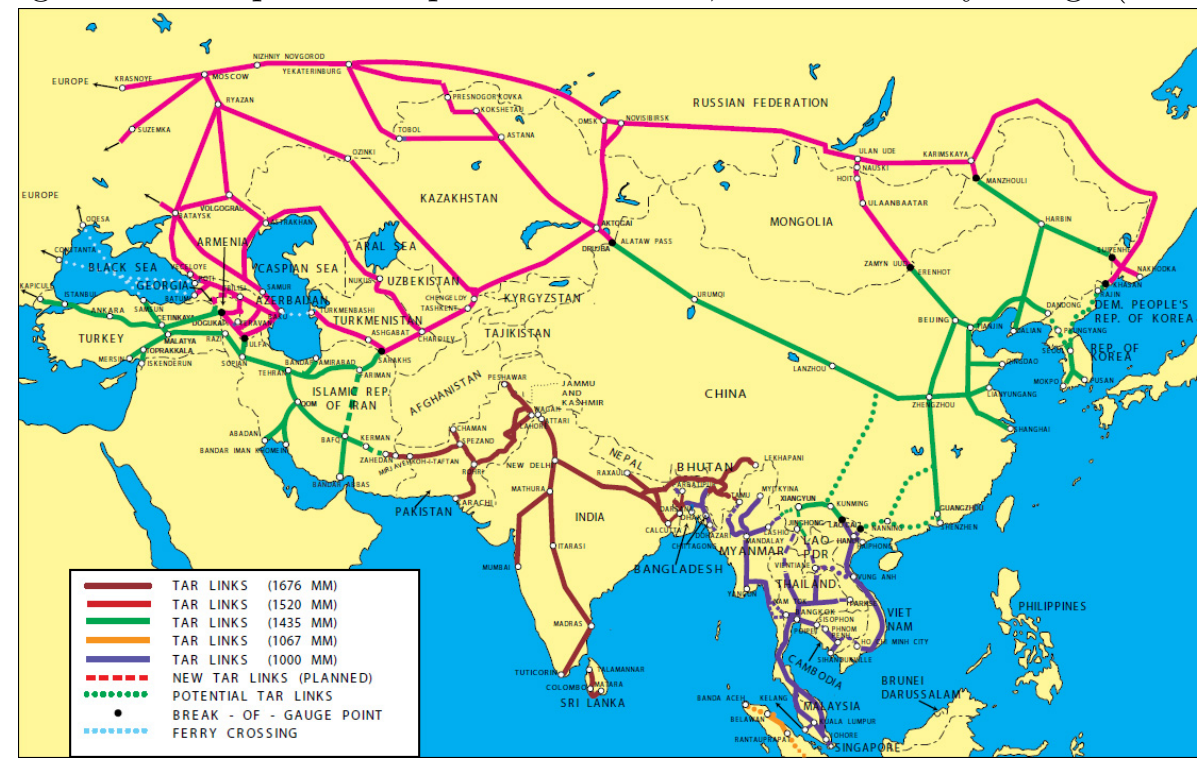

Notes: Map shows major lines in Asia covered by the Trans-Asian Railway Network Agreement (UNTC 2006), as well as links planned under the agreement, color-coding by gauge. Figure published in 1999 and available as part of the supporting documentation for the TAR. 
Table E.1: Railway Gauge of Trans-Asian Railway Members at Time of Agreement (2006)

\begin{tabular}{lccll}
\hline \hline $\begin{array}{c}1,000 \mathrm{~mm} \\
(3 ' 3.375 ")\end{array}$ & $\begin{array}{c}1,067 \mathrm{~mm} \\
\left(3^{\prime} 6 "\right)\end{array}$ & $\begin{array}{c}1,435 \mathrm{~mm} \\
\left(4^{\prime} 8.5 "\right)\end{array}$ & $\begin{array}{c}1,520 \mathrm{~mm} \\
(6,0 ")\end{array}$ & $\begin{array}{c}1,676 \mathrm{~mm} \\
\left(66^{\prime} 6^{\prime \prime}\right)\end{array}$ \\
\hline Bangladesh & Indonesia & China & Armenia & Bangladesh \\
Laos & & North Korea & Azerbaijan & India \\
Malaysia & & South Korea & Georgia & Nepal \\
Myanmar & & Iran & Kazakhstan & Pakistan \\
Singapore & Turkey & Kyrgyzstan & Sri Lanka \\
Thailand & & Mongolia & \\
Vietnam & & Russia & \\
& & Tajikistan & \\
& & & Turkmenistan & \\
& & & Uzbekistan & \\
\hline
\end{tabular}

Notes: Table lists the varying railroad gauge standards of the countries that were party to or affected by the Intergovernmental Agreement on the Trans-Asian Railway Network at the time of ratification (November 21, 2006). Data from text of the agreement (UNTC 2006).

Table E.2: Gauge Interchanges on European Country Borders at Time of Agreement (1991)

\begin{tabular}{lccc}
\hline \hline & & \multicolumn{2}{c}{ Means of Interchange } \\
\cline { 3 - 4 } Countries & $\begin{array}{c}\text { Number of } \\
\text { Interchanges }\end{array}$ & $\begin{array}{c}\text { Change of wagon } \\
\text { axles / bogies }\end{array}$ & $\begin{array}{c}\text { Transshipment by crane } \\
\text { or other equipment }\end{array}$ \\
\hline Hungary-Ukraine & 2 & $\mathrm{X}$ & $\mathrm{X}$ \\
Romania-Moldova & 2 & $\mathrm{X}$ & $\mathrm{X}$ \\
Romania-Ukraine & 2 & $\mathrm{X}$ & $\mathrm{X}$ \\
Spain-France & 2 & $\mathrm{X}$ & $\mathrm{X}$ \\
Poland-Belarus & 1 & $\mathrm{X}$ & $\mathrm{X}$ \\
Poland-Lithuania & 1 & $\mathrm{X}$ & $\mathrm{X}$ \\
Poland-Ukraine & 1 & $\mathrm{X}$ & $\mathrm{X}$ \\
Russia-North Korea & 1 & $\mathrm{X}$ & $\mathrm{X}$ \\
Russia-China & 1 & $\mathrm{X}$ & $\mathrm{X}$ \\
Kazakhstan-China & 1 & $\mathrm{X}$ & $\mathrm{X}$ \\
Slovakia-Ukraine & 1 & &
\end{tabular}

Notes: Table counts number of gauge interchange stations on the border between country pairs, and the means of interchange used to transfer freight across gauges, at the time of the European Agreement on Important International Combined Transport Lines and Related Installations (February 1, 1991). Data from text of the agreement (UNTC 1991). 